\title{
Sanxicun Landslide: An Investigation of Progressive Failure of a Gentle Bedding Slope
}

\section{Xiangjun Pei}

Chengdu University of Technology

Shenghua Cui ( $\nabla$ shenghuacui.geo@gmail.com )

state key laboratory of Geohazard Prevention and Geoenvironment protection https://orcid.org/00000002-6638-230X

\section{Ling Zhu}

Chengdu University of Technology

\section{Hui Wang}

Chengdu University of Technology

\section{Luguang Luo}

Chengdu University of Technology

Xiaochao Zhang

Chengdu University of Technology

\section{Research Article}

Keywords: Gentle bedding slope, depression belt, historical earthquakes, rainfall water, progressive failure

Posted Date: May 26th, 2021

DOI: https://doi.org/10.21203/rs.3.rs-524675/v1

License: (c) (i) This work is licensed under a Creative Commons Attribution 4.0 International License.

Read Full License

Version of Record: A version of this preprint was published at Natural Hazards on September 25th, 2021. See the published version at https://doi.org/10.1007/s11069-021-05044-6. 
${ }^{1}$ State Key Laboratory of Geohazard Prevention and Geoenvironment Protection, Chengdu University of Technology,

5 Chengdu 610059, China.

$6 \quad 2$ Disaster Prevention Research Institute, Kyoto University, Uji, 6110011, Kyoto, Japan.

$7 \quad{ }^{3}$ Priority Research Center for Geotechnical Science and Engineering, The University of Newcastle, Callaghan, NSW 2308,

8 Australia.

$9{ }^{4}$ University of Twente, Faculty of Geo-Information Science and Earth Observation (ITC), PO Box 217, Enschede, AE 7500,

10 Netherlands

11 Abstract: A gentle bedding slope (16 dip angle) failure at Sanxicun (SXC) village in Dujiangyan city was triggered by

12 heavy rainfall in 2013. The landslide (composing of sandstone and mudstone strata) has a sliding distance of up to $1200 \mathrm{~m}$

13 and caused 166 deaths. After this failure event, a detailed field survey and a series of laboratory tests were carried out by us to investigate the progressive failure mechanism of the slope. The results revealed that the slope deformation could be traced back to the Ming Dynasty in China (400 years before) at least. A sliding block with a width of $330 \mathrm{~m}$ and a length of $240 \mathrm{~m}$ detached its original position, resulting in a depression belt with $10 \mathrm{~m}$ in width and $25 \mathrm{~m}$ in depth at the rear of the sliding block. On the scarp, a large number of cracks were widely observed not only in the sandstone but also in the mudstone. The field evidence revealed that the depression belt and cracked mudstone had provided convenience for water infiltration for a long time. The shake table test results showed that these cracks could be initiated and propagated in the slope during earthquakes. Especially, seismic stresses amplifications were induced in the mudstone to degrade this layer obviously. Besides, Direct shear tests of cracked mudstone with different immersion time were carried out. It was showed 
that the shear strength of mudstone decreased rapidly in the initial immersion and then tends to be stable gradually. Finally, numerical calculation indicated that the hydrostatic pressure in the depression belt and uplift pressure in the basal layer generated by the strongest rainwater in history ( $537.4 \mathrm{~mm}$ daily) caused the kilometer- slide of the block in 2013 . We concluded that the catastrophic failure of the SXC landslide triggered by the rainwater in 2013 strongly depended on the pre- existing deformation and damage caused by historical earthquakes and rainwaters.

Keywords: Gentle bedding slope; depression belt; historical earthquakes; rainfall water; progressive failure

\section{Introduction}

From 8:00 on July 8 to 8:00 on July 10, 2013, there was a continuous heavy rainfall process in Dujiangyan city, with cumulative precipitation of $537.4 \mathrm{~mm}$. The rainfall triggered a rapid and long run-out landslide with a volume of $1.47 \times 10^{6}$ $\mathrm{m}^{3}$ in Sanxicun (SXC) village, Dujiangyan city, Sichuan Province. The SXC landslide was located at E103⒊ $33^{\prime} 48^{\prime \prime}$, $\mathrm{N} 30^{\circ} 54^{\prime} 55^{\prime \prime}$, and $68 \mathrm{~km}$ away from Chengdu city. The total volume of the source area was $1.77 \times 10^{6} \mathrm{~m}^{3}$. The whole landslide mass moved downward about 50 to $80 \mathrm{~m}$. The volume of the residual sliding mass was approximately $1.47 \times 10^{6} \mathrm{~m}^{3}$. A sliding mass with a volume of about $300 \times 10^{3} \mathrm{~m}^{3}$ was initiated at a high-level position, resulting in 166 deaths. The landslide was located southwest and $12 \mathrm{~km}$ away from the epicenter of the 2008 Wenchuan Ms 8.0 earthquake. Strong seismic shaking in the landslide area induced seismic intensity of IX degree. Besides the SXC landslide, there were three smallscale landslides triggered by the Wenchuan earthquake (Yin et al., 2016). There was a depression belt with a depth of 25 $\mathrm{m}$ and a maximum width of $10 \mathrm{~m}$ at the rear edge on the slope before the SXC landslide, suggesting it's an old landslide. According to historical records, the depression belt was formed 400 years ago (Li 1998). depression belt reached $9.8 \mathrm{~m}$. Yin et al. (2016) argued that not only hydrostatic pressure but also uplift pressure induced 
(2017) proposed a model to consider the hydrostatic pressure along the bedding plane that could effectively estimate the stability of the landslide. Although the formation of the landslide can be summarized as a "translational landslide induced by heavy rainfall" and the landslide should be returned to stability after high water pressures were relieved (Chen and Cui, 2017). Luo et al. (2018) suggested that the failure process of the SXC landslide should be simulated by a thermo- poroelastic approach coupled with the Savage-Hutter model. The 2008 Wenchuan earthquake was considered as a factor for the prefailure of the 2013 landslide event by Gao et al. (2017).

It was indisputable that the heavy rainfall event in 2013 (which was the most severe successively in history) triggered the landslide. Beyond the rainfall, it was generally believed that the historical earthquakes and long- term gravity were important contributors to this progress landslide (Gao et al., 2017). It was recognized that not only a large number of coseismic landslides were triggered, but seismic cracks and accelerated deformation in slope were also induced during a strong earthquake (Cui et al., 2012, 2014; Fu et al., 2020). These cracks in slopes provided paths for preferential flow, which was associated with rainfall- induced landslide initiation (Krzeminska et al., 2013 and Shao et al., 2015). Cumulative damage and progressive deformation induced by preparatory factors over time could destabilize a relatively stable rock slope by initiating and propagating new cracks. Thus, the initiation of catastrophic failure of slope caused by a certain earthquake or rainwater strongly depends on pre- existing damage (Gischig et al., 2016).

The SXC landslide is one with progressive failure as long as several hundred years. However, the study of the seismic-

60 dependent progressive failure of this landslide in the earthquake- prone area and its contribution to the 2013 landslide even is limited. In this study, a detailed field investigation and a series of laboratory tests were carried out for the landslide. We aimed to show the earthquake- induced pre- failure of the landslide and the role of pre- existing damage in landslide initiation. 


\section{Geological and meteorological conditions}

The study area is located in the transition zone between Chengdu Plain and Longmenshan tectonic belt (Fig. 1) where the terrain was characterized by middle- low mountain and tectonic erosion landforms. The topographic elevation of the study area is in the range from $2500 \mathrm{~m}$ asl in the northwest to $730 \mathrm{~m}$ asl in the southeast. The Longmenshan fault zone is composed of the Wenchuan-Maowen fault, Yingxiu-Beichuan fault, and Pengzhou-Guanxian fault. Among these faults, the Yingxiu- Beichuan fault with a strike of NE-SW and a dip of $300^{\circ}$ to $330^{\circ}$ and Pengzhou-Guanxian fault with a strike of NE-SW and a dip of $310^{\circ}$ to $330^{\circ}$ were both ruptured during the 2008 Wenchuan earthquake, and the PengzhouGuanxian fault is only $3 \mathrm{~km}$ away from the study landslide. The LMS belt can be divided into three main tectonostratigraphic units, i.e., a Mesoproterozoic basement, pre-Indosinian marine sediments from the Sinian to the middle-upper Triassic, and Indosinian terrestrial sediments (Cui et al. 2020). The study area is a part of the QingchengQingxia Neocathaysian structure system, which is mainly composed of a series of NNE- trending folds, faults and Quaternary depressions. The strata in this area is mainly composed of fluvial facies conglomerate, sandstone, siltstone and mudstone of Jurassic, Cretaceous and Paleogene. Li et al. (2017) reported that the intense earthquake events were induced by the NE-SW fault system. According to statistics, 197 earthquakes with Ms. > 4.7 have occurred along the belt, including three earthquakes with Ms $>8.0$.

The study area is abundance of precipitation and rainstorm. The annual average precipitation was $1131.3 \mathrm{~mm}$, and the maximum annual precipitation was $1605.4 \mathrm{~mm}$ in 1978 . By analyzing the precipitation data from 1987 to 2012 , it can be found that up to $77.1 \%$ of precipitation was concentrated on the rainy season, i.e., from May to September. Particularly from July to August, when the 2013 landslide event occurred, the precipitation reached $490.9 \mathrm{~mm}$, accounting for $45.9 \%$ of the annual precipitation (Fig. 2a). The maximum monthly precipitation was $592.9 \mathrm{~mm}$ generated on August 1981, and the maximum single-day precipitation was $213.4 \mathrm{~mm}$, also generated in June 1980, both around the time when the 2013 landslide occurred. On July 10, 2013, the study area was suffered the largest precipitation on records. The accumulated 
precipitation of $920 \mathrm{~mm}$ from 8:00 am on July 8 to 8:00 am (Fig. 2b).

\section{Method}

Field investigation was performed using Google Earth images, an unmanned aerial vehicle (UAV), 1:200,000- scale geological maps, a laser rangefinder and compasses. Using the Google Earth images and UAV, we were able to determine the overall topography and landform characteristics of the SXC landslide and its surrounding area. A digital elevation model (DEM) with a resolution of $0.2 \mathrm{~m}$ was obtained. The 1: 200,000- scale geological maps were employed to determine the geological conditions in the study area. The laser rangefinder and compass were used to determine the spatial distributions, orientations, and sizes of some tension cracks.

Field investigation results revealed that the lithology of the landslide area was mainly composed of red thick sandstone interbedded with thin mudstone. To investigate the dynamic response characteristics of this kind of slope during earthquake, a shaking table test was carried out by simplified the slope into a block model. By using the shaking table tests the dynamic behavior of the sandstone (hard layer) interbedded with mudstone (weak layer) in the SXC landslide could be estimated to show the effect of historical earthquake on the slope deformation. To investigate the influence of water on the shear strength properties of mudstone, the direct shear test for samples with different initial water contents and different immersion times were carried out. Finally, on the basis of considering cumulative damage induced by historical earthquakes and mudstone softening, the factor of stability $\left(F_{s}\right)$ of SXC gentle bedding slope in the natural state, only sliding surface in the saturated zone and different water head heights was calculated.

\section{Results}

\subsection{SXC landslide characteristics}

The landslide in 2013 involved a volume of $177 \times 10^{4} \mathrm{~m}^{3}$ with a maximum length of $1.18 \mathrm{~km}$ and an average width of 150 $\mathrm{m}$. The elevations of the failure block range between 740 and $1132 \mathrm{~m}$, and the topographic slope gradients range from $12^{\circ}$ 
to $24^{\circ}$. According to the remote sensing images, it can be found that the north and west sides of the landslide area are steep

cliffs before and after the landslide (Fig. 3), and a seasonal gully with a strike of S- N is developed on the east side of the

slope. The landslide area can be divided into three zones: source area (I), ploughing area (II) and accumulation area (III)

(Fig. 4a). The strata of the block in the source area is mainly composed of thick sandstone interbedded with thin mudstone

within the Guankou Formation of the Cretaceous system $\left(\mathrm{K}_{2} \mathrm{~g}\right)$ (Fig. 4b). A volume of approximately $300 \times 10^{3} \mathrm{~m}^{3}$ was to $1050 \mathrm{~m}$, and the height difference is $200 \mathrm{~m}$. The sliding mass continuously collides and disintegrates in the ploughing area to form debris flow in the process of movement. The debris moved downslope in two directions, subsequent forming a major slide area $\left(\mathrm{III}_{1}\right)$. A branch slide area is also can be found at the west part of the slope $\left(\mathrm{III}_{2}\right)$. $\mathrm{III}_{1}$ subjected to direction turning from the front valley, the debris flowed directly impacted the valley's right side after moving about $80 \mathrm{~m}$ resulting in 166 deaths (Yin et al., 2016). The debris on the slope is mainly composed of rock blocks, shoveled soil and trees, and the maximum diameter of the rock block is up to $5 \mathrm{~m}$ (Yin et al., 2016). the residual sliding mass were developed (Fig. 5a and b). Details of these tension cracks are listed in Table. 1. A depression belt with a strike of NE-SW, a depth of $30 \mathrm{~m}$, a width of $64 \mathrm{~m}$ and a length of $250 \mathrm{~m}$ (Fig. 5c), which was formed by the propagating and stretching during the 2013 landslide event based on a previous depression belt with a width of $10 \mathrm{~m}$, a depth of $25 \mathrm{~m}$. The previous depression belt was formed 400 years ago.

The orientation of the bedding plane is $\mathrm{N} 13^{\circ} \mathrm{W} / \mathrm{NE} / 16^{\circ}$ (strike/dip/dip angle), showing a typical gentle rock bed. Two sets of joints were developed in this area. $\mathrm{J} 1$ shows an orientation of $\mathrm{N} 63^{\circ} \mathrm{W} / \mathrm{NE} / 87^{\circ}$ and is in accordance with the orientation of the most tension cracks on the slope, including the depression belt (Fig. 6). J2 shows an orientation of S $39^{\circ}$ 
129 layer of the residual block is highly fragmented (Fig. 8a). According to the characteristics of crack propagation in mudstone

130 layer, it can be divided into three types of cracks: gently inclined cracks with dip angle below $30^{\circ}$, moderately -gently

131 inclined cracks with dip angle $30^{\circ}-60^{\circ}$, and steeply inclined cracks with dip angle above $60^{\circ}$. According to the

132 statistical results of cracks in the mudstone layer, the proportion of each type of cracks is shown in Fig. 8b. From Fig. 8b,

133 the gently inclined cracks are the most, accounting for about $47 \%$, while the steeply inclined cracks are the least, accounting

134 for about $21 \%$. In addition, salt was extracted from the fragmented mudstone. These suggested that long- term groundwater

135 activity had been in the slope, especially on interfaces and in cracks of the mudstone on the landside's basal sliding layer

136 (Fig. 8c).

\section{$137 \quad 4.2$ Experimental data}

$138 \quad$ 4.2.1 Shaking table test

139 A simplified model with bedding strata, sliding surface and slide block for the SXC landslide are shown in Fig. 9.

140 Historical seismic wave propagated to SXC slope and produced horizontal and vertical ground motion in the inclined weak

141 layer. The vertical seismic force can be decomposed into normal and tangential force components (Fig. 10a), and SN and

142 EW horizontal seismic forces can be decomposed into normal and tangential force components (Fig. 10b). To reduced the

143 topography- depended influence on the dynamic responding of model, the inclined weak layer is rotated to horizontal, the

144 seismic stress in the weak layer will be simplified into two components: vertical and horizontal (Fig. 10c). Then, the model

145 shown in Fig. 11a is recommended in our shaking table test. The acceleration, soil pressure and displacement sensors were

146 used. The soil pressure and acceleration sensors were arranged in the upper (hard) layer, weak layer and lower (hard) layer.

147 The upper and lower layer represented the sandstone strata and the middle layer represented the mudstone strata. The

148 displacement sensors were respectively installed in the upper and lower hard layers near the interfaces of the weak layer.

149 The scheme is shown in Fig. 11b. 
The similitude laws are basic theories that ensure that model experimental results are similar to those of a prototype. It is important to correctly scale down the parameters of the model experiment based on the similitude laws and select the right materials. In this paper, the elastic modulus of the mudstone layer was assumed as the most different property from the lower and upper sandstone layers. Thus, for the tests, this factor was represented as closely as possible because it should 154 have a significant influence on the response of the model. Moreover, the density ( $\rho$ ), length (L), gravity (g), seismic 155 frequency (f), and time ( $\mathrm{t}$ ) were also considered. Table. 2 presents the scaling factors for this study. Based on these 156 similitude laws, the parameters of the experimental model were set, and suitable materials were selected.

157 According to a series of physical and mechanical tests, the materials of the middle layer were mainly formed of quartz sand, clay, liquid paraffin, and plaster at ratios of 17: 80: 2: 1, and they were mixed with $17.02 \%$ of water. The materials in the upper and lower layer of the model were formed of barite: quartz sand: plaster: iron slag at ratios of 37.5: 37.5: 7:18, and they were mixed with $11.5 \%$ of water and $2.3 \%$ of glycerol. The parameters of the similar material were listed in Table. 3 .

Due to that, the tests were used to investigate the possible influences of the earthquake on the slope, not to reproduce the landslide process. Sine wave was applied in our tests, according to the Wenchuan earthquake recorded at the MZQ051 seismic station $103 \mathrm{~km}$ away from the landslide. The duration on the record from 37 to $55 \mathrm{~s}$ was the main shaking part, in which the peak acceleration was $0.84 \mathrm{~g}$ and the frequency was in the range of $1-10 \mathrm{~Hz}$. The waveform of the input shaking was a sinusoidal curve with a duration of $15 \mathrm{~s}$, a maximum acceleration of $0.8 \mathrm{~g}$ and a maximum frequency of $15 \mathrm{~Hz}$. are shown in Fig. 12. From Fig. 12a and 12b, the peak accelerations in the upper hard layer, weak layer and lower hard layer under vertical vibration are approximately equal, about $0.31 \mathrm{~g}$. However, during horizontal vibration, the peak acceleration gradually increases with the height of the model. The peak accelerations in the lower hard layer, weak layer 
and upper hard layer are $0.31 \mathrm{~g}, 0.39 \mathrm{~g}$ and $0.44 \mathrm{~g}$, respectively. The elevation amplification effect of acceleration is obvious.

172 From Fig. 12c and 12d, the peak displacements in the lower hard layer and the upper hard layer under vertical vibration 173 are $0.022 \mathrm{~mm}$ and $0.114 \mathrm{~mm}$, respectively, and the displacement difference is $0.09 \mathrm{~mm}$. The peak displacements in the 174 lower hard layer and the upper hard layer under horizontal vibration are $0.021 \mathrm{~mm}$ and $0.067 \mathrm{~mm}$, respectively, and the 175 displacement difference is $0.046 \mathrm{~mm}$. It is revealed that the peak displacements in the upper hard layer are obviously greater than that of the lower hard layer in both horizontal and vertical vibrations. Besides, an interesting note is that the 177 displacement response time of the upper hard layer is significantly delayed compared to the lower hard layer. From Fig. 12e and 12f, the soil pressure in the weak layer under vertical vibration is $0.65 \mathrm{kPa}$, and the soil pressures in the upper and 179 lower hard layers are approximately equal, about $0.056 \mathrm{kPa}$. Besides, the soil pressure in the weak layer under horizontal vibration is $1.14 \mathrm{kPa}$, and the soil pressures in the upper and lower hard layers are only $0.1 \mathrm{kPa}$. The calculation showed that the weak layer's soil pressures are 11.6 and 11.4 times these of the upper and lower layers, respectively.

The seismic wave propagates in different rock layers of the test model, the discontinuous medium (hard layer and weak layer) causes to reflection and refraction of the seismic wave at the interface. Primarily when the seismic wave propagates from hard rock to soft rock, incompatible deformation is generated as shown by our data due to hard layer and weak layer with significant differences in strength, elastic modulus and deformability (Pei et al., 2018). We found that the incompatible deformation caused two kinds of dynamic effects on the weak layer. Under the condition of vertical vibration, the displacement amplitudes in upper and lower hard layers are obviously different. In the process of downward movement of the shaking table, large displacement in the upper hard layer and small displacement in the lower hard layer caused amplified compression stress in the weak layer. Similarly, the amplified tension stress was generated in the weak layer in the upward movement (Fig. 13a). Besides, in the process of horizontal movement, the large displacement of the upper hard layer and the small displacement of the lower hard layer inevitably led to the dislocation between the upper and lower hard layers, and then amplified shear stress was generated in the weak layer (Fig. 13b). 
The direct shear test results for samples with different water contents (w) are shown in Fig. 14. It is clear that no obvious

195 peak point in the stress- displacement curves of the sample appeared under $\sigma=200 \mathrm{kPa}$ (Fig. 14a), showing hardening characteristic. According to the Trade Standard of P. R. China SL237-021 (1999), the shear stress corresponding to the 197 shear displacement $4 \mathrm{~mm}$ is selected as the shear strength. From Fig. 14b, the shear strength increases firstly and then 198 decreases with raising water content. The maximum shear strength is obtained when the water content is $9 \%$. From Fig. $19914 \mathrm{c}$, the internal friction angle and cohesion increase from $18.61^{\circ}$ and $54.8 \mathrm{kPa}(w=6 \%)$ to $21.7^{\circ}$ and $78.66 \mathrm{kPa}(w=9 \%)$, 200 respectively. Afterward, the internal friction angle and cohesion decrease with the increment of water content. When the water content is $18 \%$, the internal friction angle and cohesion are only $17.68^{\circ}$ and $15.24 \mathrm{kPa}$. Table. 4 shows the change rate of the shear strength parameters of the samples with increasing water content. The cohesion decreases obviously with increasing water content, while the influence of water content on internal friction angle is relatively small. The change ratios of internal friction angle and cohesion are $-28.17 \%$ and $-72.2 \%$, respectively.

The direct shear test results for samples with different immersion times $(t)$ are shown in Fig. 15. From Fig. 15a, the shear stress- displacement curves under $\sigma=200 \mathrm{kPa}$ tend to harden without an obvious peak point. From Fig. 15b, the shear strengths decrease with the increment of immersion time. During the first hour of immersing the samples, the shear strength reduces rapidly and then tends to be stable with increasing immersion time. From Fig. 15c, the internal friction angle and cohesion decrease from $22.24^{\circ}$ and $50.91 \mathrm{kPa}$ to $16.79^{\circ}$ and $15.22 \mathrm{kPa}$ in the first hour, respectively. Then, the cohesion remains stable. However, the internal friction angle increases to $19.81^{\circ}$ (immersion for $24 \mathrm{~h}$ ) and decreases to $16.38^{\circ}$ 211 (immersion for $96 \mathrm{~h}$ ). Table. 5 shows the change rate of shear strength parameters with increasing immersion time. After 212 immersion for $96 \mathrm{~h}$, the change rates of internal friction angle and cohesion are $-41.98 \%$ and $-79.8 \%$, respectively, which mainly occurs in the first hour. 
degradation. The absorbed suction could resist the sliding of particles, and it increased with increasing water content.

However, when the water content increased to a certain value, the pores were gradually filled with water and the area of

capillary water decreased, resulting in a gradual decrease in the absorbed suction until it disappeared. Also, the water

molecules in the red mudstone firstly cemented with free iron oxide to form a granular structure when the water content

was low, resulting in a temporary increase in the internal friction angle of the mudstone.

\subsection{Initiation model for SXC landslide}

The water pressure that affects cracked slope stability includes hydrostatic pressure along the depression belt, uplift

pressure on the sliding surface change dynamically during rainfall. If the permeability coefficient of the sliding surface is

$$
F_{s}=\frac{W \cos \theta \tan \varphi+c L}{W \sin \theta}
$$

where $F_{s}$ is the safety factor, $W$ is the weight of the landslide profile B- B', $\theta$ is the dip angle of the slip surface, $\varphi$ is the

internal friction angle of the sliding surface, $\mathrm{c}$ is the cohesion of the sliding surface, $\mathrm{L}$ is the length of the sliding surface along the sliding direction.

The safety factor considering the effect of water pressure is obtained by:

$$
F_{s}=\frac{(W \cos \theta-V \sin \theta-U) \tan \varphi+c L}{W \sin \theta+V \cos \theta+T}
$$

where $V$ is the hydrostatic pressure along the depression belt, $U$ is the uplift pressure along the sliding surface, and $T$ is the 
drag force.

The weight of the landslide profile $\mathrm{B}-\mathrm{B}^{\prime}$ is obtained by:

$$
W=\gamma A
$$

The hydrostatic pressure can be expressed as:

$$
V=\frac{1}{2} \gamma_{w} H_{w}^{2}
$$

The uplift pressure is given by:

$$
U=\frac{1}{2} \gamma_{w} H_{w} L
$$

The drag force can be written as:

$$
T=\gamma_{w} H_{w} b
$$

where $\gamma$ is the unit weight of landslide mass; $A$ is the area of the calculation profile; $\gamma_{\mathrm{w}}$ is the unit weight of water; $H_{\mathrm{w}}$ is the height of water level in the depression belt; $b$ is the width of the structural plane. So, Eq. (1) can be replaced by:

$$
F_{s}=\frac{\left[2 \gamma A \cos \theta-\gamma_{w} H_{w}^{2} \sin \theta-\gamma_{w} H_{w} L\right] \tan \varphi+2 c L}{2 \gamma A \sin \theta+\gamma_{w} H_{w}^{2} \cos \theta+2 \gamma_{w} H_{w} b}
$$

248 The results of the direct shear test were used to obtain $F_{s .}$. The mudstone used in the direct shear test was the undisturbed

249 sample obtained from the SXC landslide, which has experienced historical earthquakes. The combined effect of historical earthquakes and water on mudstone is considered in the direct shear test. Therefore, it is appropriate to use the shear strength parameters obtained from the direct shear test to calculate $F_{s}$. Considering that the sliding surface was immersed in water for a long time, the shear strength parameter of the sample immersed in water for $96 \mathrm{~h}$ was employed. The specific parameter values are shown in Table. 6. 


\subsection{Formation of the depression belt}

A large number of field monitoring shows amplification of peak ground acceleration (PGA) and it increases with the rising elevation (Wang et al., 2010; Luo et al., 2020). The SXC landslide is located on the Longmenshan tectonic belt and belongs to the Qingcheng- Qingxia Neocathaysian structure system, which is mainly composed of a series of NNE- trending folds, faults and Quaternary depressions. As stated in the second section, the Longmenshan area is earthquake- prone owing to the effect of the tectonic activity. In Fig. 17, we show the earthquakes with a magnitude greater than 3.0 occurred in the adjacent area (within $200 \mathrm{~km}$ ) since 1900. The number is up to 1921, which should have induced significant damage to the rock mass continually in the study area due to amplification of peak ground acceleration.

The influence of earthquake on the slope was firstly testified by the old tension cracks observed in the upper part of the slope in the landslide area, although these cracks also could be generated due to other environmental factors. Secondly, the landslide scarp also involved earthquake cause. The significant difference between earthquake and gravity- induced landslides was that earthquake-induced landslides generally presented steep scarp. e.g., the Daguangbao and Wenjiagou landslides triggered by the 2008 Wenchuan earthquake have steep scarps with a height difference of $700 \mathrm{~m}$ and $445 \mathrm{~m}$, respectively (Deng et al., 2017; Cui et al., 2020). Generally, an arc-shaped shear failure was presented in slope deformation caused by gravity (Bouissou et al., 2012). However, strong horizontal seismic force has more serious influence on slope deformation, and a steep release surface in slope was usually induced by tension deformation. The horizontal earthquake shaking provided seismic force in the horizontal along the landslide sliding direction. The steep- release surfaces in the

274 SXC landslide shows obvious differences in geometry from that of general gravity- induced landslides. Thus, the steeprelease surface in the SXC landslide can be reasonably attributed to horizontal shaking- induced tension failures, although this failure is not finished in one earthquake but through fracture accumulation in history. 
on the field investigation results, we infer the formation and evolution of the tension crack before the 2013 landslide event.

279 Firstly, it is noted that the joint sets provide geological conditions for the initiation, propagation and coalescence of seismic cracks. The field investigation results revealed that the orientation of $\mathrm{J} 1$ was in accordance with the most tension cracks.

The steep joint parallel to the ridge makes it easy for the rock mass to trigger tension cracks under seismic loading.

Therefore, it was considered that the seismic cracks were prone to initiate and propagate from the J1 tips under historical earthquakes and gradually forming penetrating seismic cracks after multiple earthquakes. Furthermore, the depression belt was continuously propagated under the combined effect of historical earthquakes, rainfall and gravity. Finally, the belt reached the basal layer, i.e., the mudstone layer. A large failure event just like the landslide in 2013 should be triggered by earthquake or rainfall 400 years ago. The sliding block stopped on the bedding after traveling some distance. The depression belt with a width of $10 \mathrm{~m}$, a depth of $25 \mathrm{~m}$ was formed. This process is shown in Fig. 22. Although there were no records to show the other sliding event of the block before 400 years or during the 400 years, if it has, it is reasonable due to historical earthquakes and rainfalls.

\subsection{Formation of the fractures on the basal layer}

The shaking table tests show that the weak layer is subjected to greater compressive and tensile stresses due to incompatible deformation (Fig. 18). It can be reasonably proposed that the cyclic stress amplification caused the initiation and propagation of fractures in the weak layer, which were confirmed by the a large number of cracks observed in the mudstone on the sliding basal layer of the landslide (Pei et al., 2018).

Figs. 19 and 20 were used to shows the mechanisms of the cracks observed in the mudstone layer under compression and tension stresses during the earthquake. Fig. 19 shows that compression stress will be concentrated at the tip of the original joint in the rock mass. If the compression stress exceeds the strength threshold of the joint tip, the compression crack will be initiated and propagated at the end of the joint. Further, the stress concentration position will be transferred to the interior of the rock mass. The resilience of the crack tip is weakened in the unloading process, but the elastic modulus 
of rock is much higher, resulting in the differential rebound, which will produce residual tension stress and compression

stress at the interface between the rock and the crack, causing the crack to propagate to both ends.

Fig. 20a shows mechanisms of crack propagation under tension stress. Under the condition of tension stress, the tension

stress at both tips of the joint is concentrated. When it is greater than the tensile strength of the rock mass, seismic cracks

nearly parallel to the tensile stress are formed, and almost horizontal and gently inclined cracks are formed. Because the

tension strength of rock mass is far less than the compression strength, the above-mentioned tension cracks are very easy

to occur. In addition, under the condition of compression stress, the most concentrated tension stress is located at the end

of the crack with the angle of $30^{\circ}-40^{\circ}$ with the direction of the principal compression stress. Therefore, the fracture first

appears at the end of some joints with favorable orientation and then develops into secondary cracks $\left(J_{2 t}\right)$. The angle

between the crack propagation direction and the long axis direction of the joint is about $2 \beta$, and then gradually turns parallel

to the direction of the maximum principal the most concentrated tension stress is located at the end of the crack with an

angle of $30^{\circ}-40^{\circ}$ with the direction of the principal compression stress, resulting in nearly vertical cracks with high dip angle (Fig. 20b). Under the condition of cyclic shear stress, tension and compression - torsion en- echelon cracks are developed. The propagation direction of tension en- echelon cracks $(\mathrm{T})$ is generally parallel to the maximum principal compressive stress, and sometimes two groups of conjugate secondary shear cracks (R, R') can be formed. In addition, the developed direction of compressive- torsion cracks $(\mathrm{P})$ intersects with the shear direction at an acute angle (Fig. 21).

\section{$316 \quad 5.3$ Progressive failure of SXC landslide}

317 Earthquakes have been recognized as an important factor triggering the catastrophic failure of large-scale landslides. 318 However, seismic waves are not just a trigger mechanism. They also lead to progressive failure on rock slopes, which is a 319 very effective fatigue process in deformation and damage of rock slopes (Gischig et al., 2016). Such as the progressive 320 failure of SXC landslide in at least 400 years, which is affected by joints, historical earthquakes, rainfall, gravity and other factors. 
The 2008 Wenchuan earthquake has attracted considerable attention because it triggered more than 60,000 landslides in an elliptical area along with the fault ruptures (Dai et al., 2011; Gorum et al., 2011). However, the earthquake has been given little attention in contributing to the progressive damage and the incremental destabilization of rock slopes. Considering that this study area is located in the eastern margin of the Qinghai Tibet Plateau, a lot of active fault zones are distributed in the region due to the Indian plate squeezing the Eurasian plate (e.g., Longmenshan fault zone, Xianshuihe fault zone, Anninghe fault zone and Xiaojiang fault zone, etc.). In history, several disastrous earthquakes occurred in these active faults, including the 1786 Ms 7.8 Kangding earthquake (Petley 2008), 1933 Diexi Ms 7.5 earthquake (Ren et al., 2018) and 2008 Wenchuan Ms 8.0 earthquake (Huang and Fan 2013). These induced the damage accumulation in slopes 330 in this region.

Similarly, rainfall plays the same role, and the hydrostatic pressure and softening on sliding surfaces induced by repeated

332 rainfall might cause instantaneous deformation of slope. Our shaking table tests, immersion tests and direct shear tests simulate one earthquake, one rainfall, or one shear failure. Their results should be coupled and accumulated, which should

334 be further study. In this study, the rainstorm in 2013 accelerated the slope deformation to reach the critical state, resulting 335 in the landslide initiation. It can be inferred that the catastrophic failure of the SXC landslide triggered by the rainfall in 3362013 strongly depends on the pre- existing deformation and damage caused by historical earthquakes, rains and gravity (Fig. 23).

The progressive deformation and failure of slope are the results of the integrated influence of several factors, which includes geological structure, preparatory factors and triggering factors (Fig. 24) (Gunzburger et al., 2005). The SXC 340 landslide with a failure history of more than 400 years is a typical example for progressive failure study. Based on our understanding of its history, we made Fig. 24 to illustrate the possible effect factor of the landslide from stability to be instability. 
The rock mass structure is mainly composed of the primary structure determined by the rock formation environment and secondary structure caused by tectonic activity after diagenesis. Some common primary structures include contact surface,

345 flow layer and primary joint in magmatic rock, bedding plane, foliation and weak rock in sedimentary rock, and schistosity 346 and gneissic in metamorphic rock. Typical secondary structures include joint, fault fracture zone and bedding fault zone.

347 The presence of these structures provides convenience for the initiation and propagation of shear and tension cracks under endogenic and exogenic processes, which is the geological basis for the formation of landslide boundaries (Liu et al., 2018;

349 Song et al., 2018).

350 Over a long period of time (e.g., 10-100,000 years), different types of preparatory factors gradually reduce the rock mass strength and slope resistance. The fatigue process has been discussed; e.g., water pressure changes induced by rainfall, snowmelt or reservoir level (Bonzanigo et al., 2007; Zangerl et al., 2010), thermal stress changes (Gischig et al., 2011; Grämiger et al., 2018), seismic stress (Gischig et al., 2016), glacial loading and unloading (Leith et al., 2014) and longterm weathering (Jaboyedoff et al., 2004; Li et al., 2018), etc. These preparation factors can also be regarded as triggering factors to trigger slope failure. The triggering factors are the change of driving force acting on the slope in a short period (e.g., several seconds to several years), which eventually causes catastrophic failure of the slope. Triggering factors are usually reported to be the cause of slope failure. It is noted that these factors can affect slope stability simultaneously and jointly. For example, repeated seismic loading may cause significant incremental damage in the form of crack initiation and propagation, which causes the rock mass to reach a highly critical state (Moore et al., 2012). On this basis, a small disturbance- an earthquake or water pressure induced by rainfall or snowmelt- may cause the catastrophic failure of the slope, and even the increase of pressure during the ordinary seasonal cycle may trigger the slope failure if the slope is in a sufficiently critical state. As a whole, these factors may not directly cause slope failure but can contribute to cumulative damage and progressive deformation of rock slope. 


\section{Conclusion}

In this study, to investigate the initiation mechanism of the cracked slope in earthquake- prone areas, a detailed field

investigation and a series of laboratory tests were carried out. It is revealed that a sliding block with a width of $330 \mathrm{~m}$ and

a length of $240 \mathrm{~m}$ detached its original position, resulting in a depression belt with $10 \mathrm{~m}$ in width and $25 \mathrm{~m}$ in depth at the

rear of the sliding block. The cyclic stress amplification induced by incompatible deformation caused the initiation and

propagation of a large number of cracks in the mudstone. The shear strength of cracked mudstone decreased rapidly in the

initial immersion and then tends to be stable gradually. Finally, the landslide was triggered by hydrostatic pressures induced

by the most significant precipitation in Dujiangyan City since meteorological records. It is proposed that the catastrophic

failure of the SXC landslide triggered by the rainwater in 2013 strongly depended on the pre- existing deformation and

damage caused by historical earthquakes and rainwaters.

\section{Acknowledgments}

375 This study was partially supported by the National Key R\&D Program of China (Grants No. 2017YFC1501002) and the

National Natural Science Foundation of China (Grants No. 41931296, 41907254, 41521002).

\section{Declarations}

Conflict of interest The authors declare that they have no known competing financial interests or personal relationships

that could have appeared to influence the work reported in this paper.

\section{References}

Bonzanigo, L., Eberhardt, E., \& Loew, S. (2007). Long-term investigation of a deep-seated creeping landslide in crystalline rock. Part I. Geological and hydromechanical factors controlling the Campo Vallemaggia landslide. Canadian Geotechnical Journal, 44(10), 1157-1180.

Bouissou, S., Darnault, R., Chemenda, A., Rolland, Y., 2012. Evolution of gravity-driven rock slope failure and associated fracturing: Geological analysis and numerical modelling. Tectonophysics 526, 157-166.

Chen, X. Z., \& Cui, Y. F. (2017). The formation of the Wulipo landslide and the resulting debris flow in Dujiangyan City, China. Journal of Mountain Science, 14(6), 1100-1112.

Cui, P., Guo, C. X., Zhou, J. W., Hao, M. H., \& Xu, F. G. (2014). The mechanisms behind shallow failures in slopes comprised of landslide deposits. Engineering geology, 180, 34-44. 
Cui, P., Lin, Y. M., \& Chen, C. (2012). Destruction of vegetation due to geo-hazards and its environmental impacts in the Wenchuan earthquake areas. Ecological Engineering, 44, 61-69.

Cui, S., Yang, Q., Pei, X., Huang, R., Guo, B., \& Zhang, W. (2020). Geological and morphological study of the Daguangbao landslide triggered by the Ms. 8.0 Wenchuan earthquake, China. Geomorphology, 370, 107394.

Dai, F. C., Tu, X. B., Xu, C., Gong, Q. M., \& Yao, X. (2011). Rock avalanches triggered by oblique-thrusting during the 12 May 2008 Ms 8.0 Wenchuan earthquake, China. Geomorphology, 132(3-4), 300-318.

Deng, Q., Gong, L., Zhang, L., Yuan, R., Xue, Y., Geng, X., \& Hu, S. (2017). Simulating dynamic processes and hypermobility mechanisms of the Wenjiagou rock avalanche triggered by the 2008 Wenchuan earthquake using discrete element modelling. Bulletin of Engineering Geology and The Environment, 76(3), 923-936.

Du, G. L., Zhang, Y. S., \& Yao, X. (2016). Formation mechanism analysis of Wulipo landslide-debris flow in Dujiangyan City. Rock and Soil Mechanics, 37(S2), 492-501. (In Chinese)

Fan, X., Xu, Q., Scaringi, G., Dai, L., Li, W., Dong, X., ... \& Havenith, H. B. (2017). Failure mechanism and kinematics of the deadly June 24th 2017 Xinmo landslide, Maoxian, Sichuan, China. Landslides, 14(6), 2129-2146.

Fu, X., Sheng, Q., Li, G., Zhang, Z., Zhou, Y., \& Du, Y. (2020). Analysis of landslide stability under seismic action and subsequent rainfall: a case study on the Ganjiazhai giant landslide along the Zhaotong-Qiaojia road during the 2014 Ludian earthquake, Yunnan, China. Bulletin of Engineering Geology and the Environment, 1-20.

Gao, Y., Yin, Y., Li, B., Feng, Z., Wang, W., Zhang, N., \& Xing, A. (2017). Characteristics and numerical runout modeling of the heavy rainfall-induced catastrophic landslide-debris flow at SXC, Dujiangyan, China, following the Wenchuan Ms 8.0 earthquake. Landslides, 14(4), 1361-1374.

Gischig, V. S., Moore, J. R., Evans, K. F., Amann, F., \& Loew, S. (2011). Thermomechanical forcing of deep rock slope deformation: 1. Conceptual study of a simplified slope. Journal of Geophysical Research: Earth Surface, 116(F4).

Gischig, V., Preisig, G., \& Eberhardt, E. (2016). Numerical investigation of seismically induced rock mass fatigue as a mechanism contributing to the progressive failure of deep-seated landslides. Rock Mechanics and Rock Engineering, 49(6), 2457-2478.

Gorum, T., Fan, X., van Westen, C. J., Huang, R. Q., Xu, Q., Tang, C., \& Wang, G. (2011). Distribution pattern of earthquake-induced landslides triggered by the 12 May 2008 Wenchuan earthquake. Geomorphology, 133(3-4), 152167.

Grämiger, L. M., Moore, J. R., Gischig, V. S., \& Loew, S. (2018). Thermomechanical stresses drive damage of Alpine valley rock walls during repeat glacial cycles. Journal of Geophysical Research: Earth Surface, 123(10), $2620-2646$.

Gunzburger, Y., Merrien-Soukatchoff, V., \& Guglielmi, Y. (2005). Influence of daily surface temperature fluctuations on rock slope stability: case study of the Rochers de Valabres slope (France). International Journal of Rock Mechanics and Mining Sciences, 42(3), 331-349.

Huang, R., \& Fan, X. (2013). The landslide story. Nature Geoscience, 6(5), 325-326.

Jaboyedoff, M., Baillifard, F., Bardou, E., \& Girod, F. (2004). The effect of weathering on Alpine rock instability. Quarterly Journal of Engineering Geology and Hydrogeology, 37(2), 95-103.

Krzeminska, D. M., Bogaard, T. A., Malet, J. P., \& Van Beek, L. P. H. (2013). A model of hydrological and mechanical feedbacks of preferential fissure flow in a slow-moving landslide. Hydrology and Earth System Sciences, 17(3), 947959.

Lajtai, E. Z. (1977). A mechanistic view of some aspects of jointing in rocks. Tectonophysics, 38(3-4), 327-338.

Leith, K., Moore, J. R., Amann, F., \& Loew, S. (2014). Subglacial extensional fracture development and implications for Alpine Valley evolution. Journal of Geophysical Research: Earth Surface, 119(1), 62-81.

Li YQ (1998) Master Zhang Daqian and Mt. Qiangcheng. Sichuan Today 11(4):32-34. (In Chinese)

Li, J., Zhou, K., Liu, W., \& Zhang, Y. (2018). Analysis of the effect of freeze-thaw cycles on the degradation of mechanical parameters and slope stability. Bulletin of Engineering Geology and the Environment, 77(2), 573-580. 
Li, Y., Zhou, R.J., Yan, L., Yan, Z.K., Ding, H.R., \& Shao, C.J., 2017. Active tectonics and historical earthquakes in Longmenshan. In: Feng, B. (Ed.), Tectonic Geomorphology and Surface Process of Longmen Shan. 56. Science Press, Beijing. (In Chinese)

Liu, X., Liu, Y., He, C., \& Li, X. (2018). Dynamic stability analysis of the bedding rock slope considering the vibration deterioration effect of the structural plane. Bulletin of Engineering Geology and the Environment, 77(1), 87-103.

Luo, Y., Fan, X., Huang, R., Wang, Y., Yunus, A. P., \& Havenith, H. B. (2020). Topographic and near-surface stratigraphic amplification of the seismic response of a mountain slope revealed by field monitoring and numerical simulations. Engineering Geology, 271, 105607.

Luo, Y., Liu, W., He, S., Yuanjun, J., \& Lei, X. (2018). Dynamic process simulation of rainfall-induced SXC landslide based on a thermo-poro-elastic approach. Natural Hazards, 92(1), 415-428.

Moore, J. R., Gischig, V., Amann, F., Hunziker, M., \& Burjanek, J. (2012). Earthquake-triggered rock slope failures: Damage and site effects. In Proceedings 11th International \& 2nd North American Symposium on Landslides (Vol. 1, pp. 869-875). Banff, Canada: CRC Press.

Pei, X. J., Guo, B., Cui, S. H., Wang, D. P., Xu, Q., \& Li, T. T. (2018). On the initiation, movement and deposition of a large landslide in Maoxian County, China. Journal of Mountain Science, 15(6), 1319-1330.

Petley D (2008) The Sichuan earthquake. Geogr Rev 22:2-4

Ren, J., Xu, X., Zhang, S., Yeats, R. S., Chen, J., Zhu, A., \& Liu, S. (2018). Surface rupture of the 1933 M 7.5 Diexi earthquake in eastern Tibet: implications for seismogenic tectonics. Geophysical Journal International, 212(3), 16271644.

Shao, W., Bogaard, T. A., Bakker, M., \& Greco, R. (2015). Quantification of the influence of preferential flow on slope stability using a numerical modelling approach. Hydrology and Earth System Sciences, 19(5), 2197.

Song, D., Che, A., Chen, Z., \& Ge, X. (2018). Seismic stability of a rock slope with discontinuities under rapid water drawdown and earthquakes in large-scale shaking table tests. Engineering Geology, 245, 153-168.

Song, D., Liu, X., Huang, J., Wang, E., \& Zhang, J. (2021). Characteristics of wave propagation through rock mass slopes with weak structural planes and their impacts on the seismic response characteristics of slopes: A case study in the middle reaches of Jinsha River. Bulletin of Engineering Geology and the Environment, 80(2), 1317-1334.

Stead, D., Coggan, J. S., \& Eberhardt, E. (2004). Realistic simulation of rock slope failure mechanisms: the need to incorporate principles of fracture mechanics. International Journal of Rock Mechanics and Mining Sciences, 41, 563568.

Trade Standard of P.R. China, SL237-021 (1999) Standard method for direct shear test of soils. Specification of Soil Test, The Ministry of Water Resources of P. R. China, Beijing. (in Chinese)

Wang, J., Yao, L., \& Hussain, A. (2010). Analysis of earthquake-triggered failure mechanisms of slopes and sliding surfaces. Journal of Mountain Science, 7(3), 282-290.

Wu, L. Z., Shi, J. S., \& Xu, Q. (2017). The rainfall-induced Wulipo rockslide, China: a modified model for rockslide initiation. Environmental Earth Sciences, 76(14), 497.

Xu, Q., Liu, H., Ran, J., Li, W., \& Sun, X. (2016). Field monitoring of groundwater responses to heavy rainfalls and the early warning of the Kualiangzi landslide in Sichuan Basin, southwestern China. Landslides, 13(6), 1555-1570.

Yin, Y., Cheng, Y., Liang, J., \& Wang, W. (2016). Heavy-rainfall-induced catastrophic rockslide-debris flow at SXC, Dujiangyan, after the Wenchuan Ms 8.0 earthquake. Landslides, 13(1), 9-23.

Yong, R., Ye, J., Li, B., \& Du, S. G. (2018). Determining the maximum sampling interval in rock joint roughness measurements using Fourier series. International Journal of Rock Mechanics and Mining Sciences, 101, 78-88.

Zangerl, C., Eberhardt, E., \& Perzlmaier, S. (2010). Kinematic behaviour and velocity characteristics of a complex deepseated crystalline rockslide system in relation to its interaction with a dam reservoir. Engineering Geology, 112(1-4), 53-67. 
478 Zhang, S., Xu, Q., \& Hu, Z. (2016). Effects of rainwater softening on red mudstone of deep-seated landslide, Southwest $479 \quad$ China. Engineering Geology, 204, 1-13. 
Table. 1 Details of these tension cracks

\begin{tabular}{ccccc}
\hline No & $\begin{array}{c}\text { Strike } \\
\left({ }^{\circ}\right)\end{array}$ & $\begin{array}{c}\text { Length } \\
(\mathrm{m})\end{array}$ & $\begin{array}{c}\text { Width } \\
(\mathrm{m})\end{array}$ & $\begin{array}{c}\text { Depth } \\
(\mathrm{m})\end{array}$ \\
\hline (1) & $\mathrm{N} 63^{\circ} \mathrm{W}$ & 153 & $\backslash$ & 3 \\
$(2)$ & $\mathrm{N} 76^{\circ} \mathrm{W}$ & 694 & $\backslash$ & 16 \\
$(3)$ & $\mathrm{N} 49^{\circ} \mathrm{W}$ & 350 & $\searrow$ & 10 \\
$(4)$ & $\mathrm{N} 52^{\circ} \mathrm{W}$ & 242 & 5 & 9 \\
$(5)$ & $\mathrm{N} 28^{\circ} \mathrm{W}$ & 106 & $\searrow$ & 6 \\
(6) & $\mathrm{N} 23^{\circ} \mathrm{W}$ & 97 & 7 & 8 \\
$(7)$ & $\mathrm{N} 78^{\circ} \mathrm{W}$ & 182 & 3 & 5 \\
$(8)$ & $\mathrm{N} 84^{\circ} \mathrm{E}$ & 261 & 3 & 7 \\
(9) & $\mathrm{N} 73^{\circ} \mathrm{E}$ & 108 & 5 & 6 \\
(10) & $\mathrm{N} 71^{\circ} \mathrm{W}$ & 106 & 8 & 8 \\
(11) & $\mathrm{N} 84^{\circ} \mathrm{W}$ & 690 & $\searrow$ & 6 \\
\hline
\end{tabular}

Table. 2 Similarity system for shaking table test

\begin{tabular}{cccc}
\hline \multirow{2}{*}{ Physical parameters } & Similarity relation & \multicolumn{2}{c}{ Similarity coefficient } \\
& & Sandstone & Mudstone \\
\hline Density $\rho$ & $C_{\rho}$ & $1^{*}$ & $1^{*}$ \\
Elastic modulus $E$ & $C_{E}$ & $30^{*}$ & $10^{*}$ \\
Time $t$ & $C_{t}$ & $10^{*}$ & $10^{*}$ \\
Length $l$ & $C_{l}=C_{\rho}^{-0.5} C_{E}{ }^{0.5} C_{t}$ & 55 & 32 \\
Poisson's ratio $\mu$ & $C_{\mu}$ & 1 & 1 \\
Cohesion $c$ & $C_{c}=C_{E}$ & 30 & 10 \\
Internal friction angle $\varphi$ & $C_{\varphi}$ & 1 & 1 \\
Stress $\sigma$ & $C_{\sigma}=C_{E} C_{\varepsilon}$ & 54 & 32 \\
Strain $\varepsilon$ & $C_{\varepsilon}=C_{\rho} C_{g} C_{l} C_{E}^{-1}$ & 1.8 & 3.2 \\
Frequency $f$ & $C_{f}=C_{t}^{-1}$ & 0.1 & 0.1 \\
Displacement $u$ & $C_{u}=C_{l} C_{\varepsilon}$ & 99 & 102 \\
Speed $v$ & $C_{v}=C_{u} C_{t}^{-1}$ & 9.9 & 10.2 \\
Acceleration $a$ & $C_{a}=C_{u} C_{t}^{-2}$ & 0.01 & 0.01 \\
Gravitational acceleration $g$ & $C_{g}$ & 1 & 1 \\
\hline
\end{tabular}

484

Table. 3 Physical and mechanical parameters

\begin{tabular}{|c|c|c|c|c|c|c|c|}
\hline \multicolumn{2}{|c|}{ Material types } & \multirow{2}{*}{$\begin{array}{c}\begin{array}{c}\text { Density } \\
\rho\left(\mathrm{t} / \mathrm{m}^{3}\right)\end{array} \\
1.8\end{array}$} & \multirow{2}{*}{$\begin{array}{c}\text { Elastic modulus } \\
\qquad E(\mathrm{MPa}) \\
2\end{array}$} & \multirow{2}{*}{$\begin{array}{c}\text { Poisson's ratio } \\
\mu \\
0.35\end{array}$} & \multirow{2}{*}{$\begin{array}{c}\text { Strength } \\
\frac{\sigma_{\mathrm{c}}(\mathrm{MPa})}{7}\end{array}$} & \multirow{2}{*}{$\begin{array}{l}\text { Cohesion } \\
\frac{c(\mathrm{MPa})}{600}\end{array}$} & \multirow{2}{*}{$\begin{array}{l}\text { Internal friction angle } \phi \\
\qquad\left(^{\circ}\right) \\
25\end{array}$} \\
\hline & Site & & & & & & \\
\hline Finustone & Mode & 1.8 & 0.94 & 0.35 & 0.23 & 20 & 25 \\
\hline \multirow{2}{*}{ Sandstone } & Site & 2.5 & 8400 & 0.2 & 62 & 1 & 42 \\
\hline & Mode & 2.5 & 280 & 0.2 & 1.2 & 0.1 & 42 \\
\hline
\end{tabular}

Table. 4 Effect of water content on shear strength parameters

\begin{tabular}{lllll} 
Water content $(\%)$ & Internal friction angle $\left({ }^{\circ}\right)$ & Change rate $(\%)$ & Cohesion $(\mathrm{kPa})$ & Change rate $(\%)$ \\
\hline
\end{tabular}




\begin{tabular}{|c|c|c|c|c|}
\hline 6 & 18.61 & $\backslash$ & 54.8 & $\lambda$ \\
\hline 9 & 21.7 & -11.81 & 78.66 & 43.53 \\
\hline 12 & 19.12 & -22.32 & 55.62 & 1.5 \\
\hline 15 & 19.02 & -22.7 & 51.91 & -5.27 \\
\hline 18 & 17.68 & -28.17 & 15.24 & -72.2 \\
\hline \multicolumn{5}{|l|}{488} \\
\hline 489 & \multicolumn{3}{|c|}{ Table. 5 Effect of immersion time on shear strength parameters. } & \\
\hline Immersing time $(\mathrm{h})$ & Internal friction angle $\left({ }^{\circ}\right)$ & Change rate $(\%)$ & Cohesion $(\mathrm{kPa})$ & Change rate $(\%)$ \\
\hline $0 \mathrm{~h}$ & 22.24 & $\searrow$ & 50.91 & $\backslash$ \\
\hline $1 \mathrm{~h}$ & 16.79 & -40.53 & 15.22 & -70.11 \\
\hline $3 \mathrm{~h}$ & 16.71 & -40.81 & 13.25 & -73.98 \\
\hline $6 \mathrm{~h}$ & 17.84 & -36.84 & 9.69 & -80.98 \\
\hline $12 \mathrm{~h}$ & 17.69 & -37.35 & 9.09 & -82.15 \\
\hline $24 \mathrm{~h}$ & 19.81 & -29.84 & 10.83 & -78.74 \\
\hline $48 \mathrm{~h}$ & 18.26 & -35.33 & 12.32 & -75.81 \\
\hline $96 \mathrm{~h}$ & 16.38 & -41.98 & 10.28 & -79.8 \\
\hline
\end{tabular}

490

491

Table. 6 Parameter value for calculation

\begin{tabular}{cccccc}
\hline Conditions & $\begin{array}{c}\text { Gravity } \\
\gamma\left(\mathrm{kN} / \mathrm{m}^{3}\right)\end{array}$ & $\begin{array}{c}\text { The inclination of sliding } \\
\text { surface } \theta\left(^{\circ}\right)\end{array}$ & $\begin{array}{c}\text { Water gravity } \\
\gamma_{\mathrm{w}}\left(\mathrm{kN} / \mathrm{m}^{3}\right)\end{array}$ & $\begin{array}{c}\text { Internal friction angle } \\
\varphi\left({ }^{\circ}\right)\end{array}$ & $\begin{array}{c}\text { Cohesion } \\
c(\mathrm{kPa})\end{array}$ \\
\hline Natural state & 21 & 16 & 10 & 22.4 & 54.8 \\
Only groundwater & 21 & 16 & 10 & 16.4 & 10.3 \\
Rainstorm & 21 & 16 & 10 & 16.4 & 10.3 \\
\hline
\end{tabular}

492

493

Table. 7 Calculating results of the factor of safety $\left(F_{s}\right)$ with various depths of groundwater

\begin{tabular}{cccccccccc}
\hline \multirow{2}{*}{ Conditions } & \multirow{2}{*}{$\begin{array}{c}\text { Natural state } \\
\text { (no groundwater) }\end{array}$} & $\begin{array}{c}\text { Only sliding surface in the } \\
\text { saturated zone }\end{array}$ & \multicolumn{5}{c}{ Water depth to the sliding surface (m) } \\
\cline { 3 - 9 }$F_{S}$ & 1.59 & 1.055 & 1.051 & 1.034 & 1.004 & 0.982 & 0.961 & 0.939 & 0.916 \\
\hline
\end{tabular}




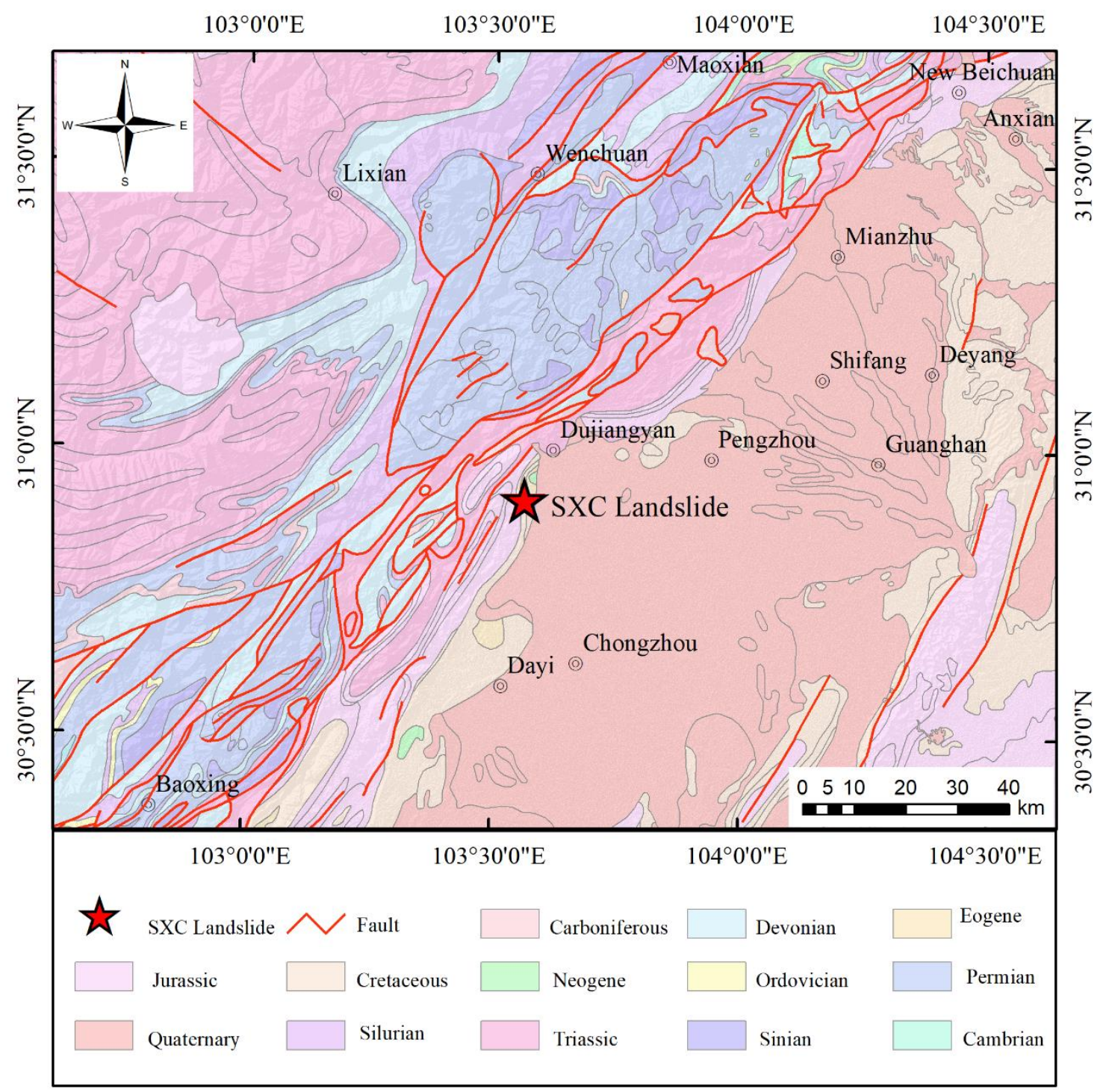

Fig. 1 Geologic setting of the study area

497
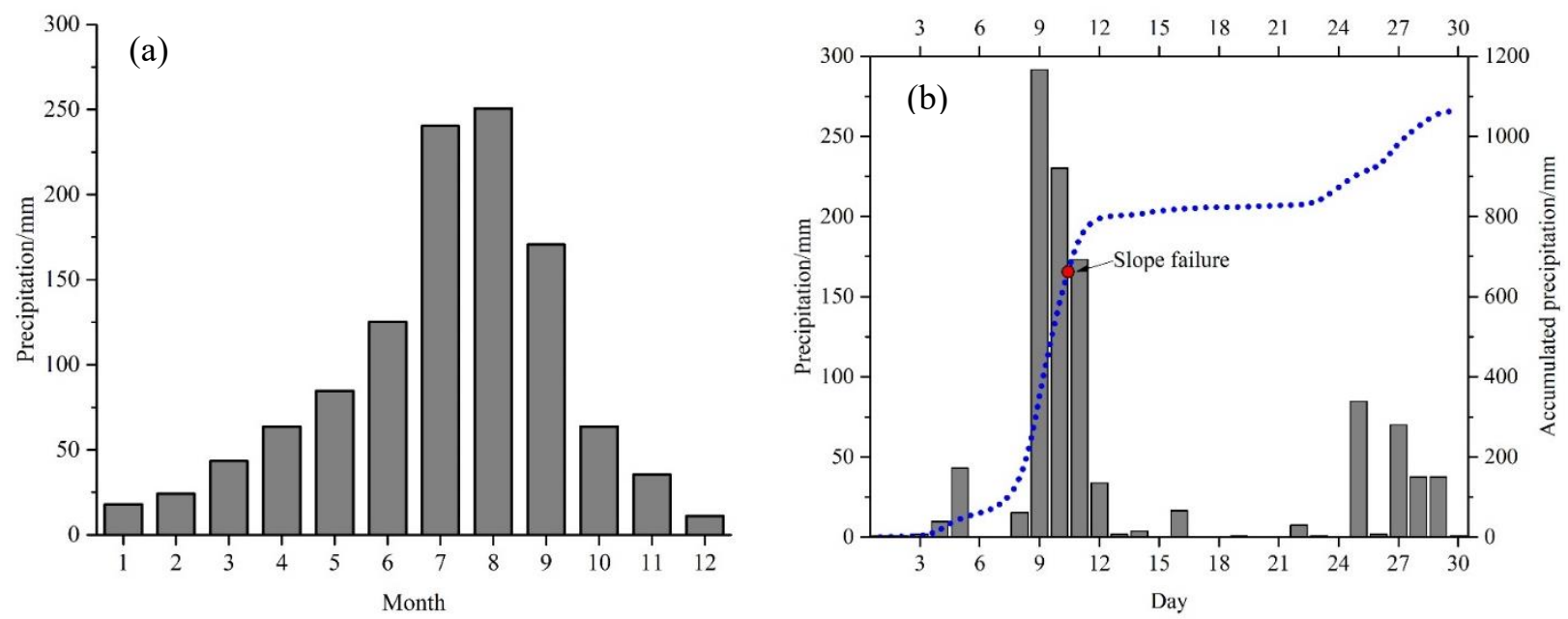

Fig. 2 Diagram of mean month precipitation at Dujiangyan from 1987 to 2012 (a) and precipitation and accumulated precipitation before and after the initiation of SXC landslide (b) 



Fig. 3 Pre-sliding image on April 17th, 2013 (a) and post-sliding image on June 5th, 2016 (b)

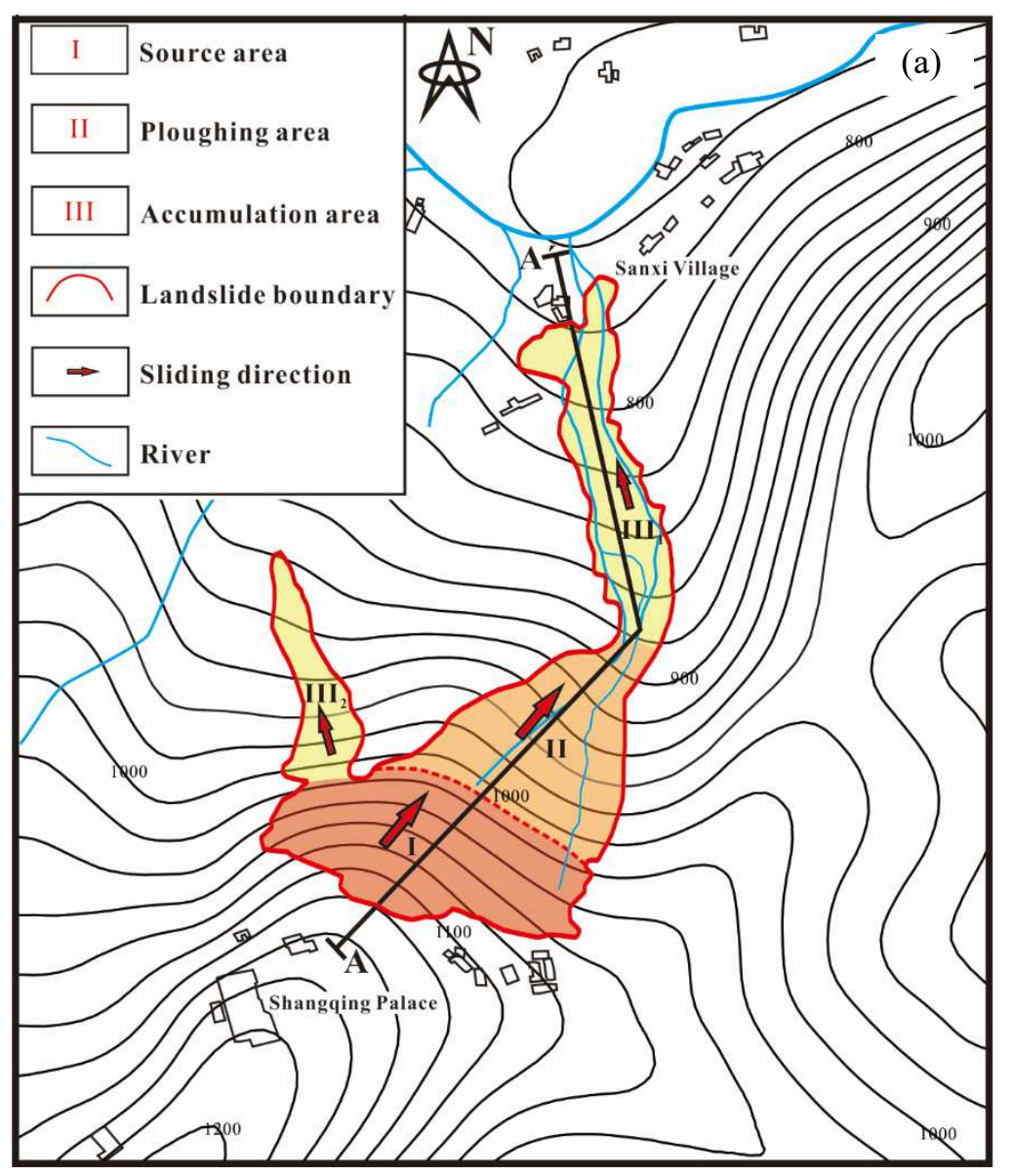




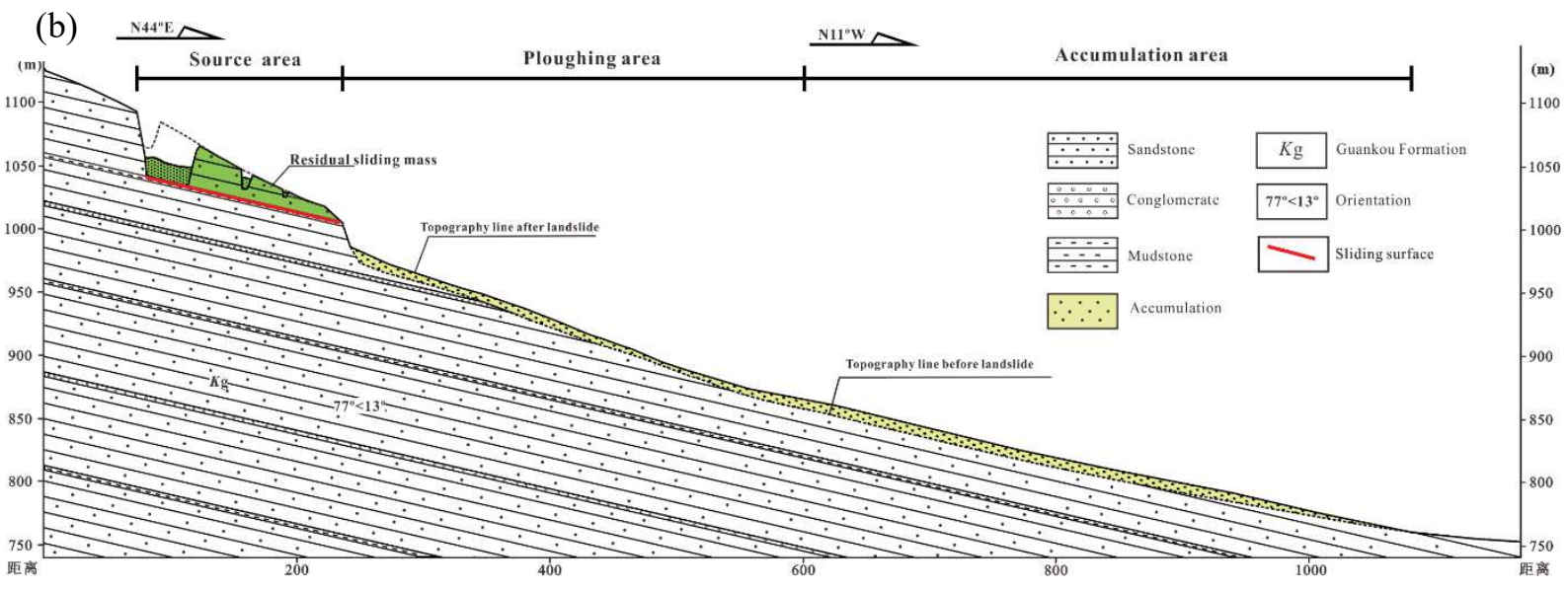

Fig. 4 SXC landslide map (a) and longitudinal profile of the landslide area (b)
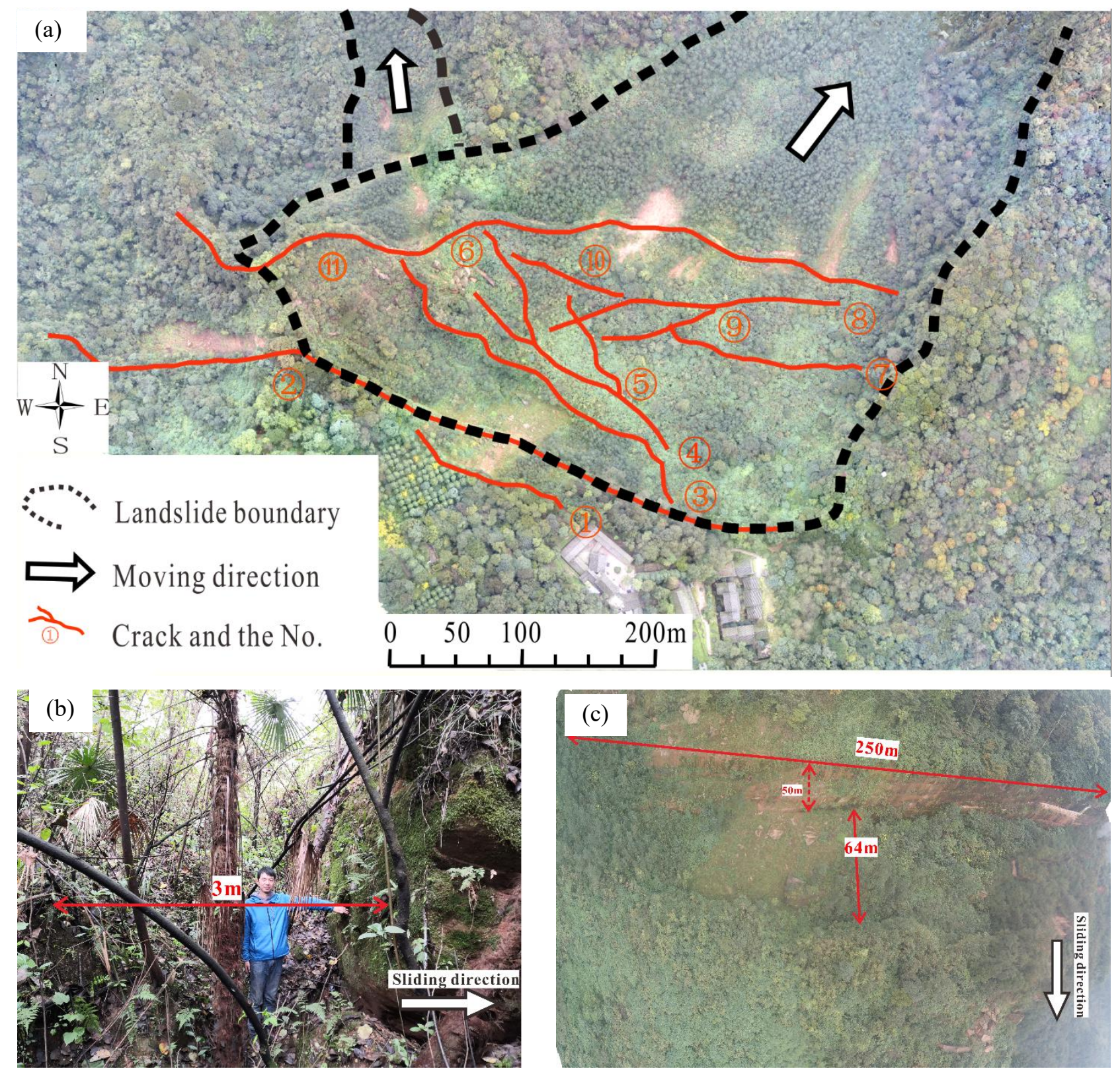
Fig. 5 The distribution of tension cracks in the source area (a), typical tension crack in the middle of residual sliding mass (b) and depression belt (c)
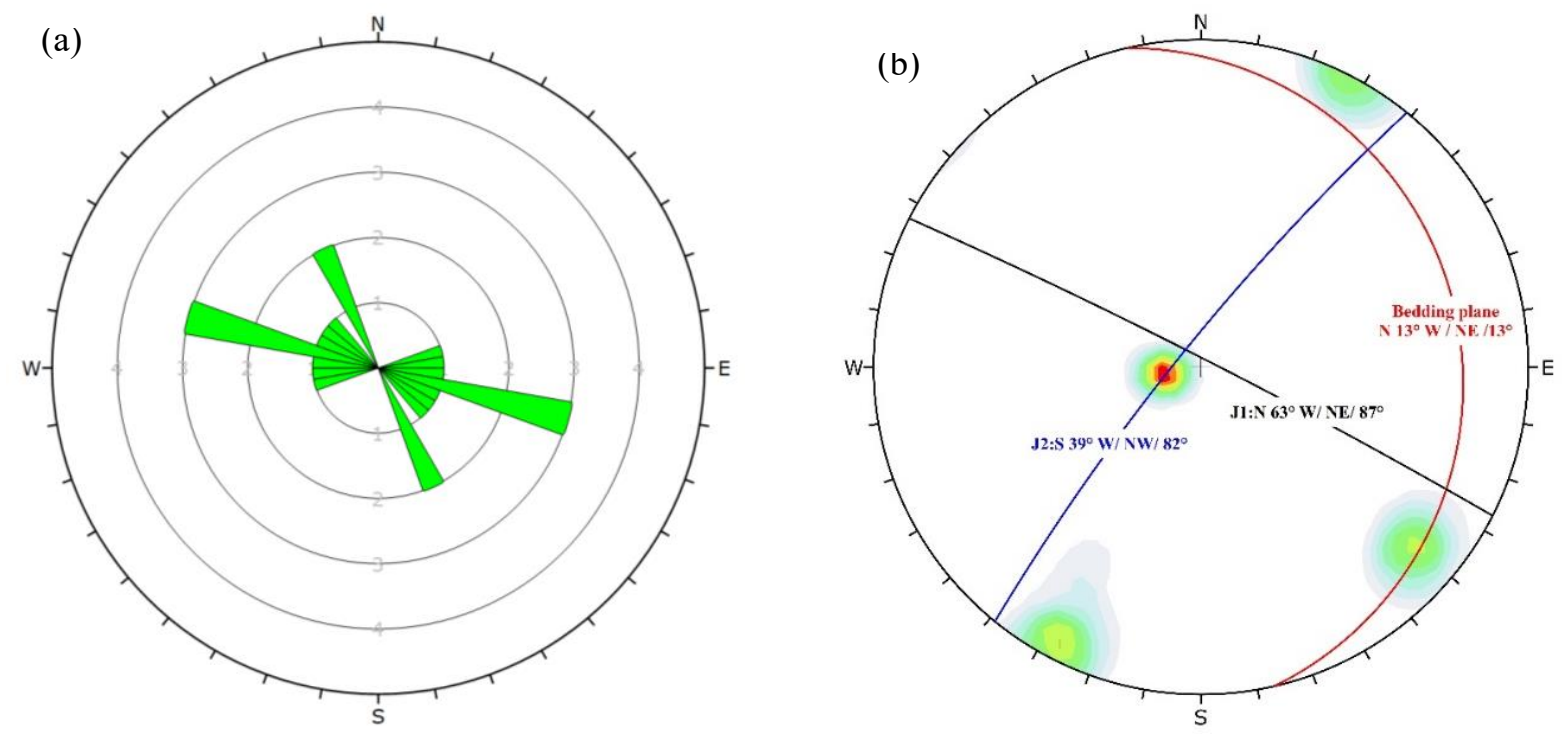

Fig. 6 Rose diagram of the tension crack strike (a) and stereographic projection of joints in the source area (b)

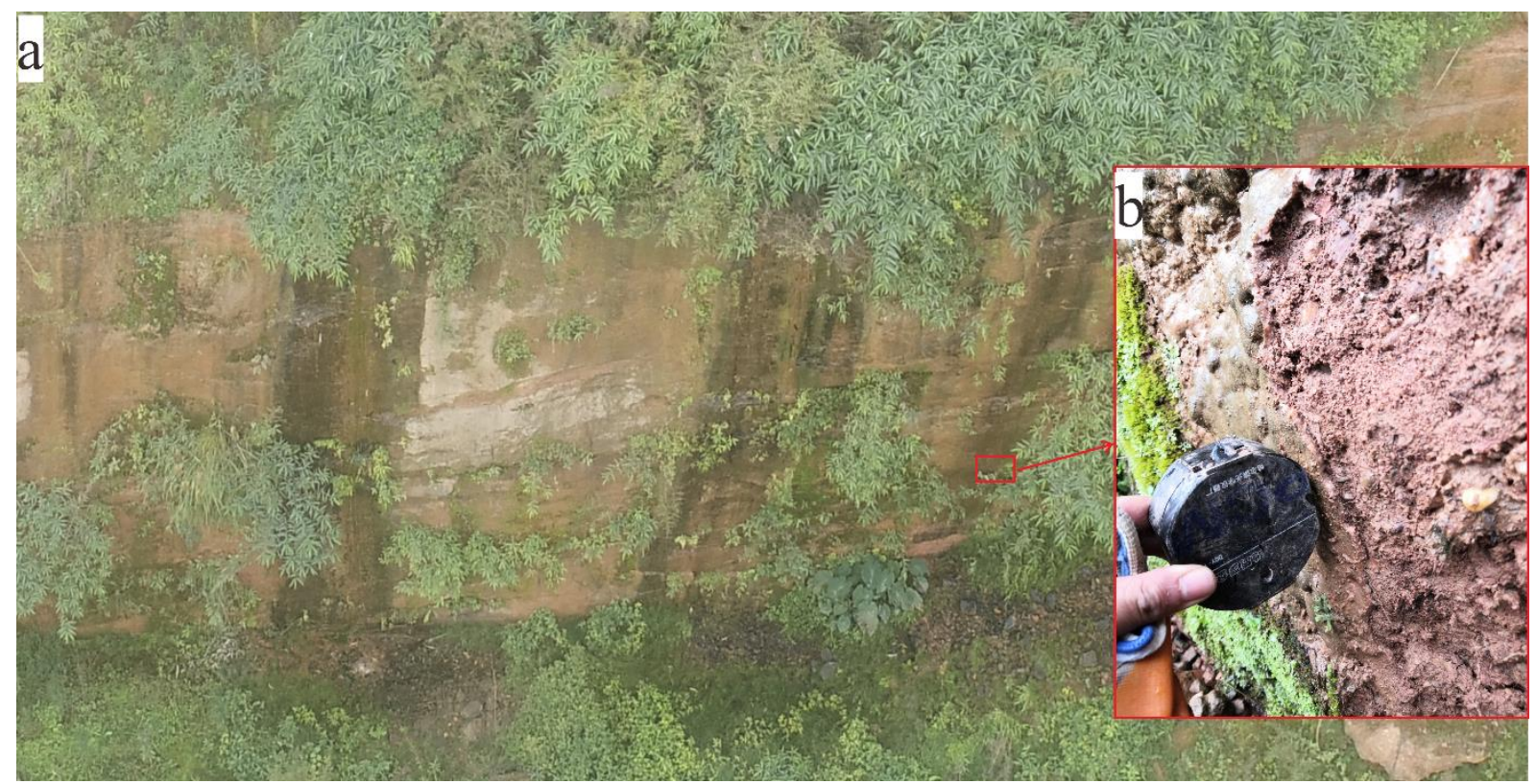

Fig. 7 Solution traces on the scarp surface (a) and a layer of calcareous film 

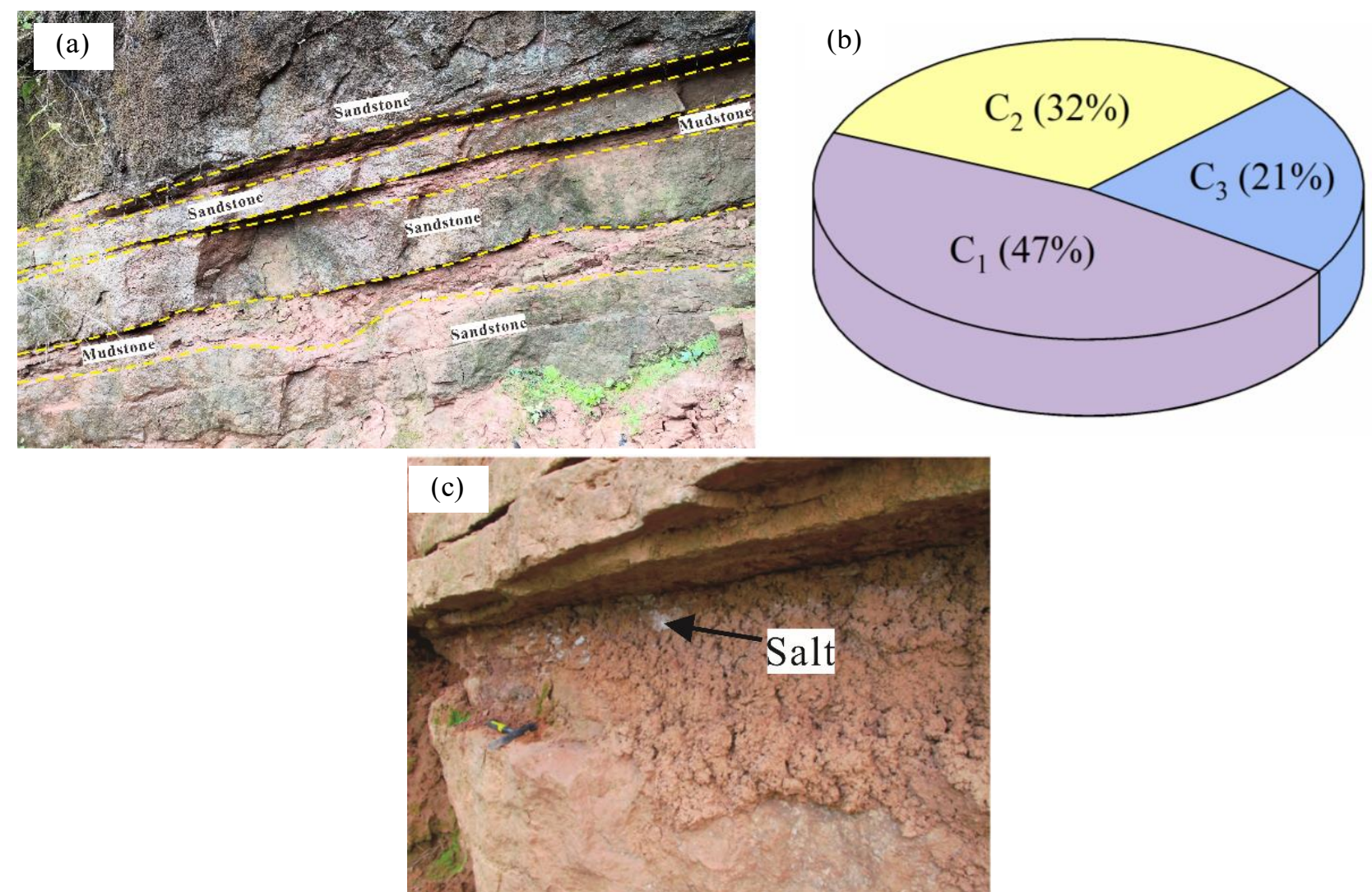

Fig. 8 Strata characteristic in the source area (a), the statistical results of cracks in mudstone layer (b), $\mathrm{C}_{1}$ : gently inclined cracks, $\mathrm{C}_{2}$ : 514 moderately -gently inclined cracks, $\mathrm{C}_{3}$ : steeply inclined cracks, and salt extracted from mudstone (c) (Du et al., 2016)

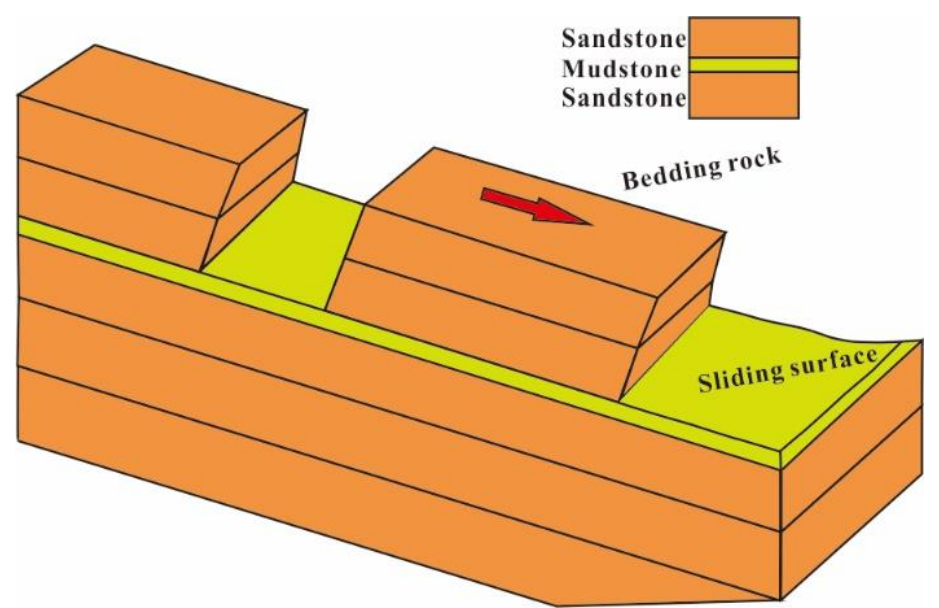

Fig. 9 Diagram of strata, sliding surface, and slide block
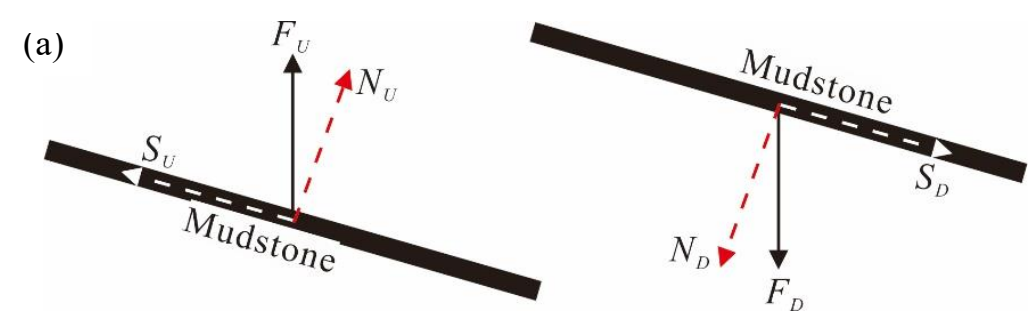

(b) 


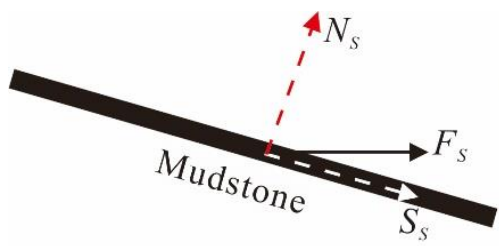

519

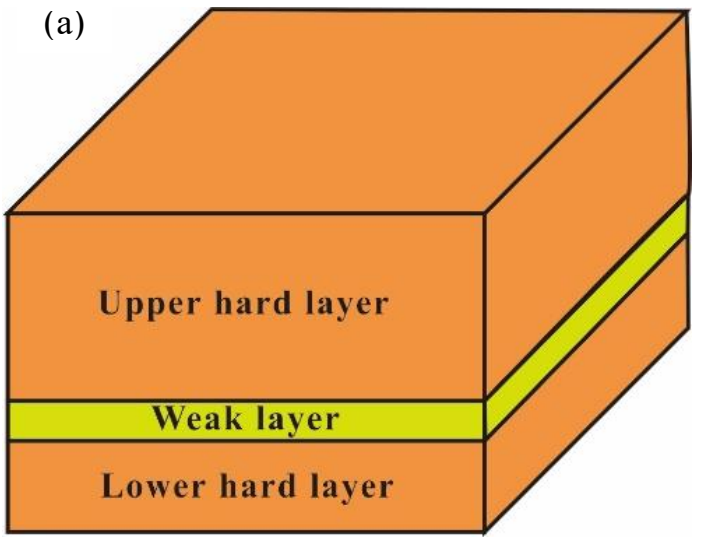

(b)

(c)
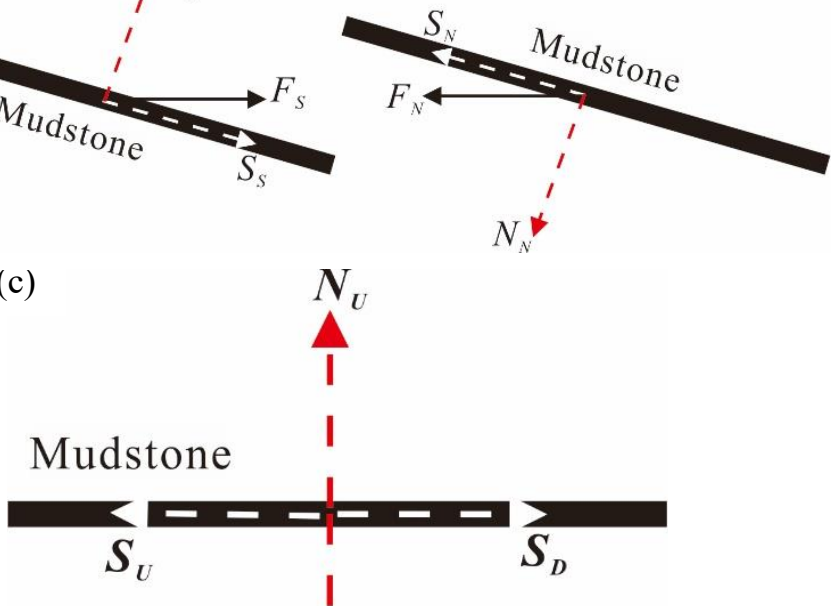

$N_{D}^{\mathrm{I}}$

Fig. 10 Simplified mechanical mode: (a) decomposition of vertical seismic force, (b) decomposition of horizontal seismic force, and (c) seismic force composition
)
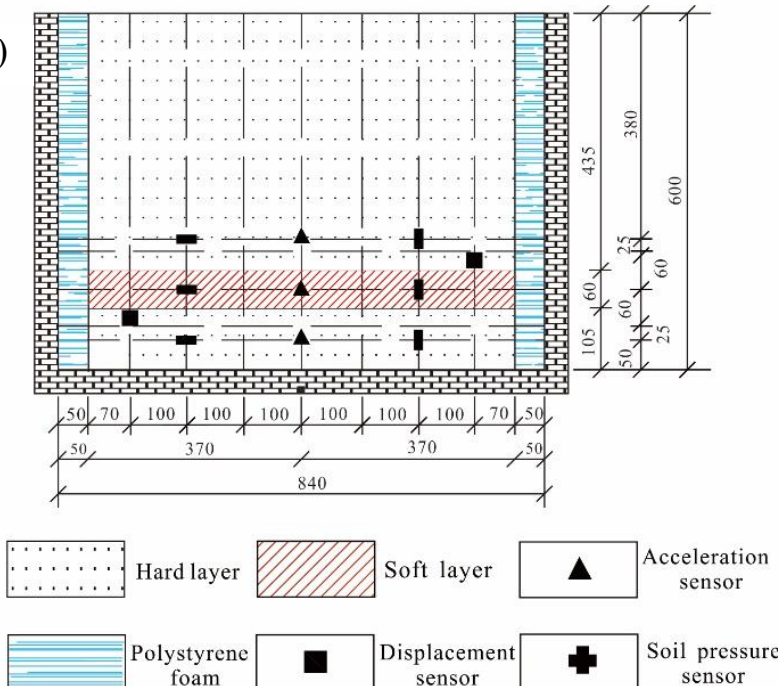


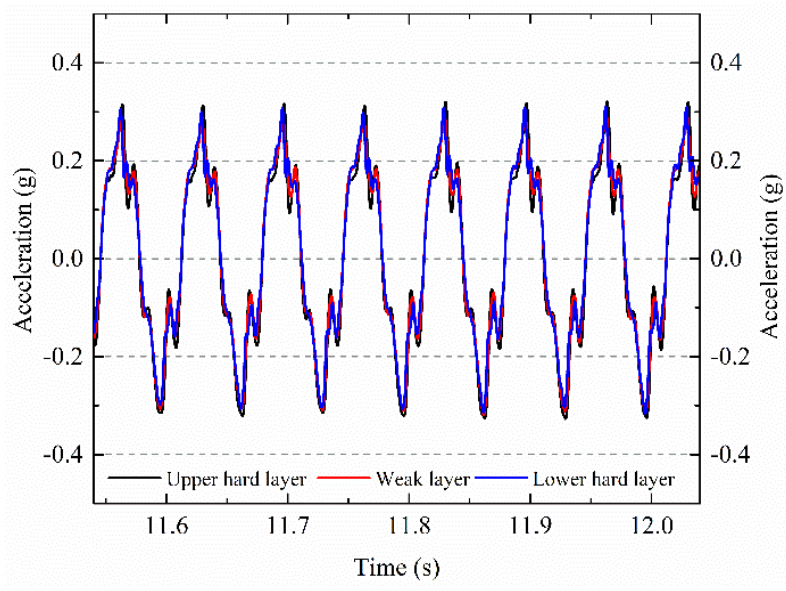

(a) Vertical vibration

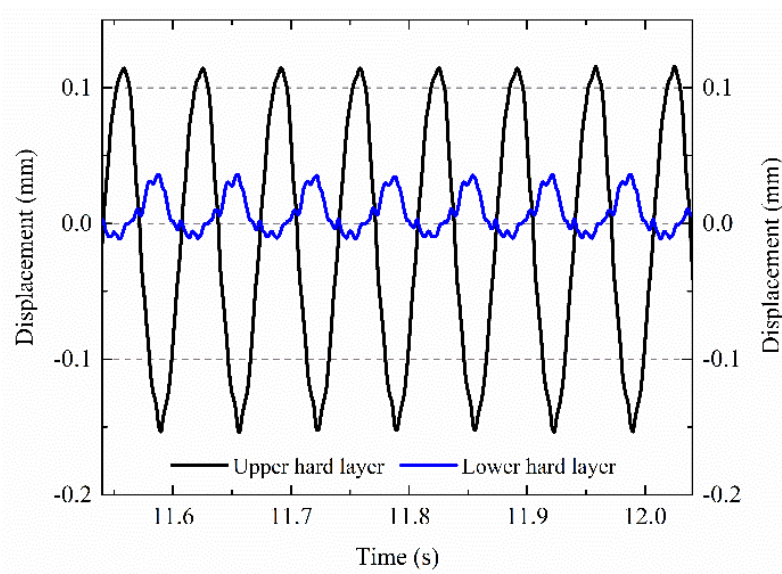

(c) Vertical vibration

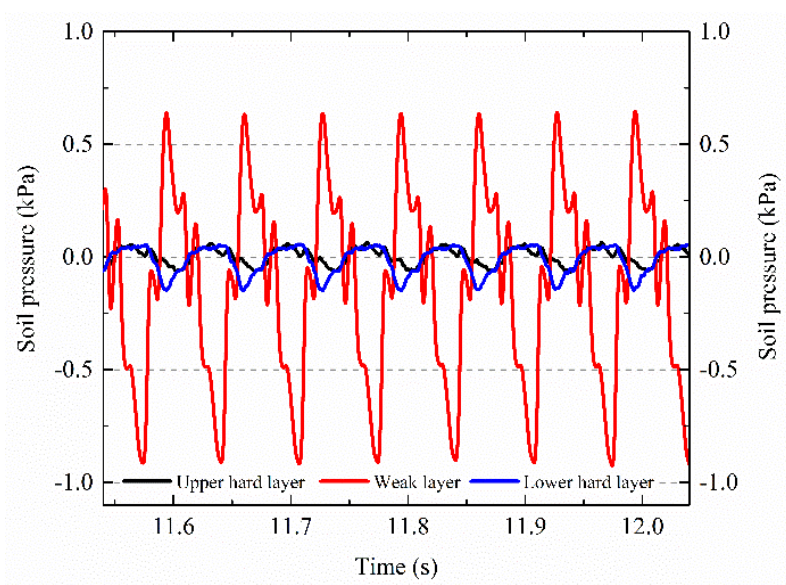

(e) Vertical vibration

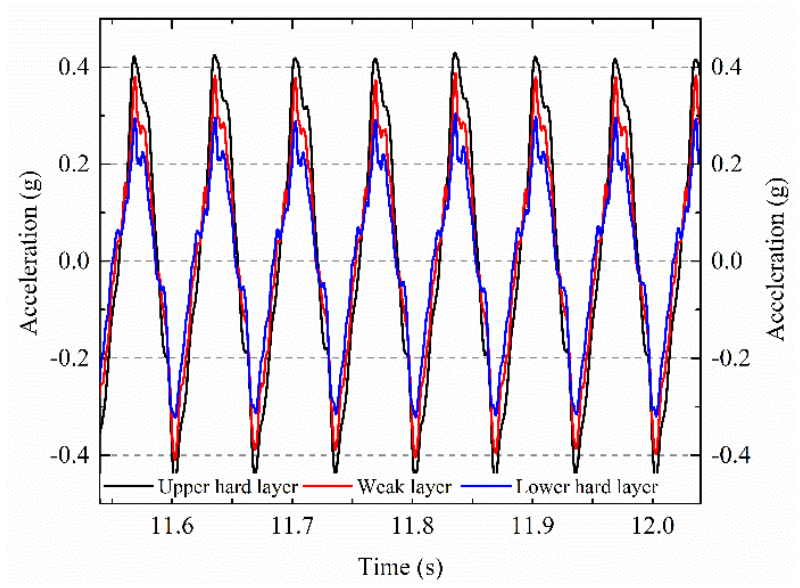

(b) Horizontal vibration

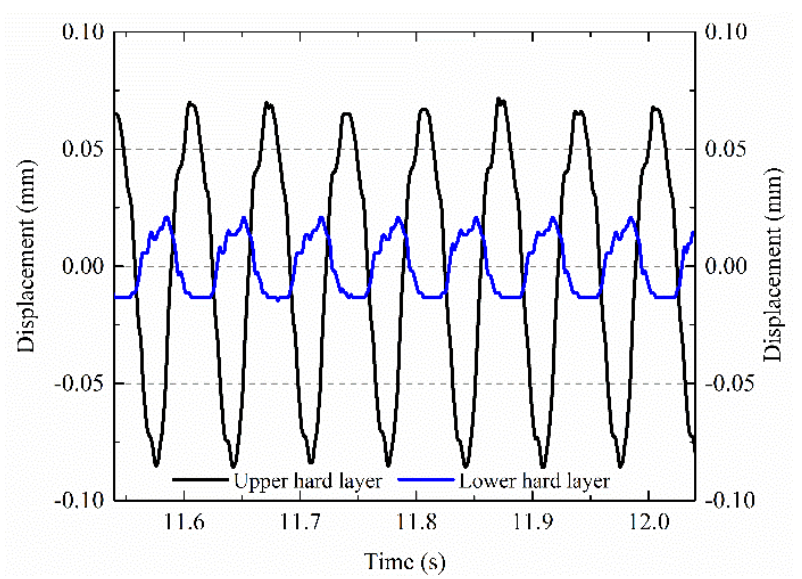

(d) Horizontal vibration

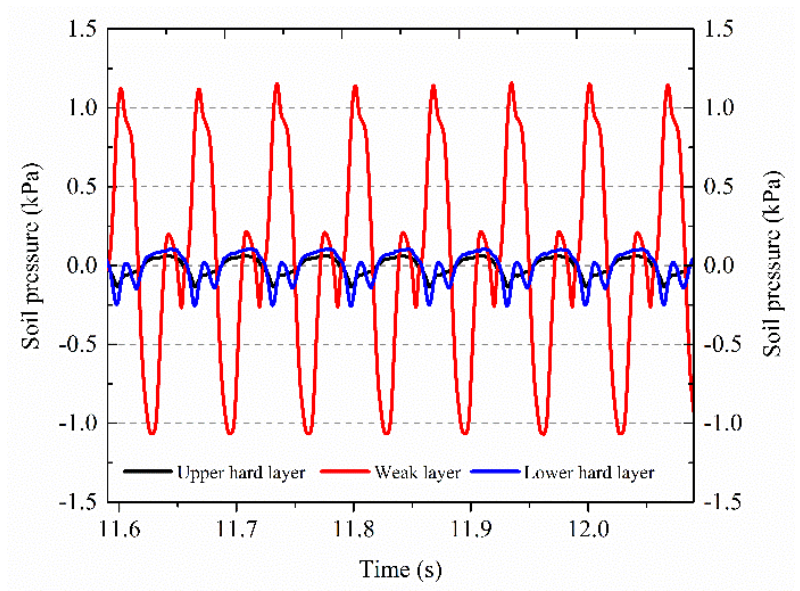

(f) Horizontal vibration 

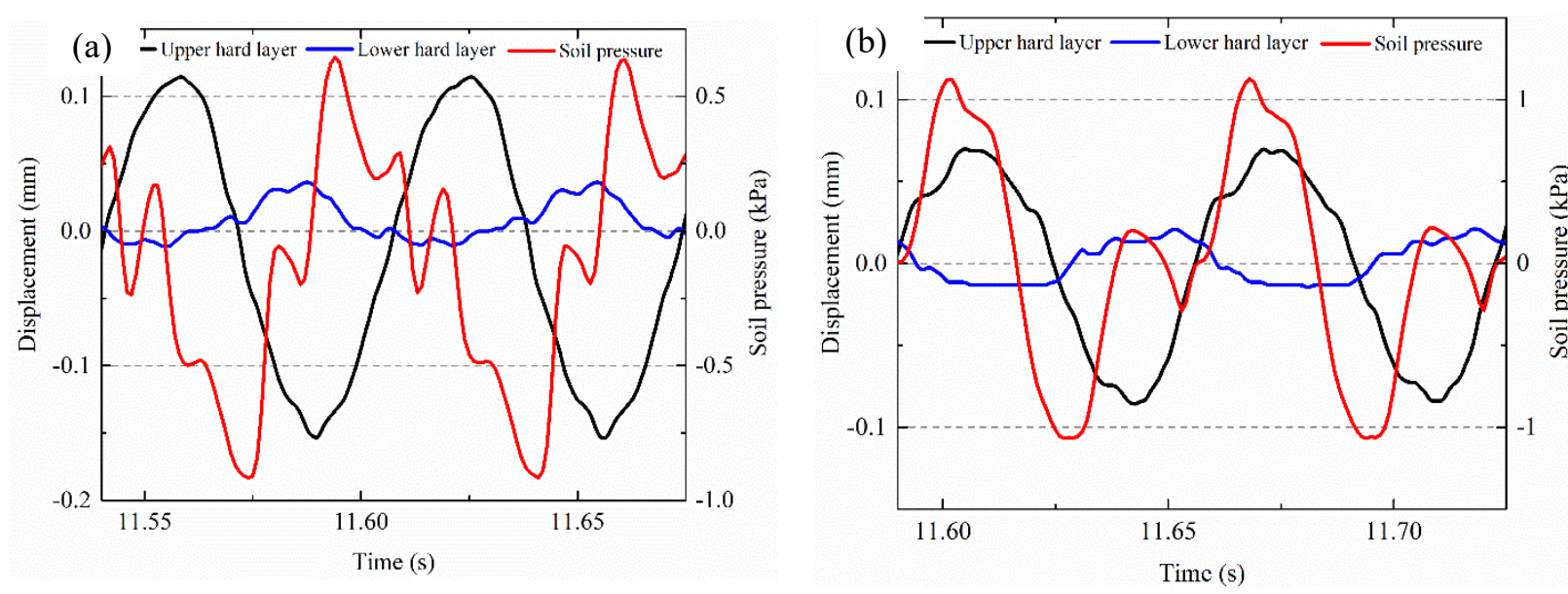

Fig. 13 Curves of displacement, soil pressure versus time: (a) vertical vibration, and (b) horizontal vibration
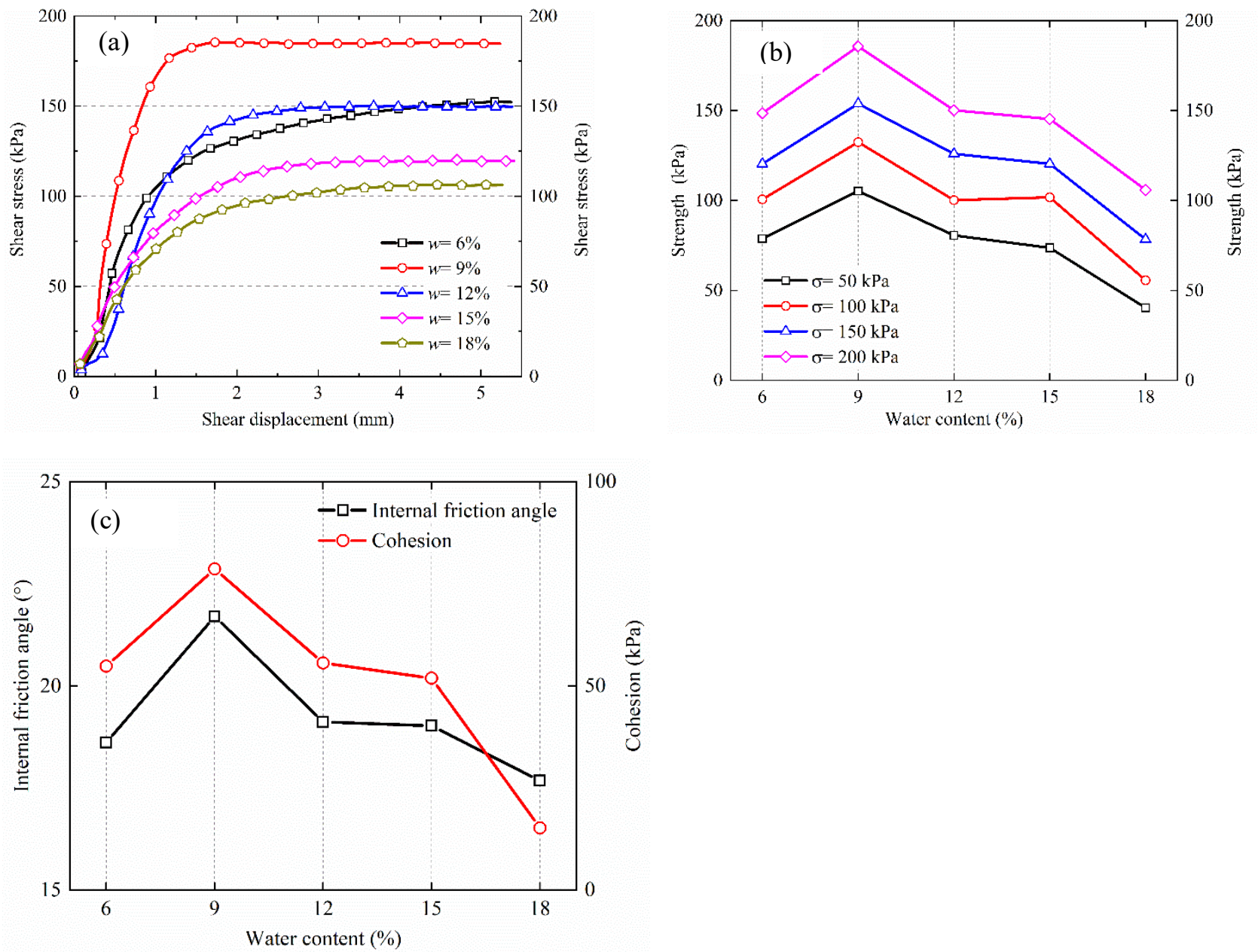

Fig. 14 Direct shear test results for samples with different water contents: (a) shear stress versus displacement curves, (b) shear strength versus water content curves, and (c) internal friction angle and cohesion versus water content curves 

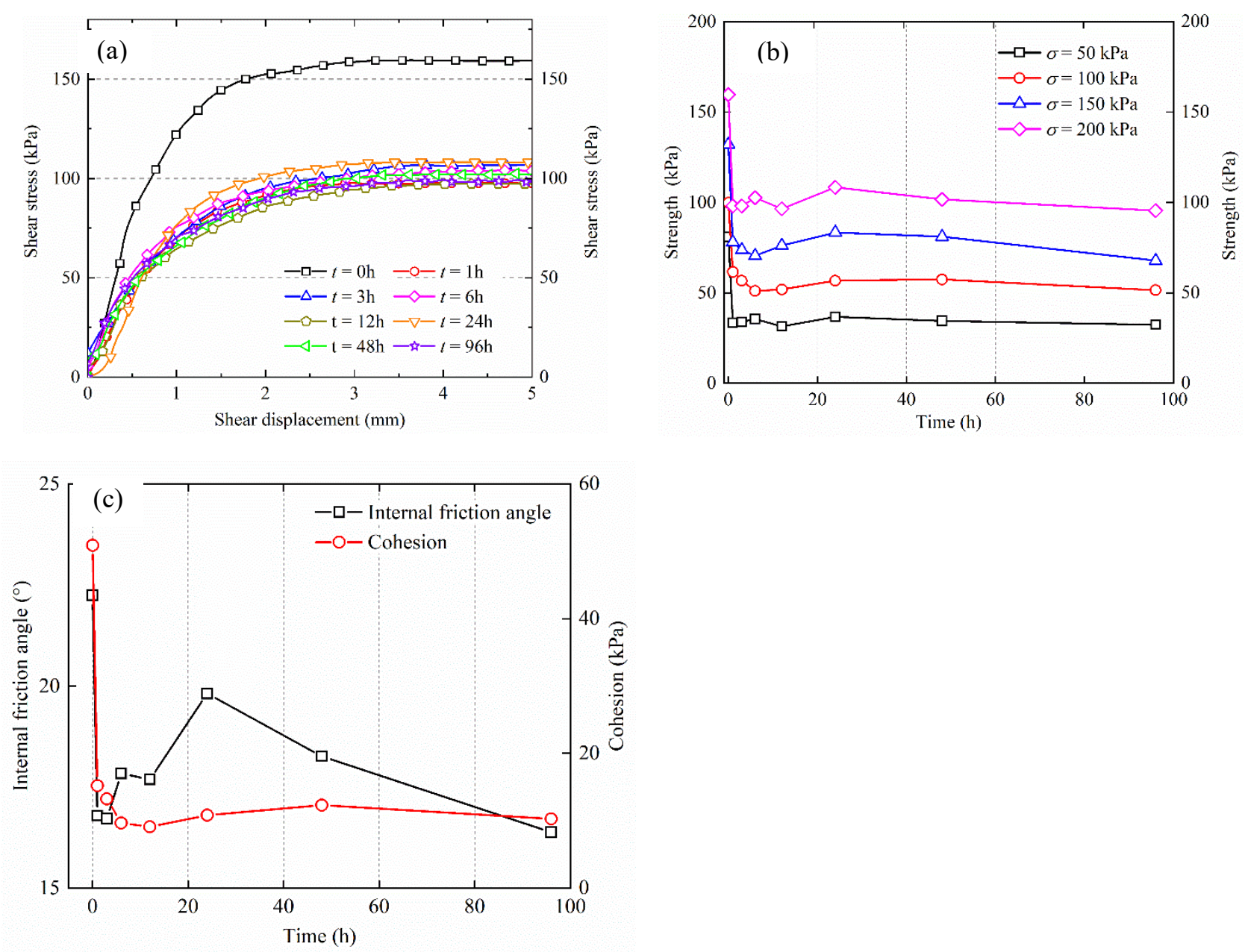

Fig. 15 Direct shear test results for samples with different immersion times: (a) shear stress versus displacement curves for $\sigma=200 \mathrm{kPa}$,

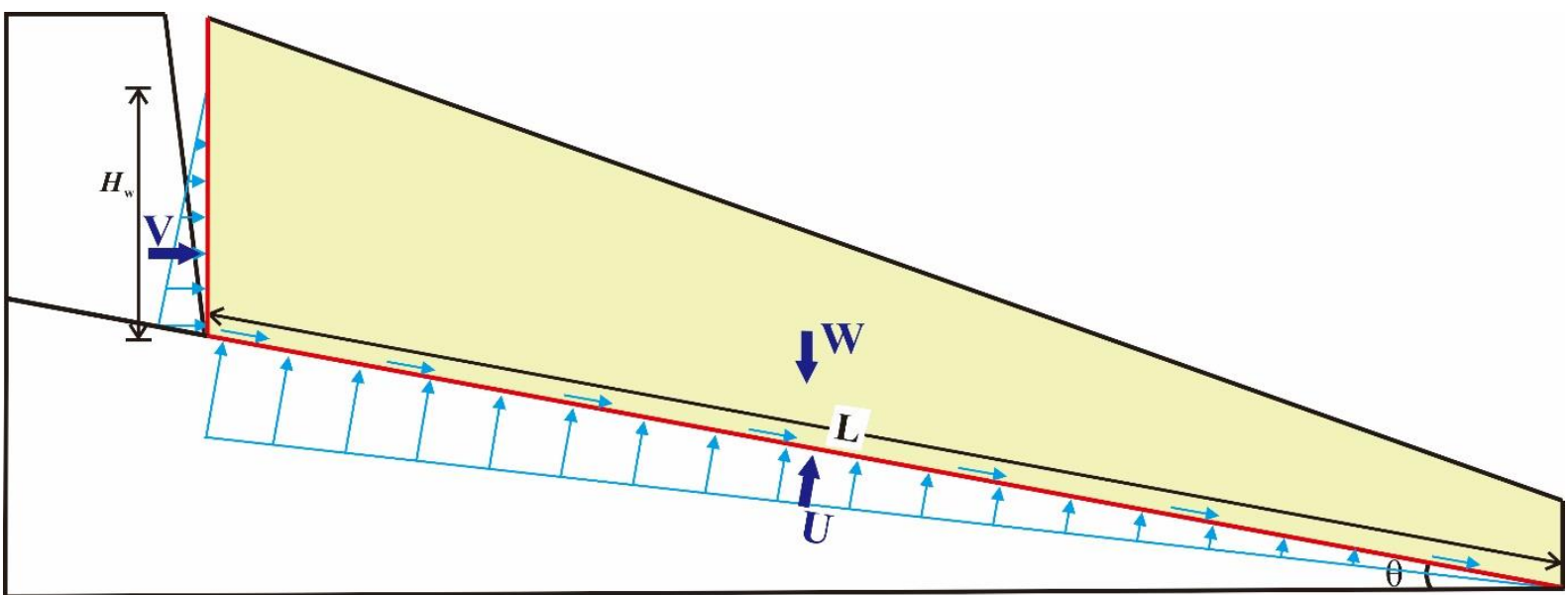

Fig. 16 Stability calculation of profile B-B' 


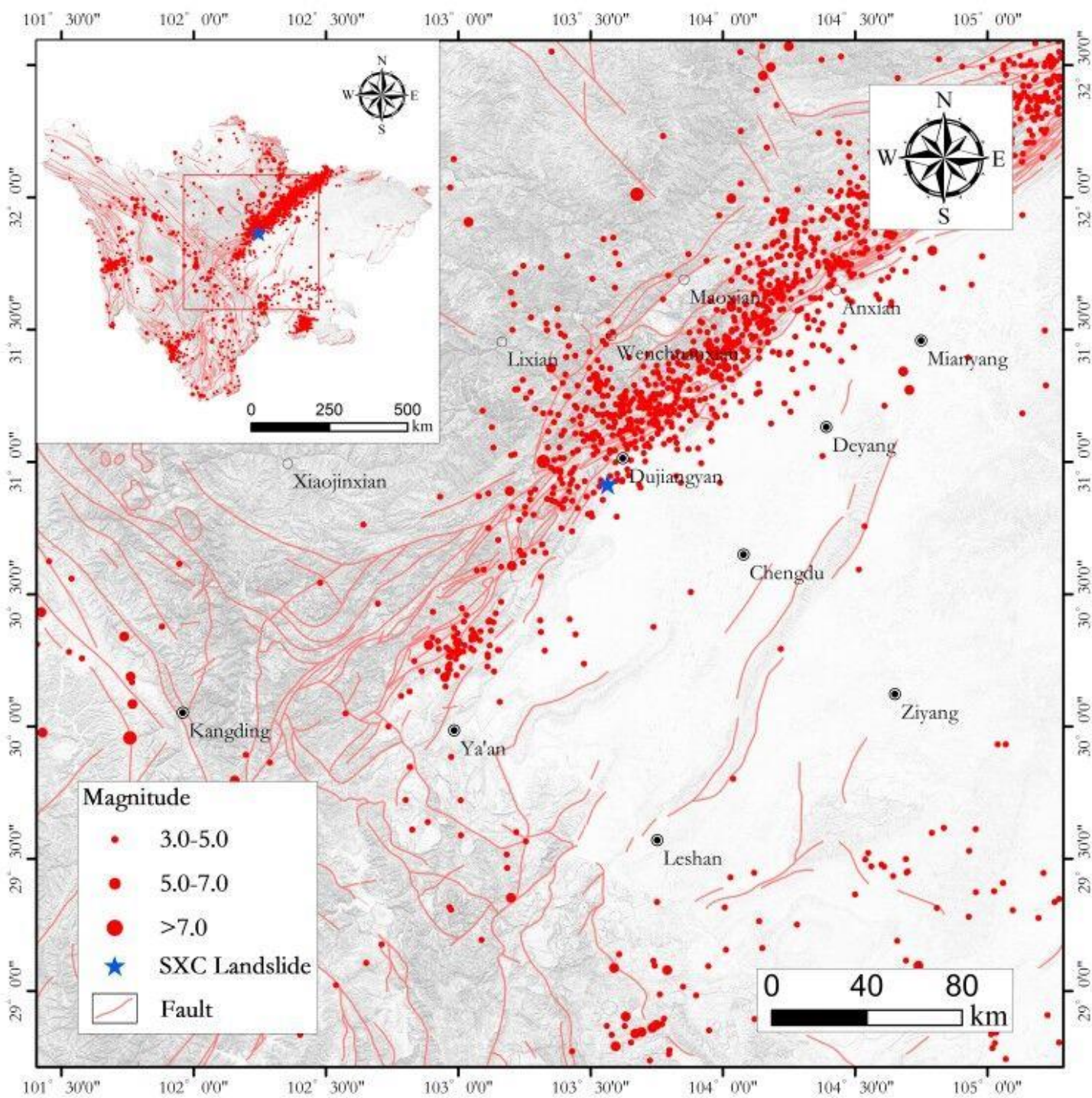

Fig. 17 Earthquake events occurring in the adjacent area since 1900
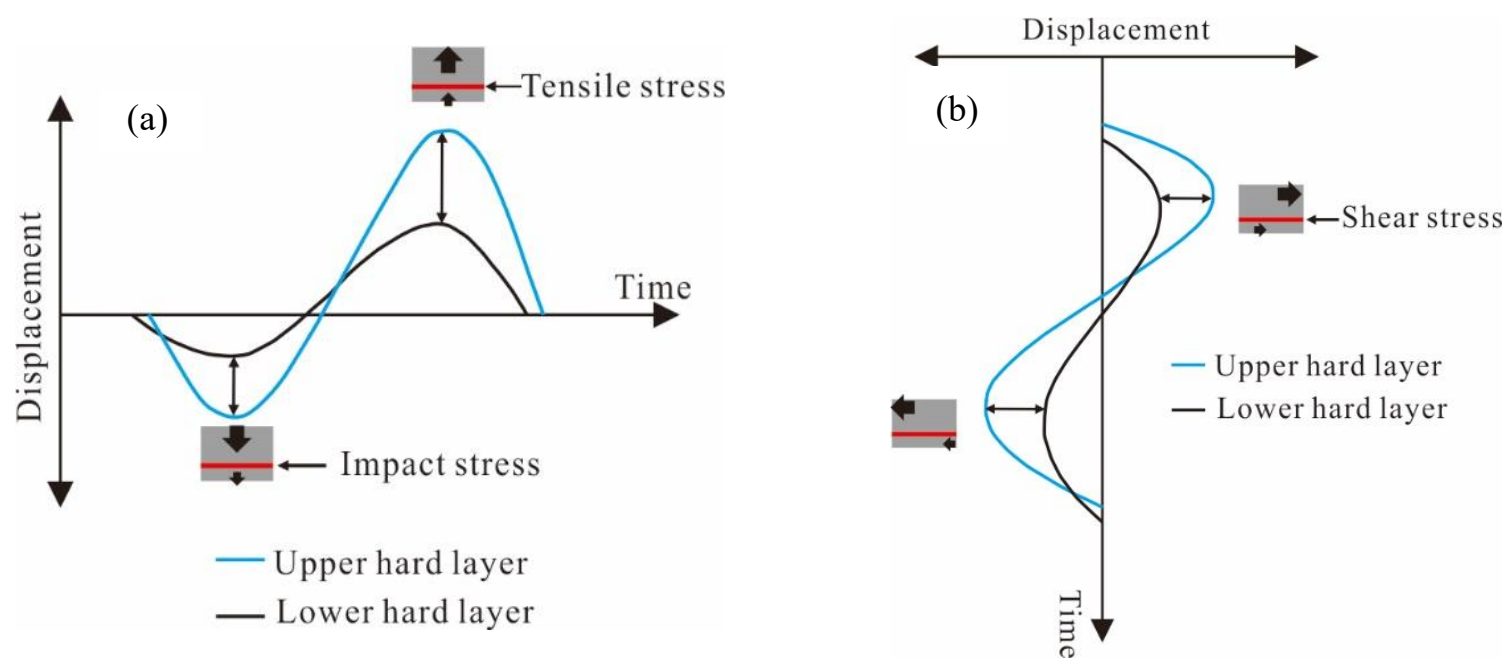

Fig. 18 Diagram of incompatible deformation in the model: (a) impact and tension stresses, (b) shear stress 

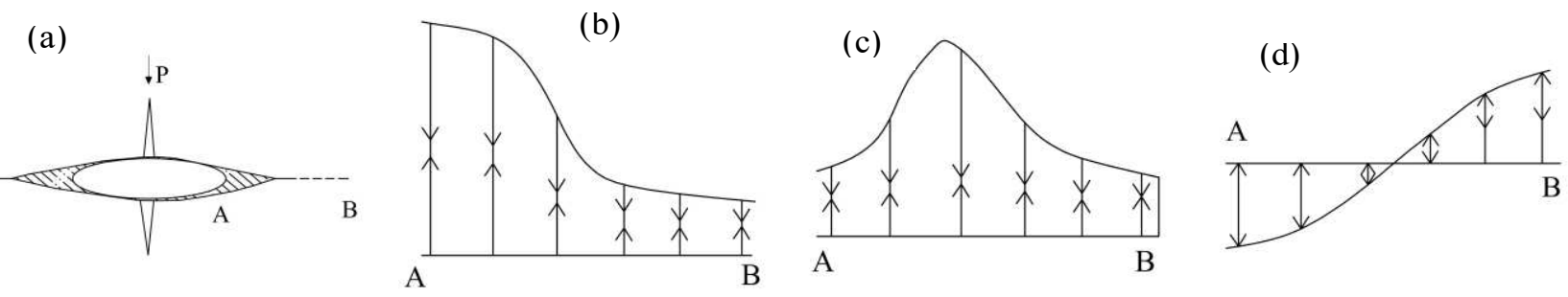

Fig. 19 Mechanisms of crack propagation under compression stress (modified by Lajtai 1977): (a) the tension fracture pattern of the original crack, (b) the stress concentration position at the crack tip, (c) transfer of stress concentration position, and (d) residual tension
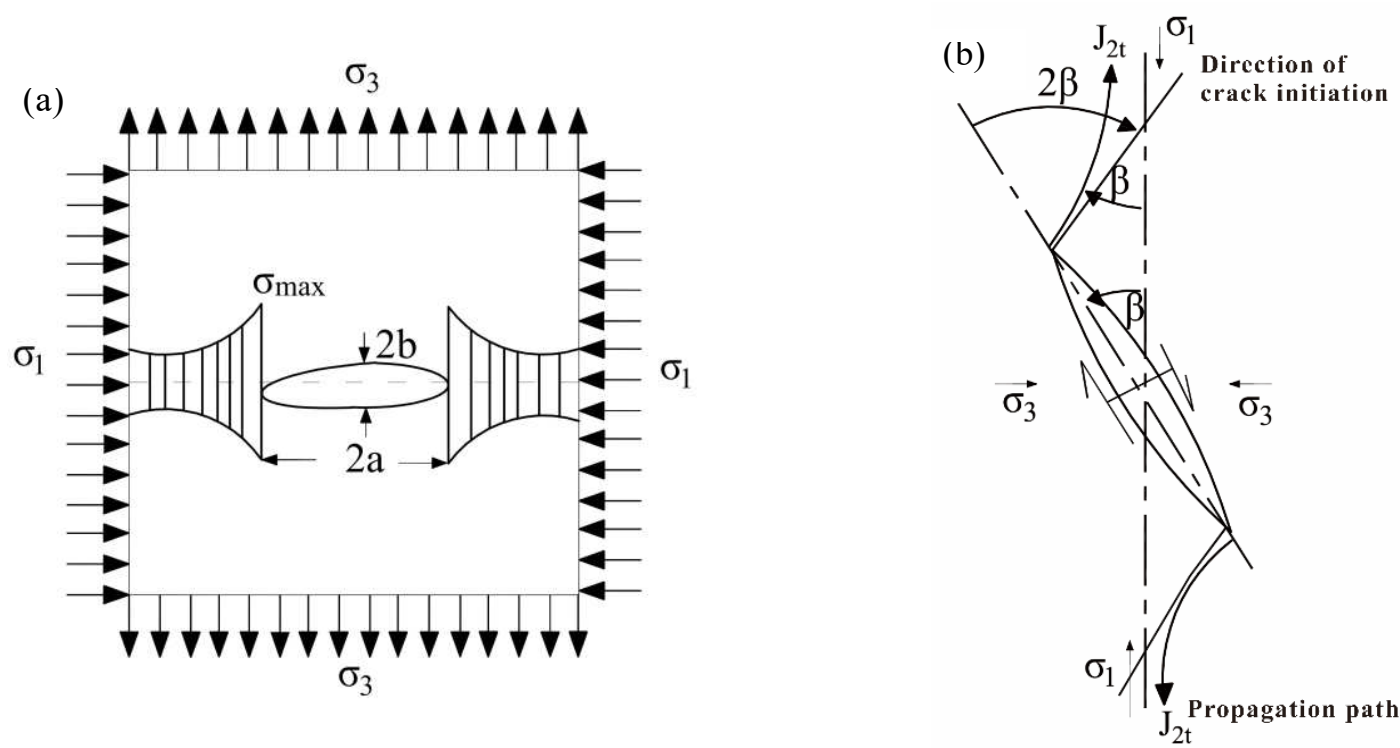

(a)

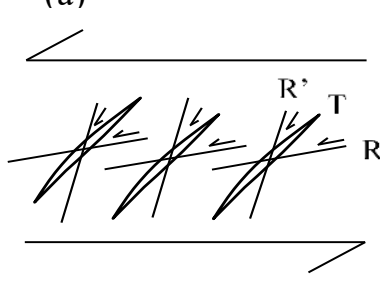

(b)

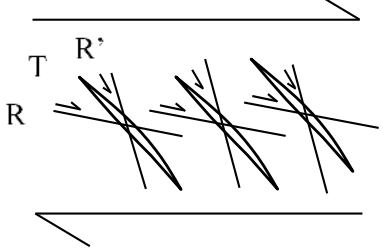

(c)

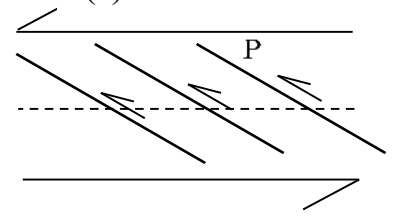

(d)

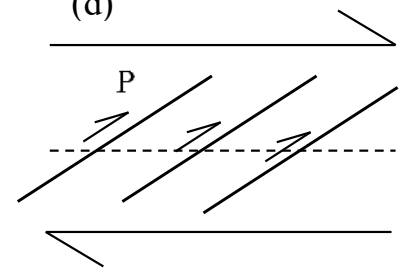

Fig. 21 Mechanisms of crack propagation under cyclic shear stress, a. sinistral tension cracks, b. dextral tension cracks, c sinistral 

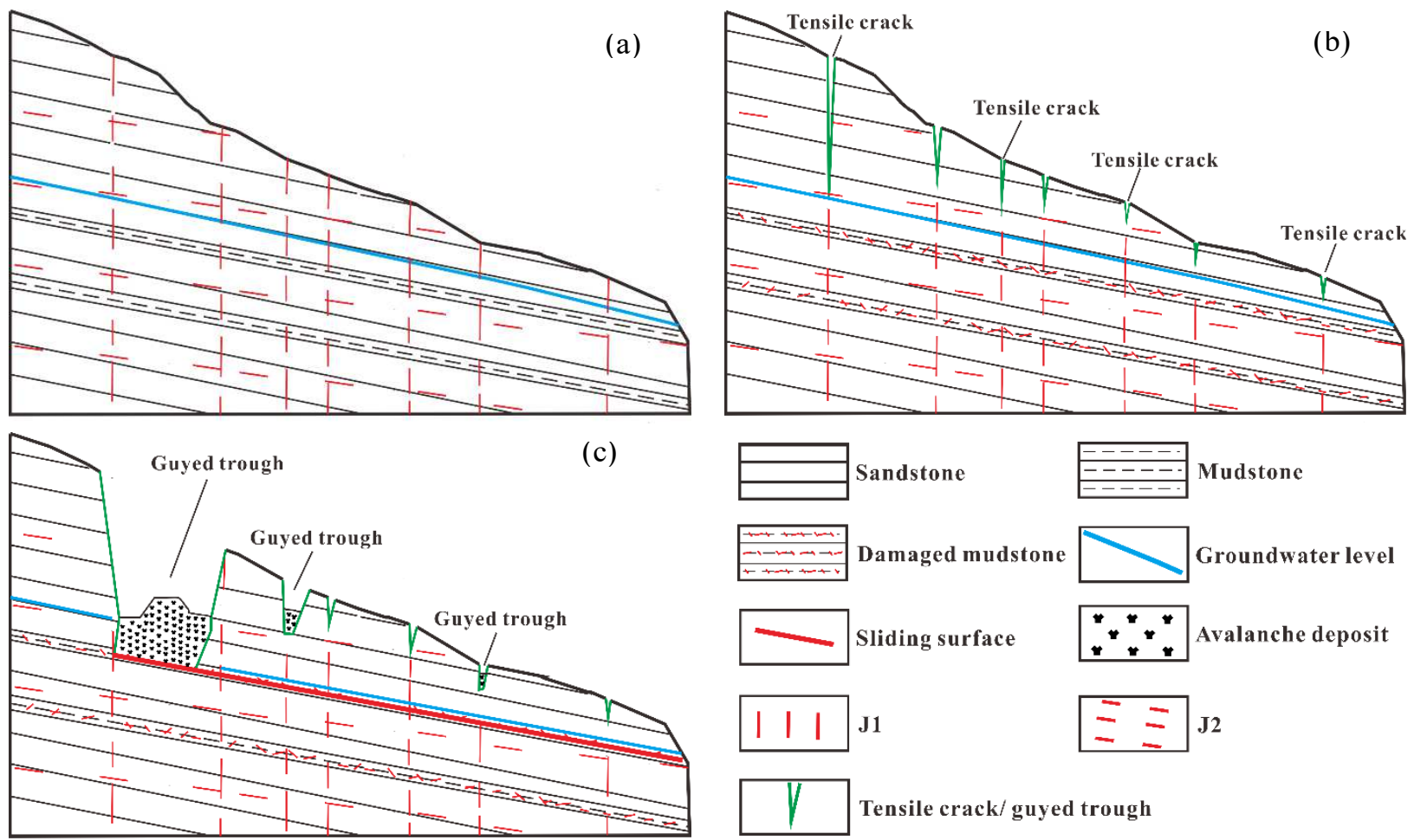

Fig. 22 Formation and evolution process of the cracked slope, (a) original slope with joints (b) seismic cracks formed by historical earthquakes, (c) progressive deformation of slope and the formation of tension cracks under the combined influence of earthquake,

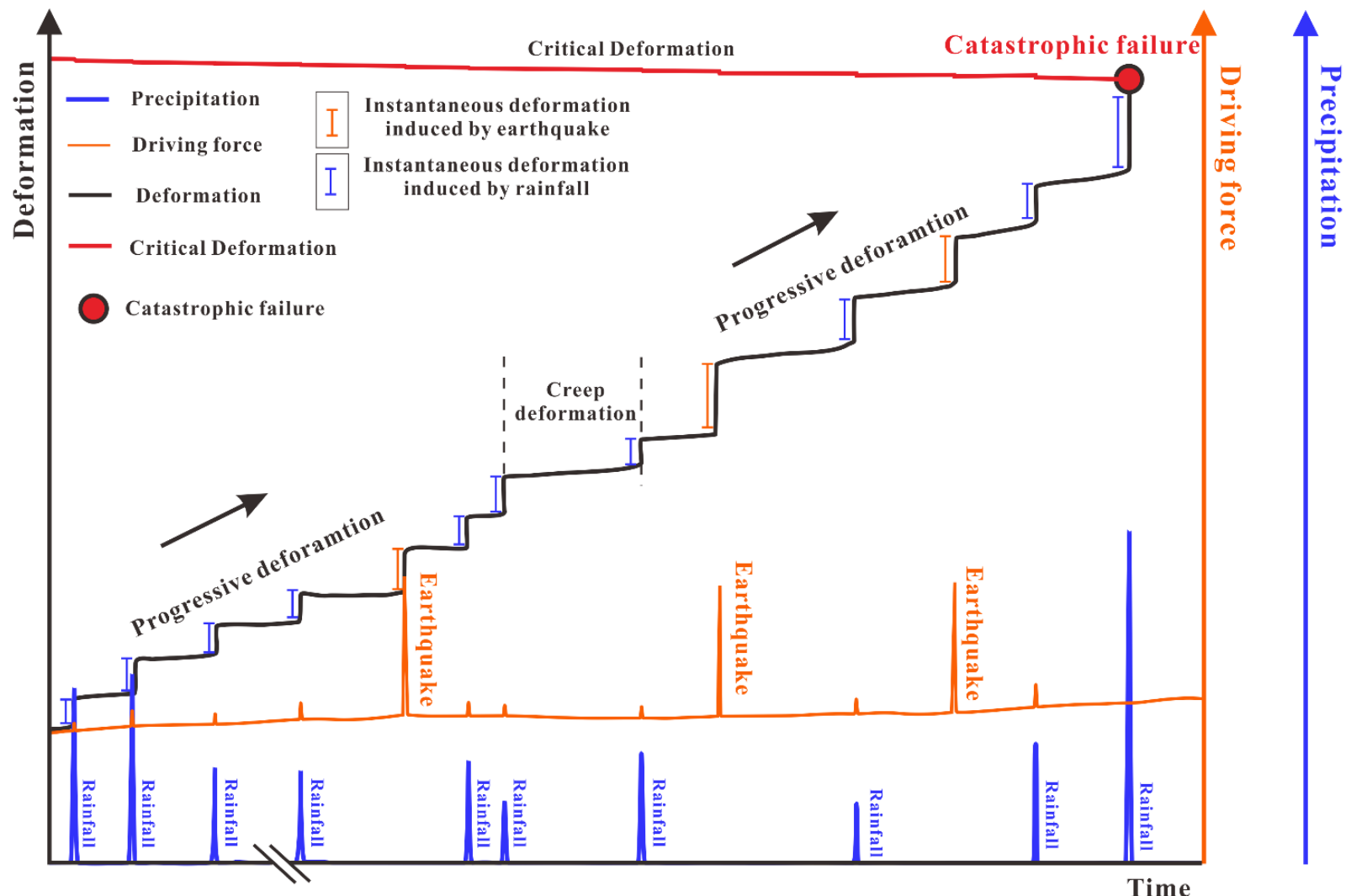

Fig. 23 Progressive deformation process of SXC slope under the influence of historical earthquakes, gravity and rainfall 
Topographic condiction

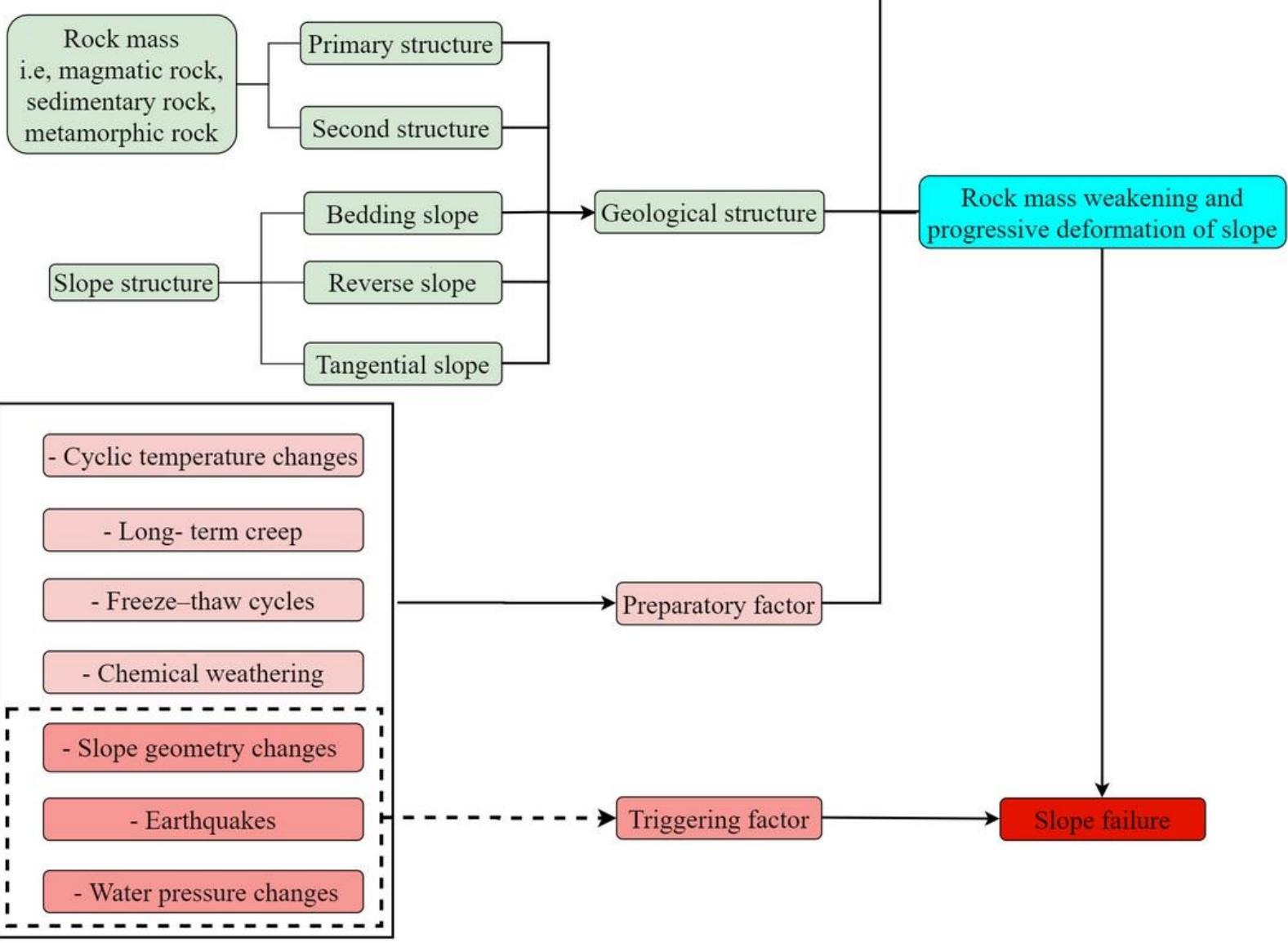

Fig. 24 Flowchart illustrating the rock mass weakening and progressive failure of slope 


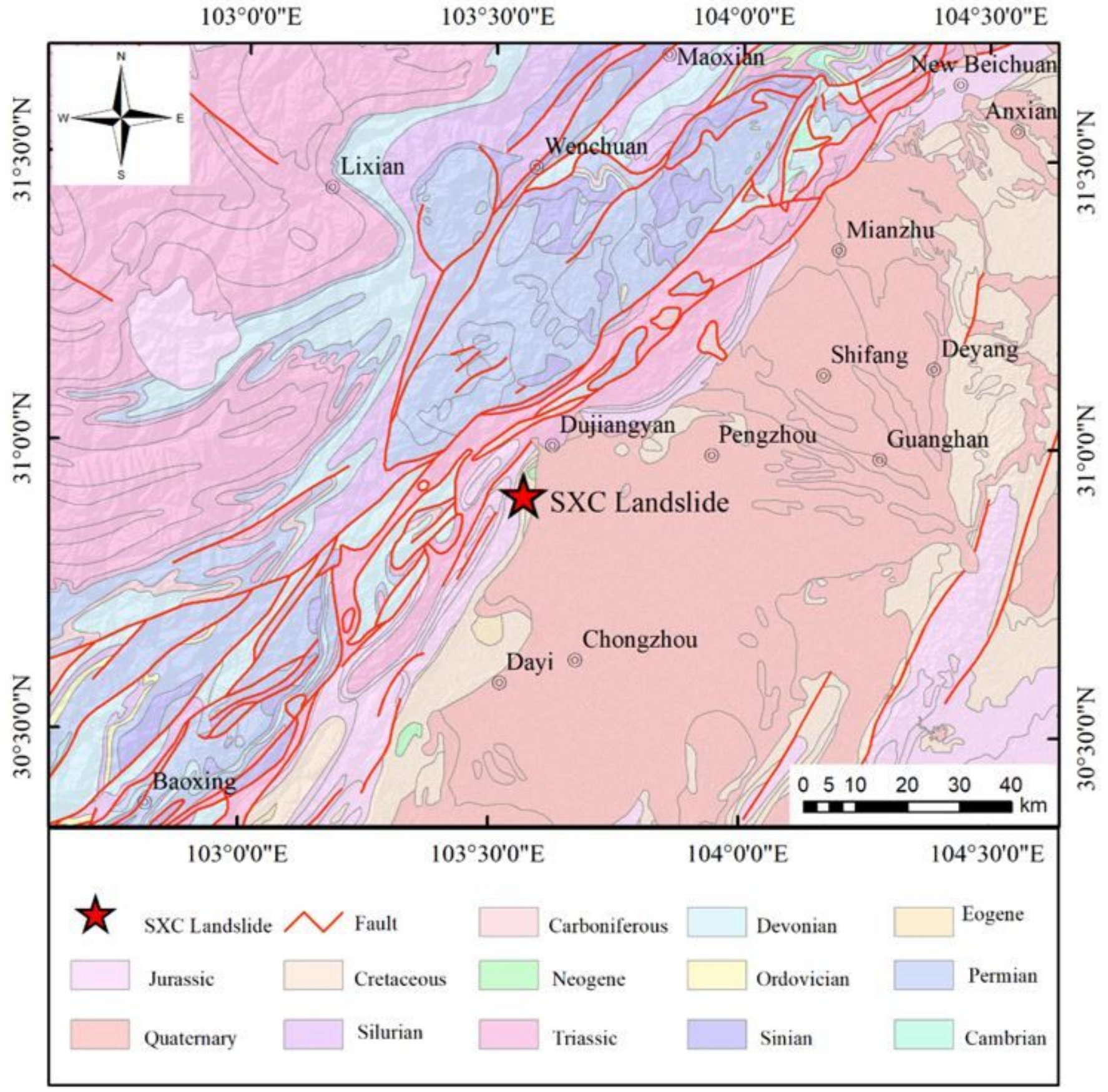

\section{Figure 1}

Geologic setting of the study area Note: The designations employed and the presentation of the material on this map do not imply the expression of any opinion whatsoever on the part of Research Square concerning the legal status of any country, territory, city or area or of its authorities, or concerning the delimitation of its frontiers or boundaries. This map has been provided by the authors. 

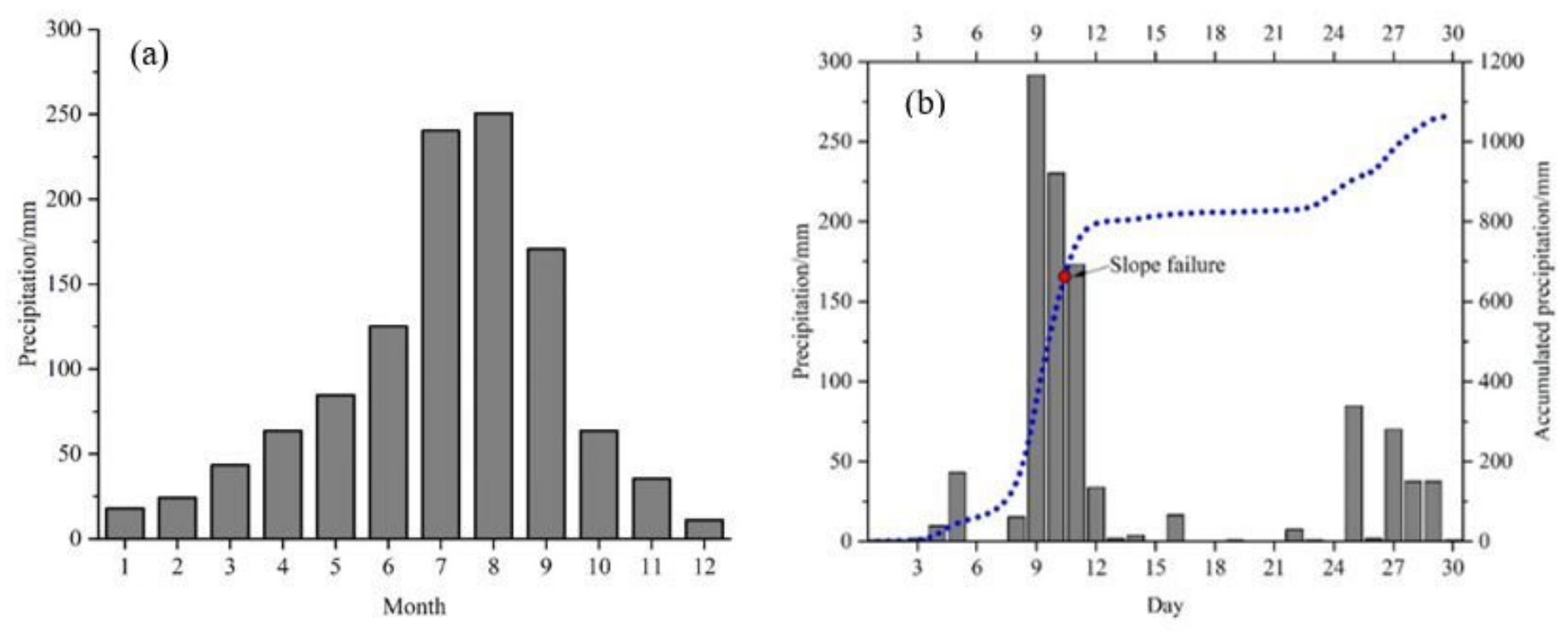

Figure 2

Diagram of mean month precipitation at Dujiangyan from 1987 to 2012 (a) and precipitation and accumulated precipitation before and after the initiation of SXC landslide (b)
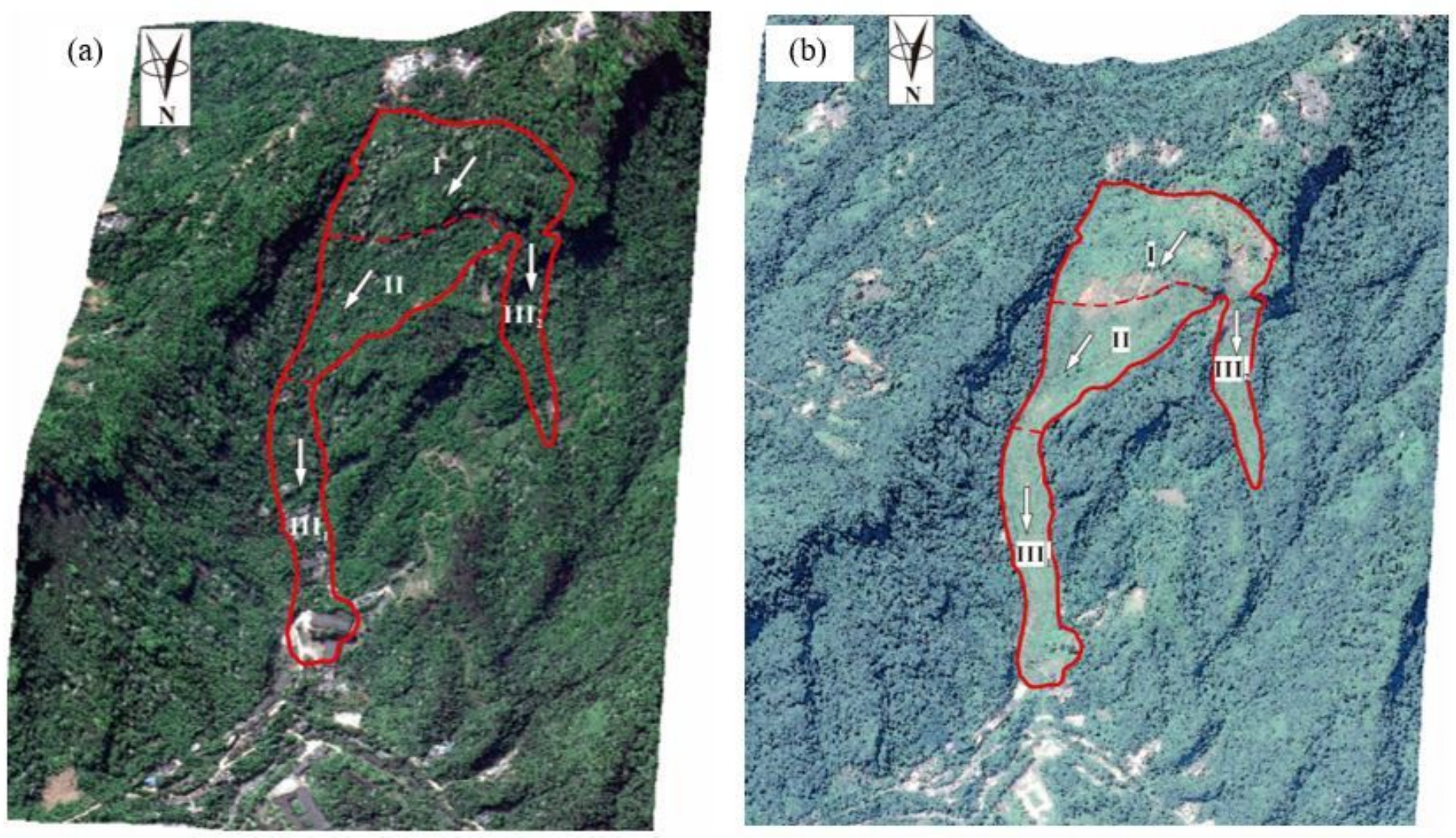

Figure 3 
Pre-sliding image on April 17th, 2013 (a) and post-sliding image on June 5th, 2016 (b) Note: The designations employed and the presentation of the material on this map do not imply the expression of any opinion whatsoever on the part of Research Square concerning the legal status of any country, territory, city or area or of its authorities, or concerning the delimitation of its frontiers or boundaries. This map has been provided by the authors.
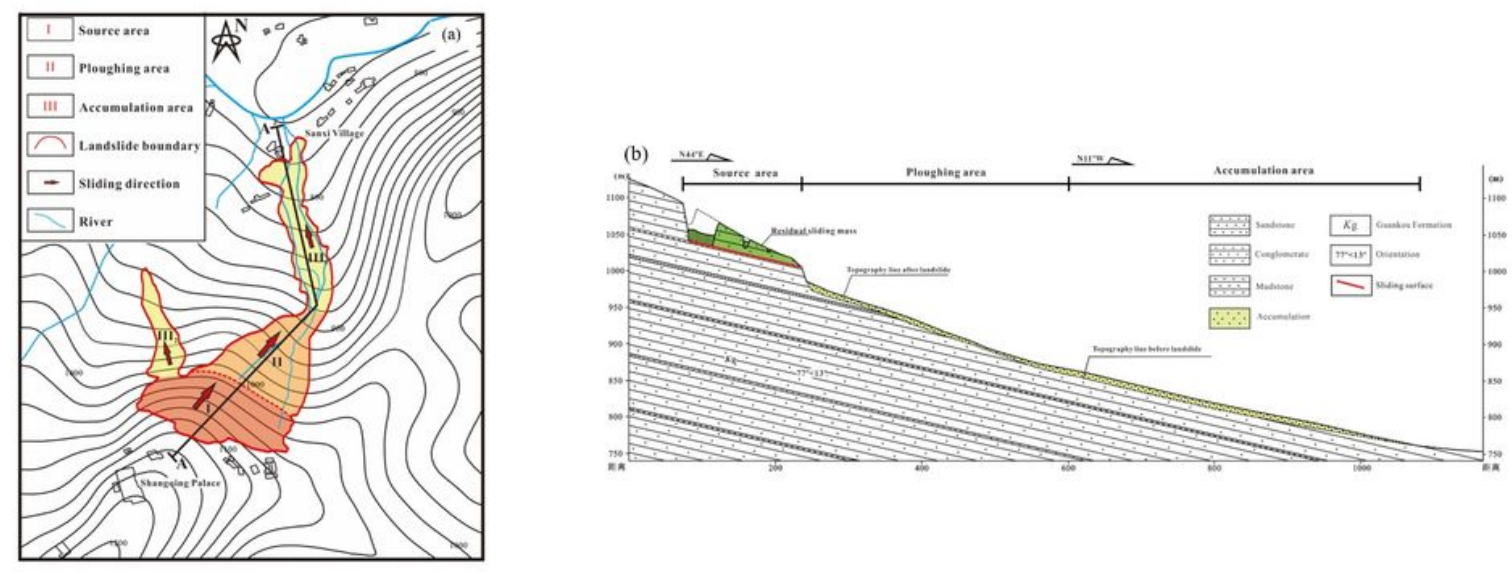

\section{Figure 4}

SXC landslide map (a) and longitudinal profile of the landslide area (b) Note: The designations employed and the presentation of the material on this map do not imply the expression of any opinion whatsoever on the part of Research Square concerning the legal status of any country, territory, city or area or of its authorities, or concerning the delimitation of its frontiers or boundaries. This map has been provided by the authors. 

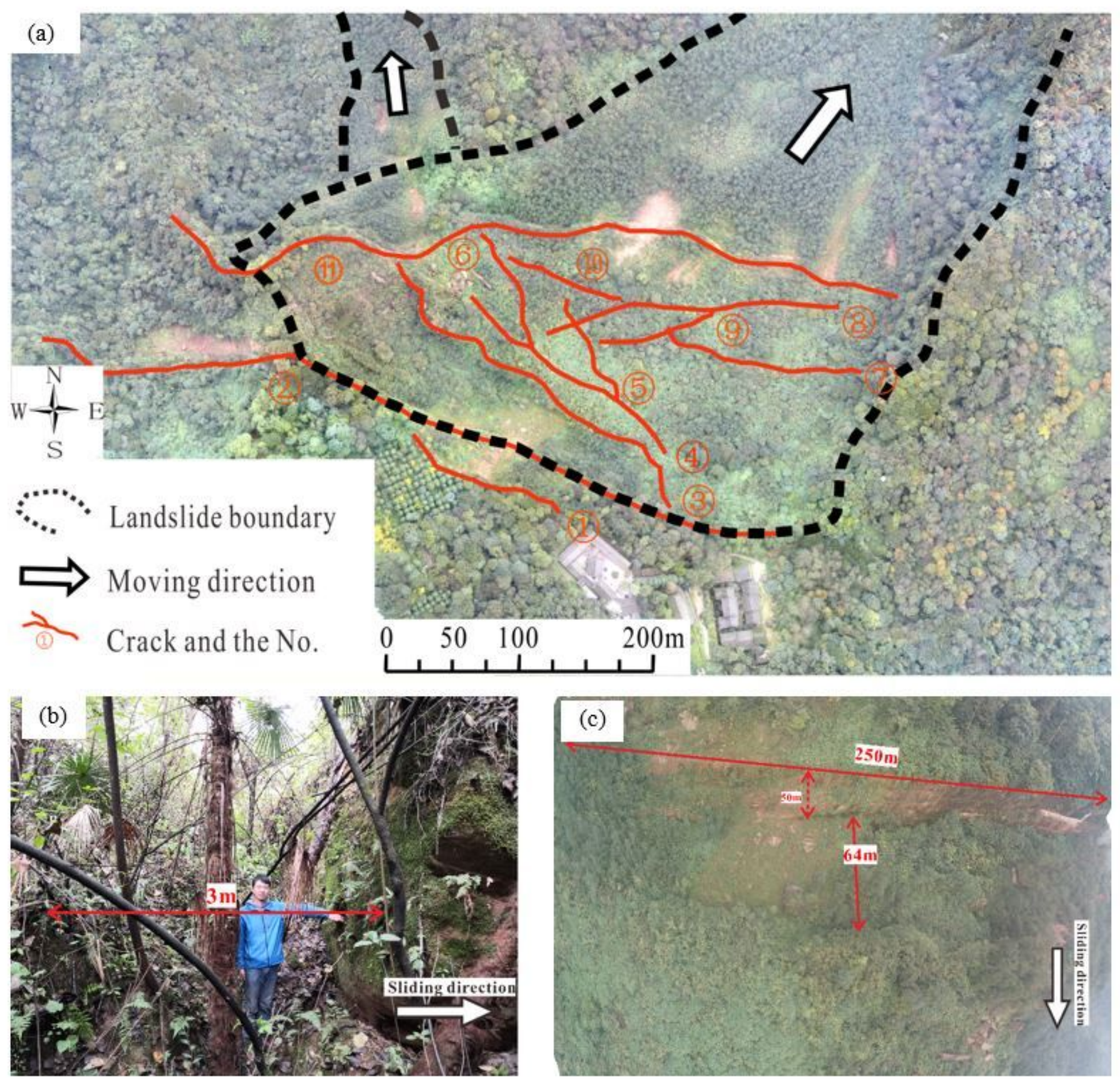

\section{Figure 5}

The distribution of tension cracks in the source area (a), typical tension crack in the middle of residual sliding mass (b) and depression belt (c) Note: The designations employed and the presentation of the material on this map do not imply the expression of any opinion whatsoever on the part of Research Square concerning the legal status of any country, territory, city or area or of its authorities, or concerning the delimitation of its frontiers or boundaries. This map has been provided by the authors. 

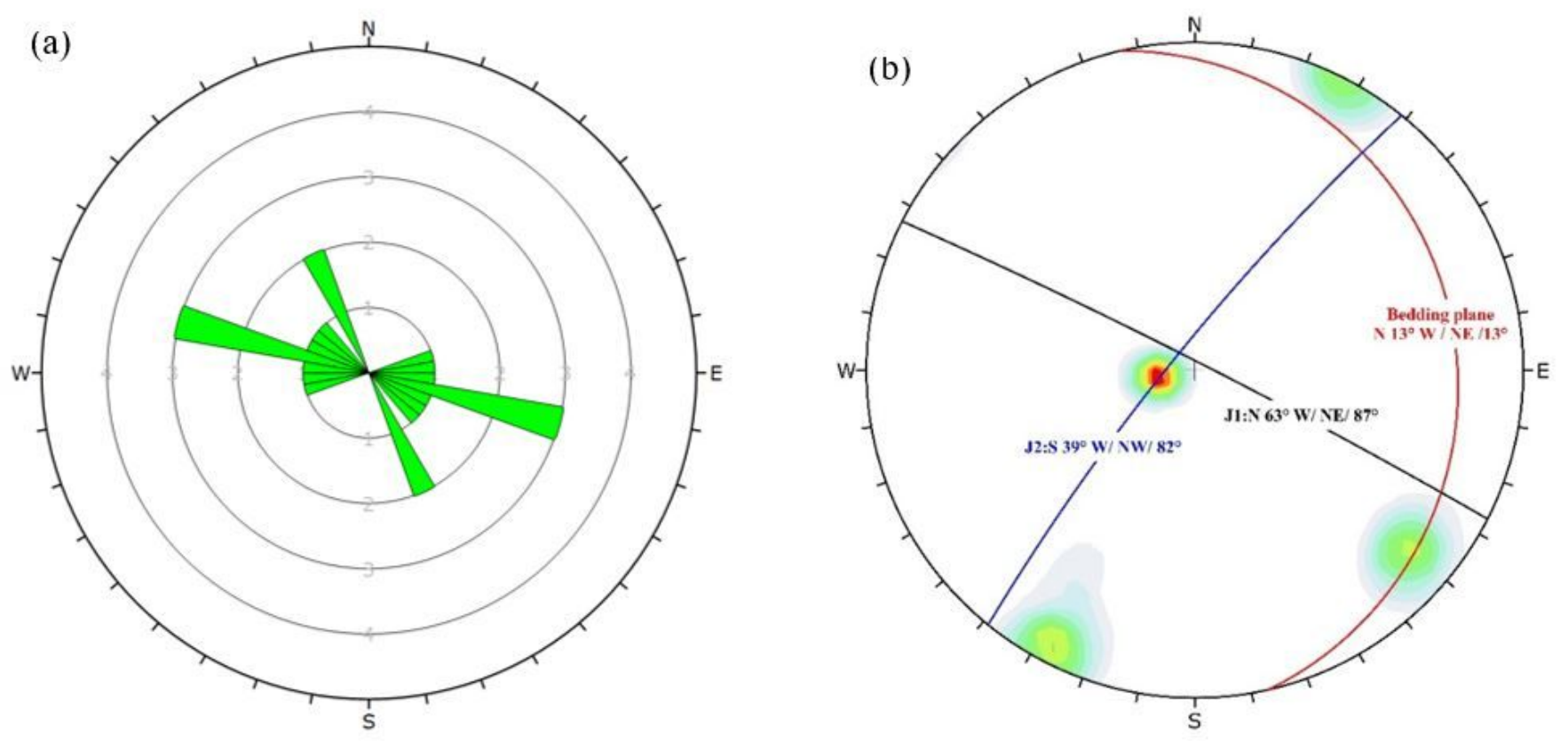

\section{Figure 6}

Rose diagram of the tension crack strike (a) and stereographic projection of joints in the source area (b)

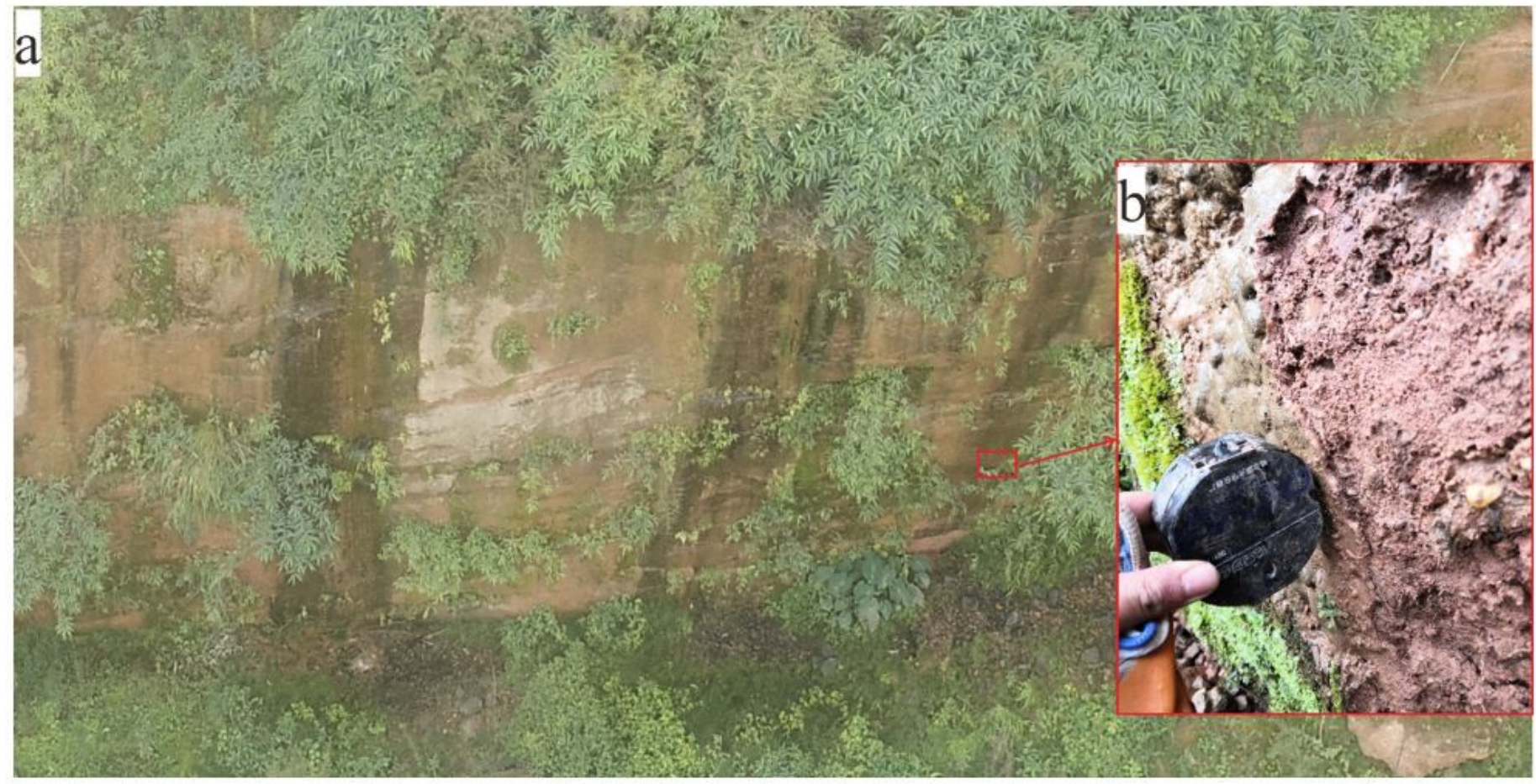

\section{Figure 7}

Solution traces on the scarp surface (a) and a layer of calcareous film 

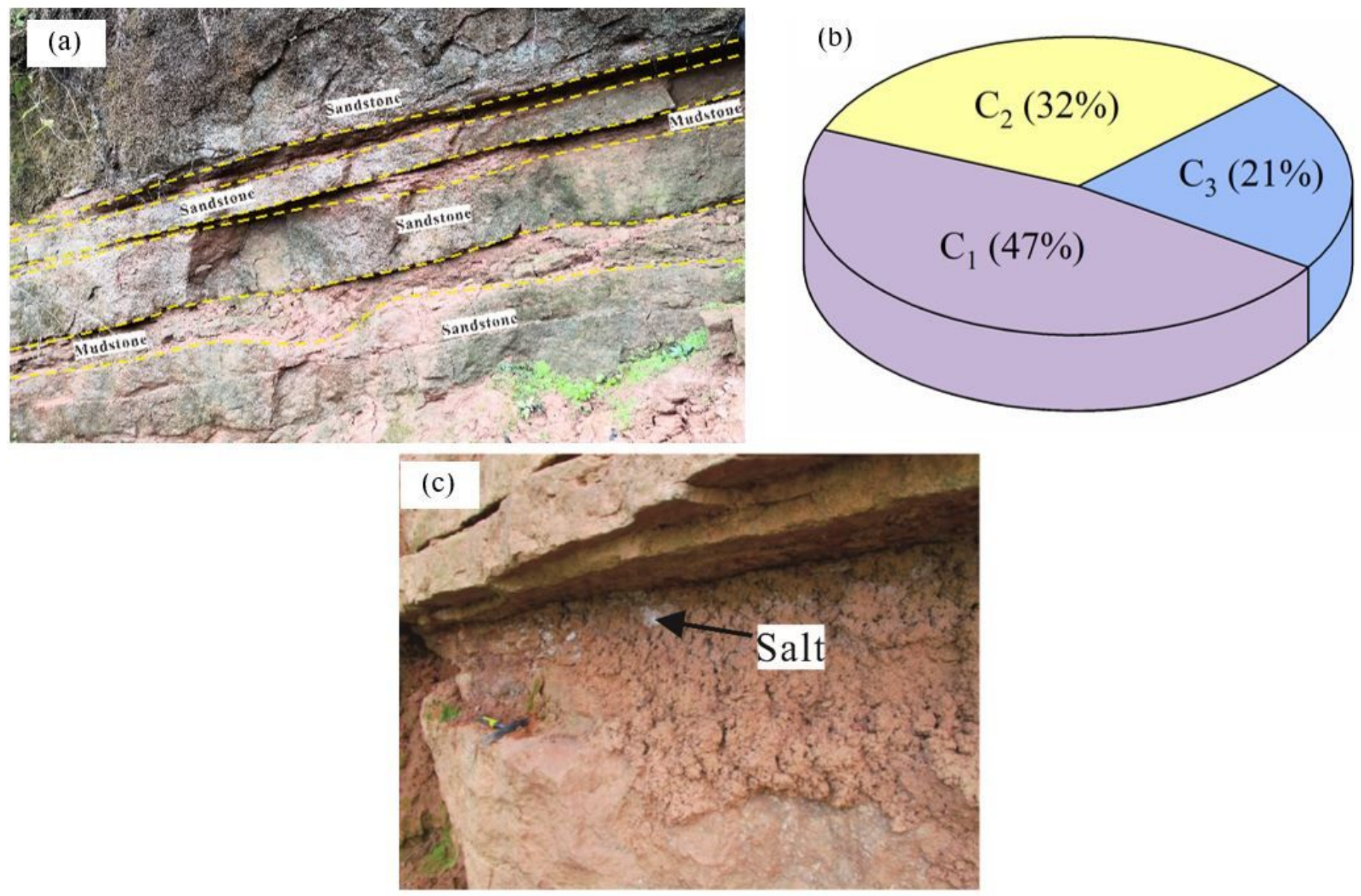

\section{Figure 8}

Strata characteristic in the source area (a), the statistical results of cracks in mudstone layer (b), c1: gently inclined cracks, C2: moderately -gently inclined cracks, C3: steeply inclined cracks, and salt extracted from mudstone (c) (Du et al., 2016) 


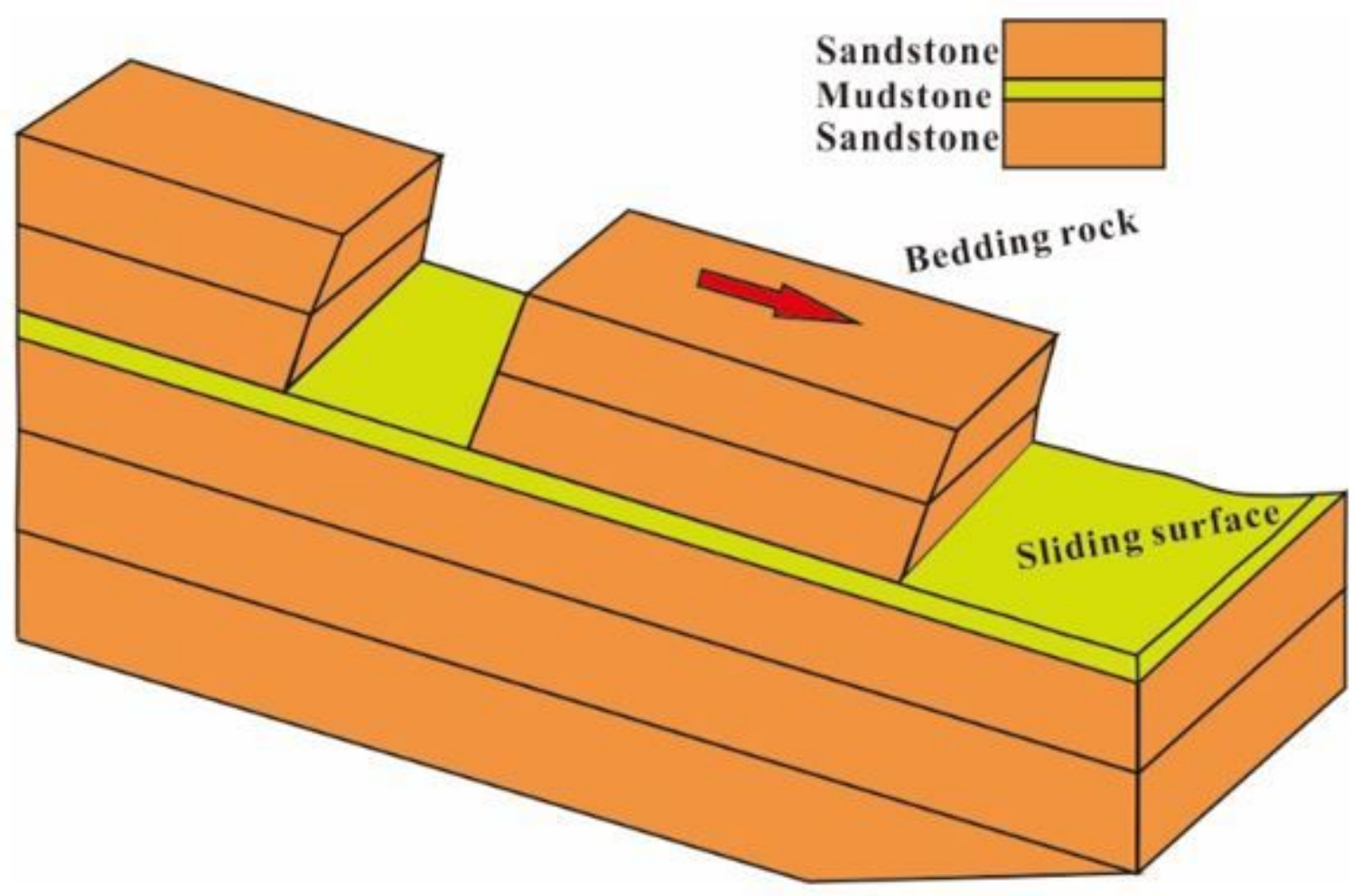

Figure 9

Diagram of strata, sliding surface, and slide block 

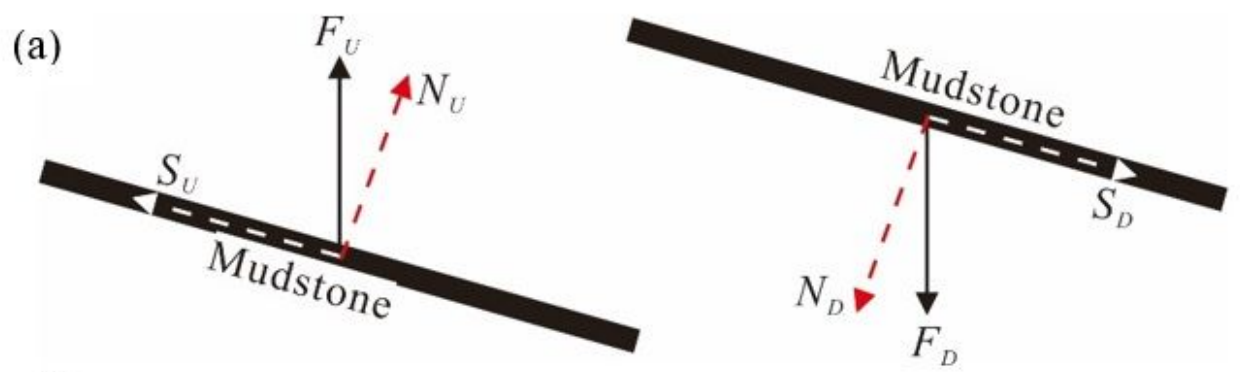

(b)
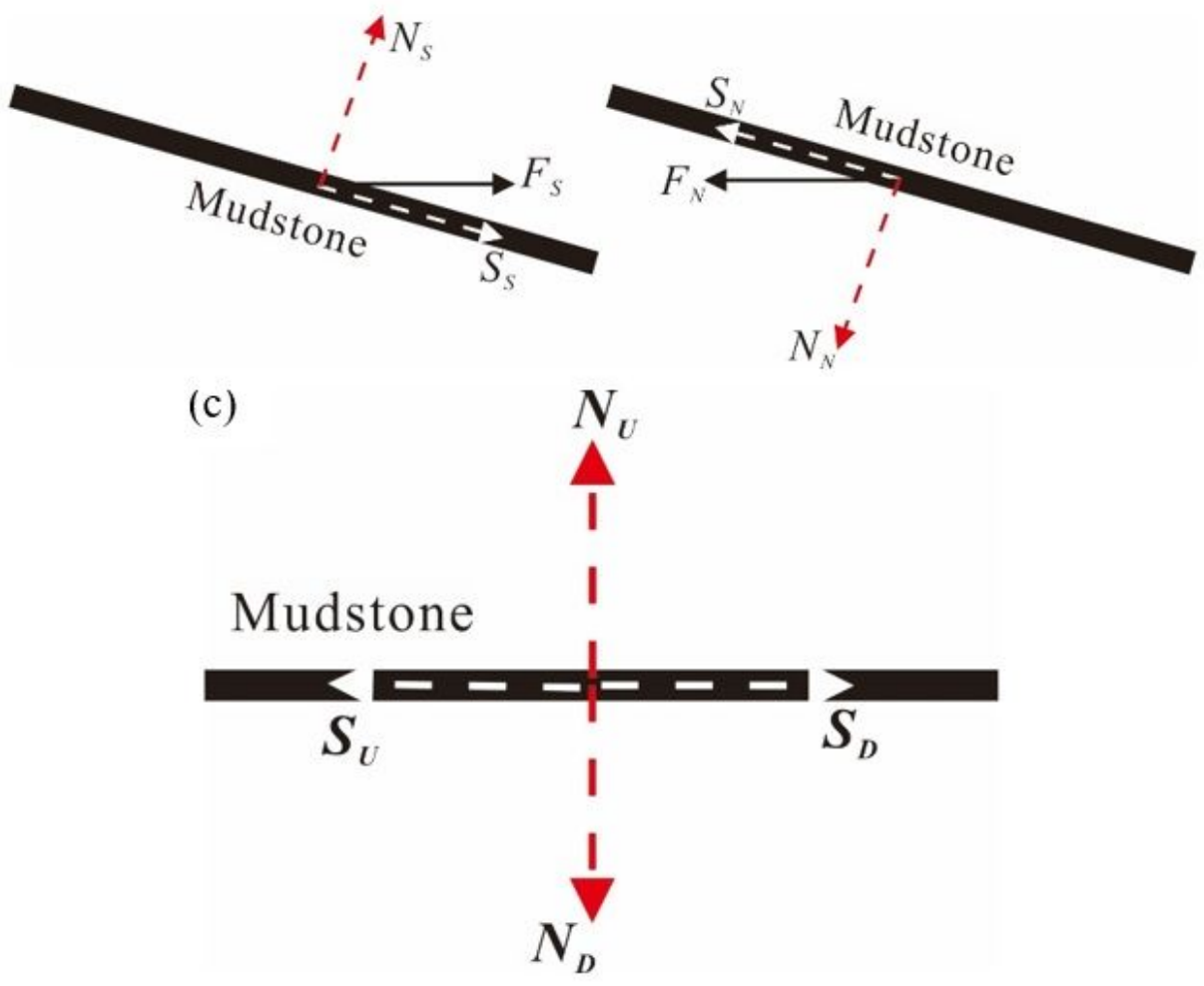

Figure 10

Simplified mechanical mode: (a) decomposition of vertical seismic force, (b) decomposition of horizontal seismic force, and (c) seismic force composition 
(b)
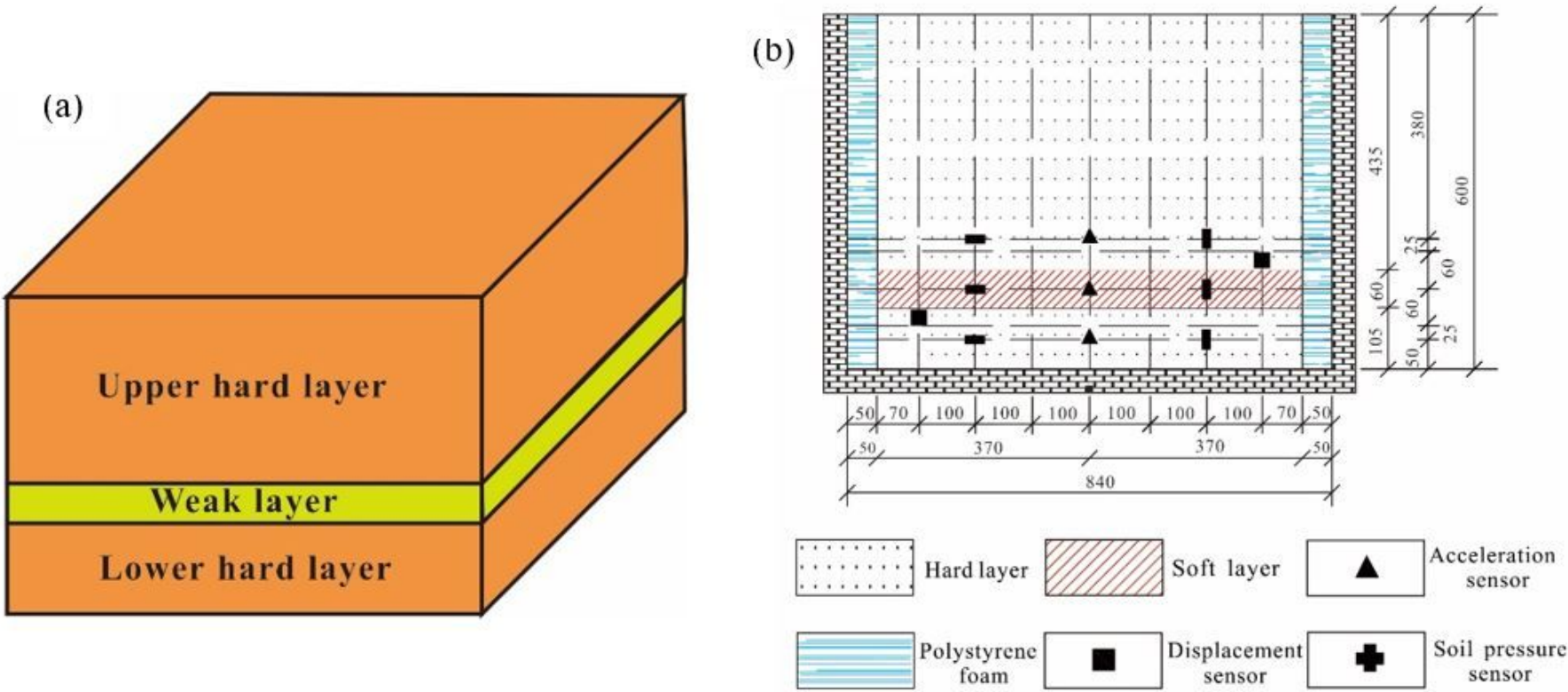

Figure 11

simplified model (a) and a shaking table test model and sensor placement scheme (b) 


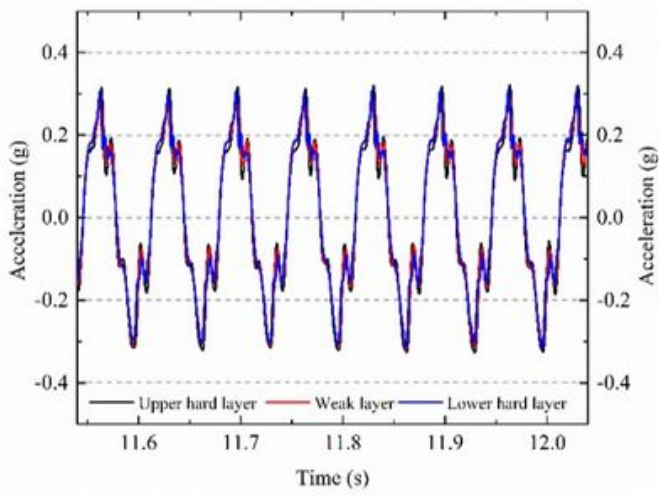

(a) Vertical vibration

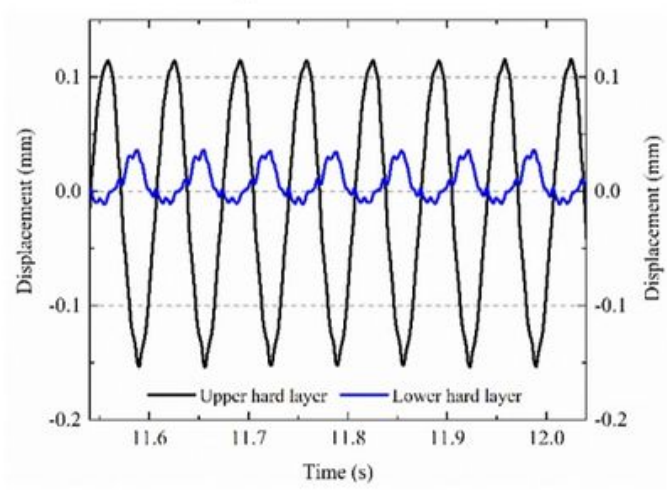

(c) Vertical vibration

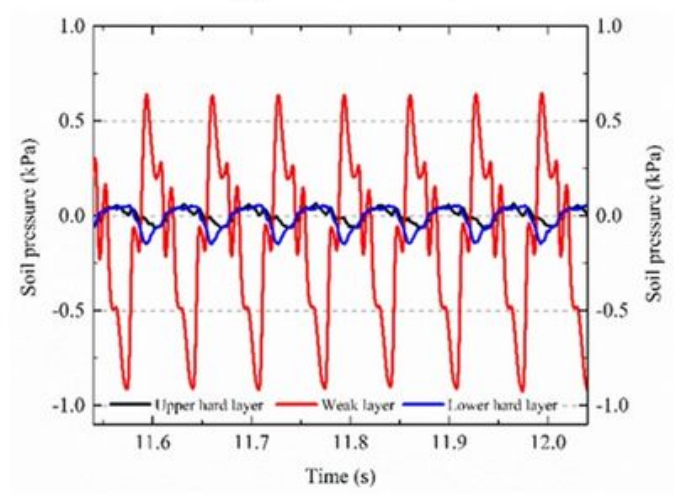

(e) Vertical vibration

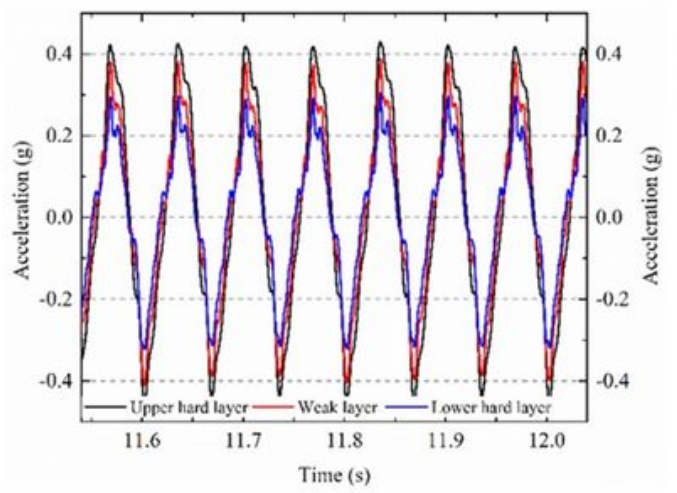

(b) Horizontal vibration

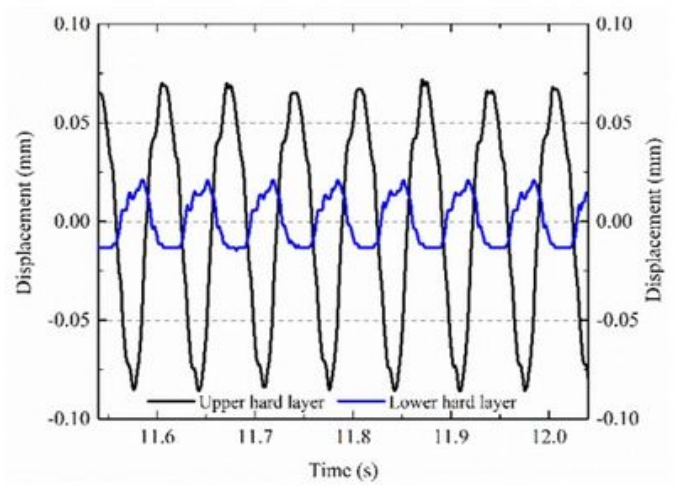

(d) Horizontal vibration

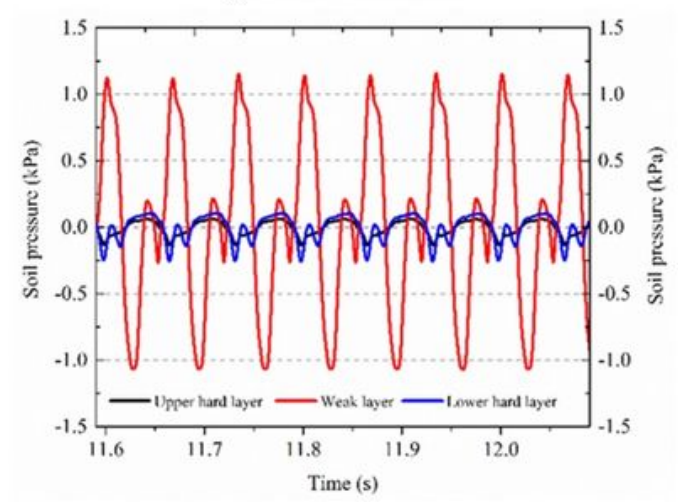

(f) Horizontal vibration

Figure 12

Shaking table test results 

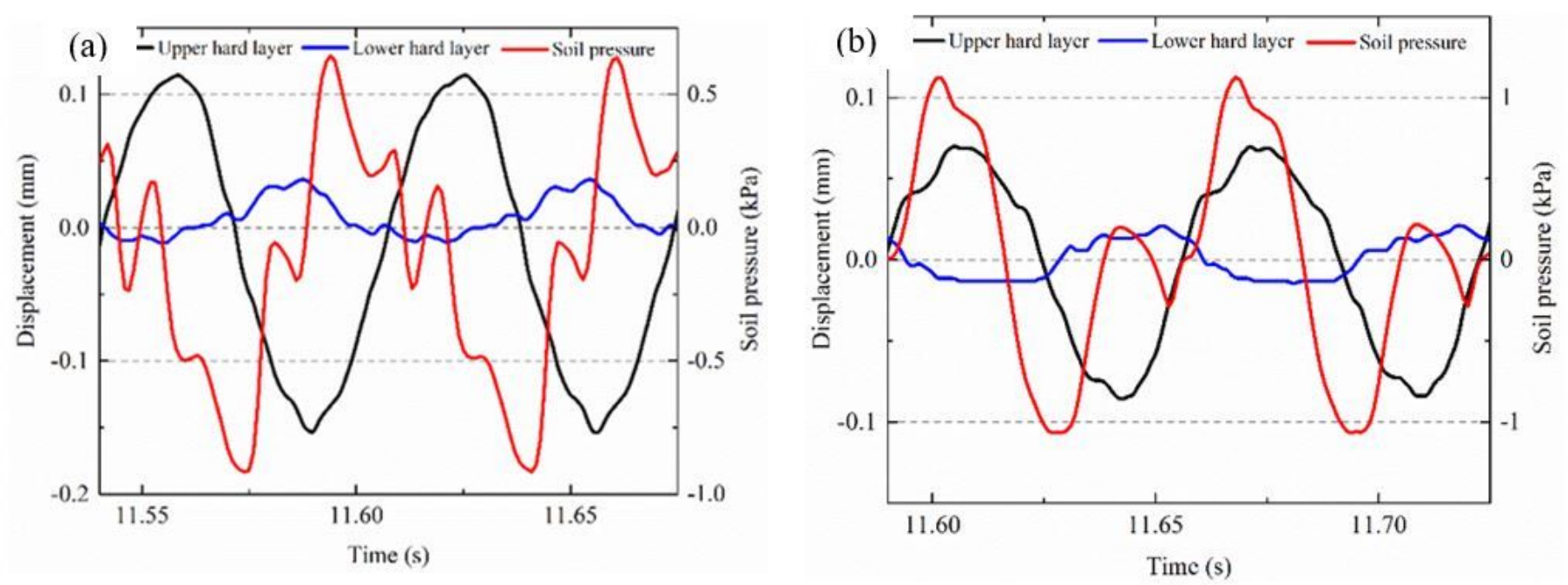

Figure 13

Curves of displacement, soil pressure versus time: (a) vertical vibration, and (b) horizontal vibration
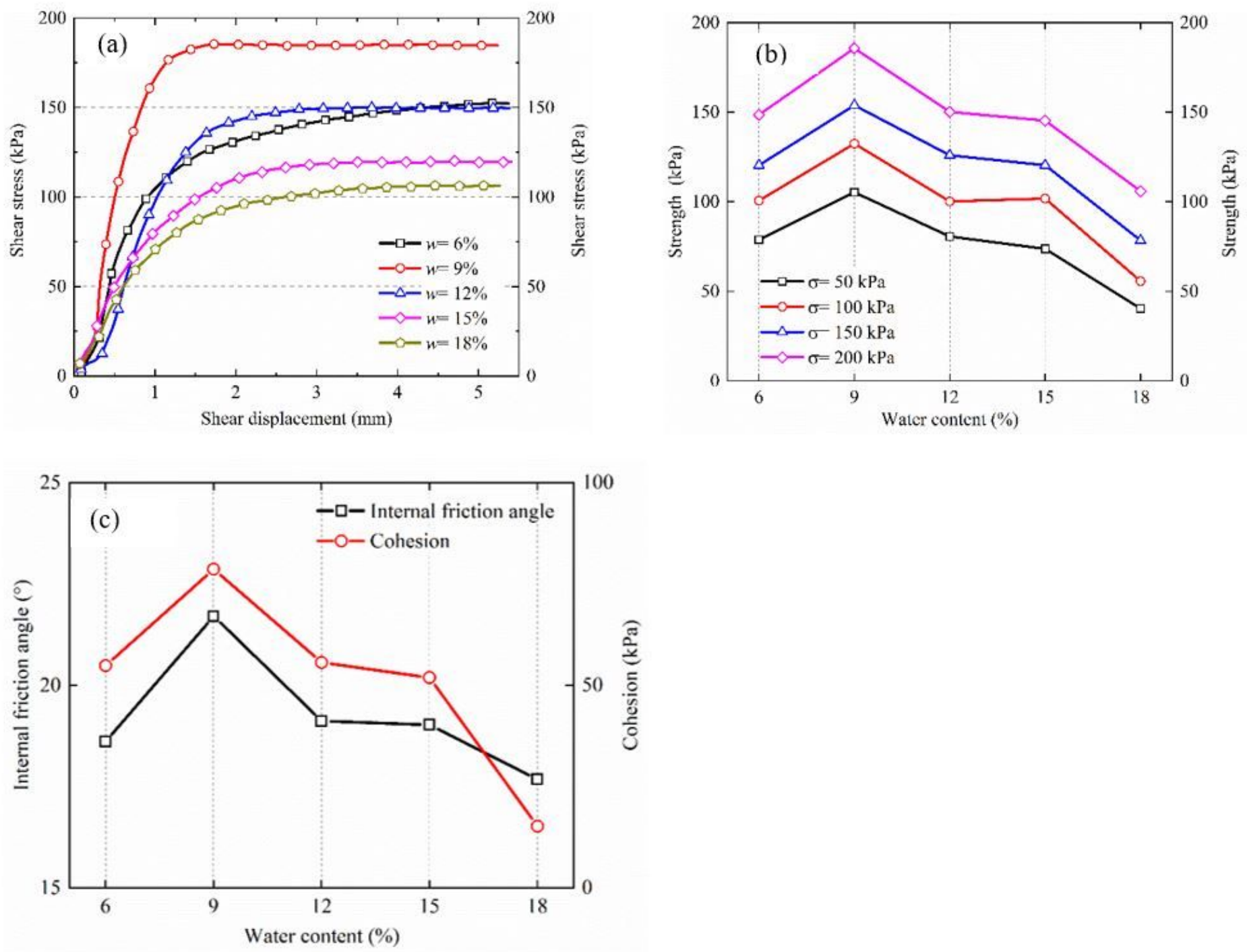
Figure 14

Direct shear test results for samples with different water contents: (a) shear stress versus displacement curves, (b) shear strength versus water content curves, and (c) internal friction angle and cohesion versus water content curves
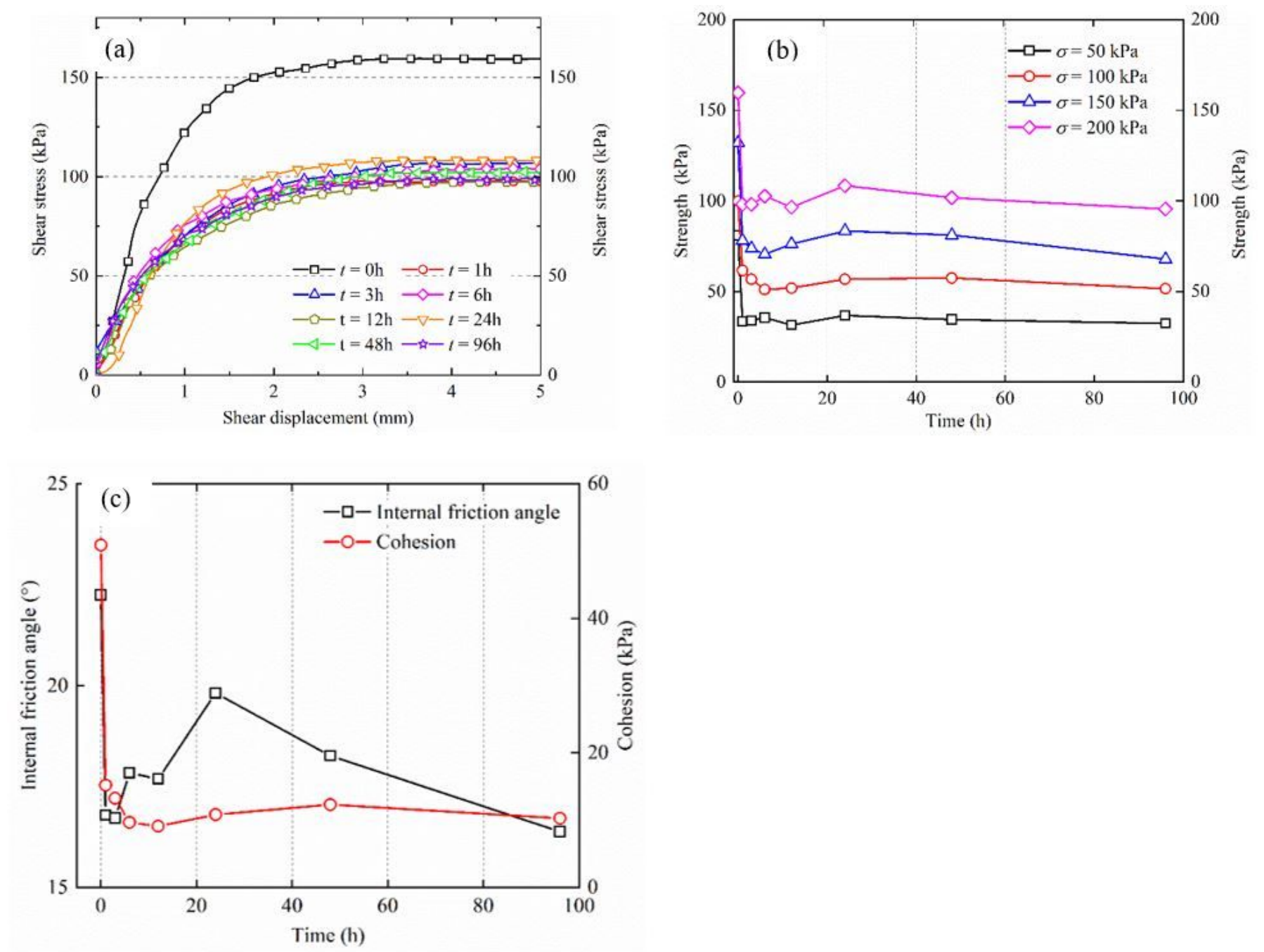

\section{Figure 15}

Direct shear test results for samples with different immersion times: (a) shear stress versus displacement curves for $\sigma=200 \mathrm{kPa}$, (b) shear strength versus water immersion time curves, (c) internal friction angle and cohesion versus immersion time curves 


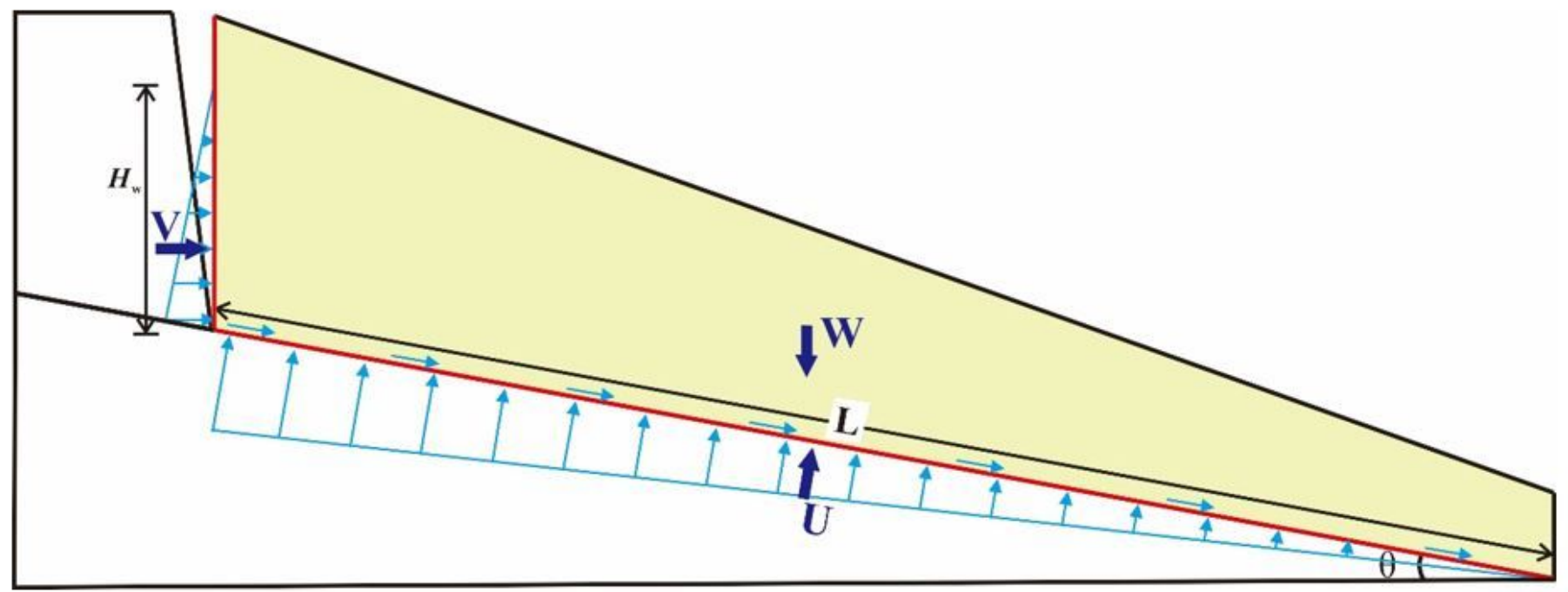

Figure 16

Stability calculation of profile B-B' 


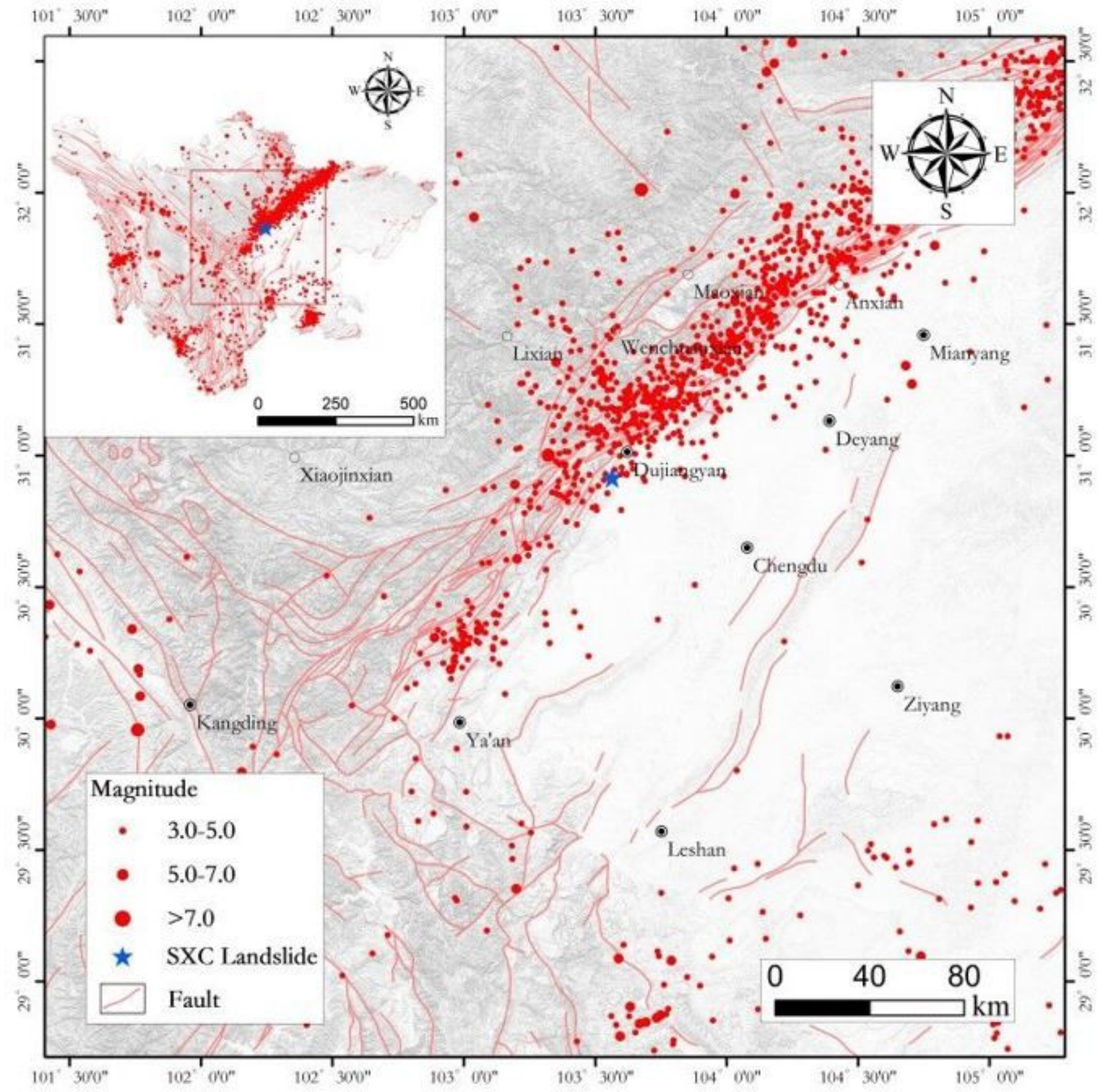

Figure 17

Earthquake events occurring in the adjacent area since 1900 Note: The designations employed and the presentation of the material on this map do not imply the expression of any opinion whatsoever on the part of Research Square concerning the legal status of any country, territory, city or area or of its authorities, or concerning the delimitation of its frontiers or boundaries. This map has been provided by the authors. 

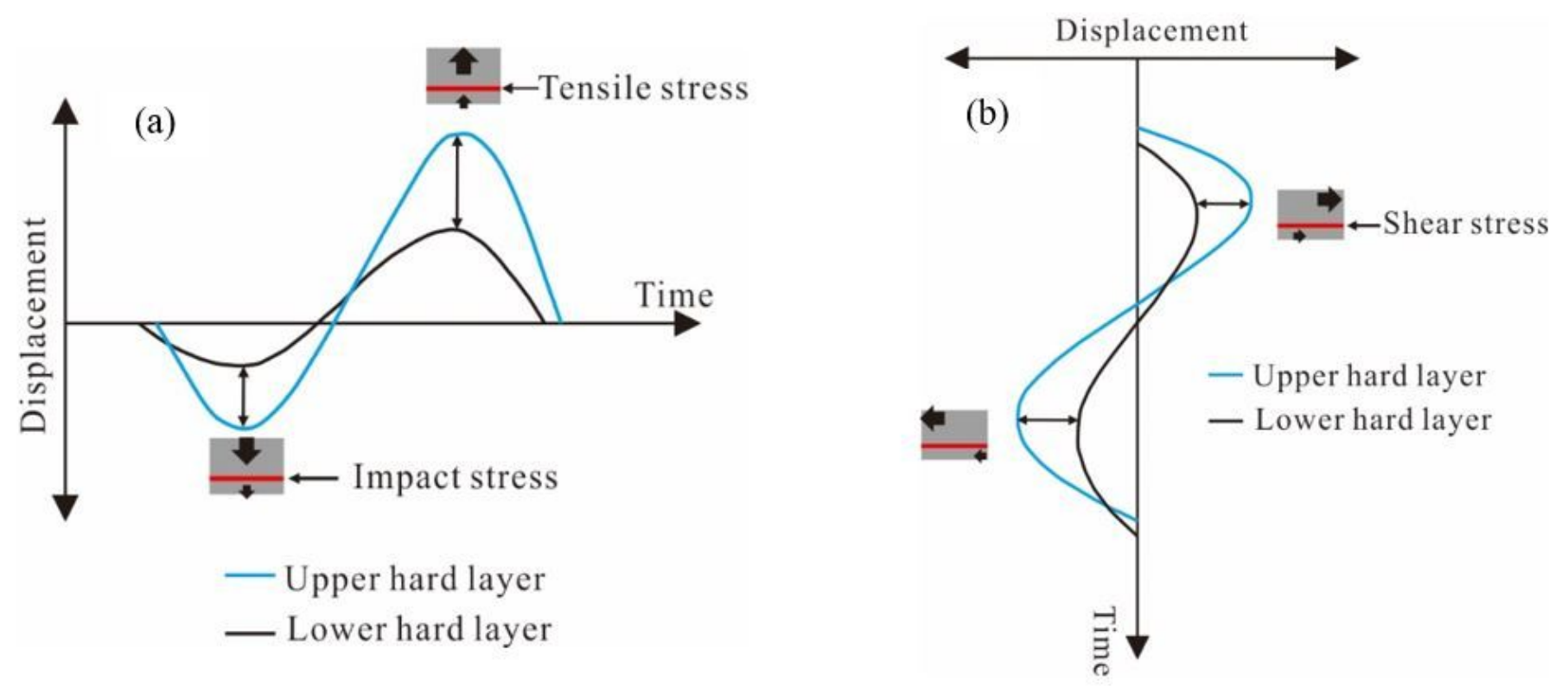

Figure 18

Diagram of incompatible deformation in the model: (a) impact and tension stresses, (b) shear stress
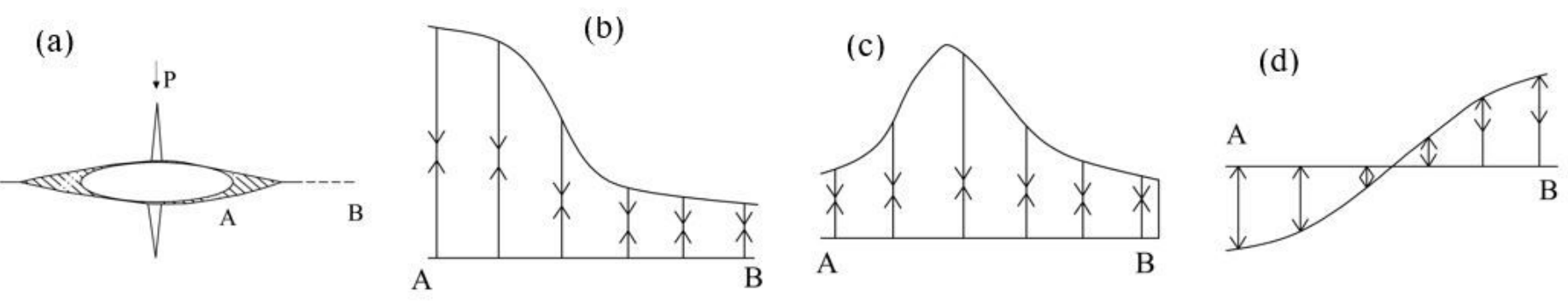

Figure 19

Mechanisms of crack propagation under compression stress (modified by Lajtai 1977): (a) the tension fracture pattern of the original crack, (b) the stress concentration position at the crack tip, (c) transfer of stress concentration position, and (d) residual tension stress 

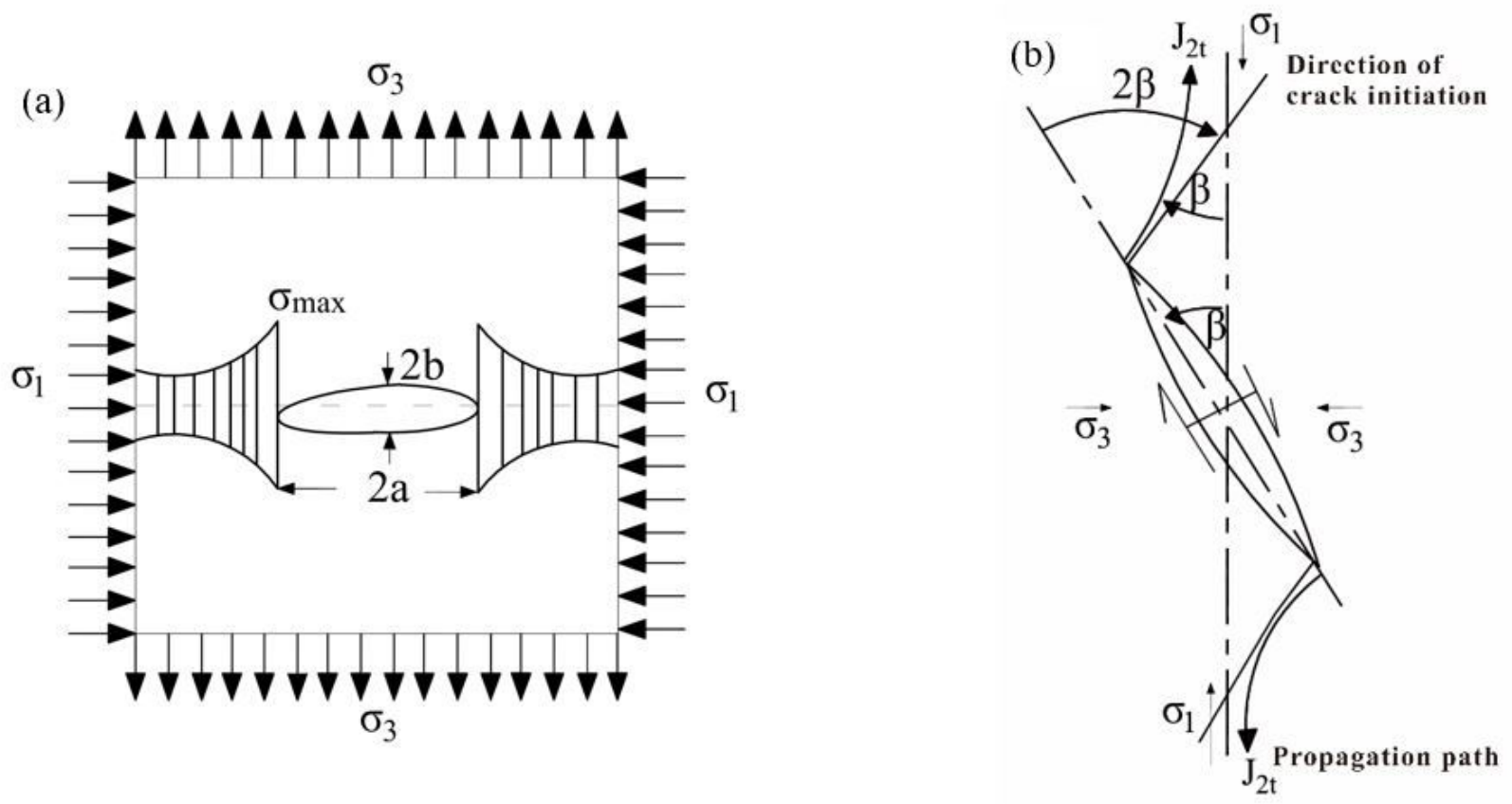

Figure 20

Mechanisms of crack propagation under tension stress (a) and mechanisms of tension failure under compression stress (b)

(a)

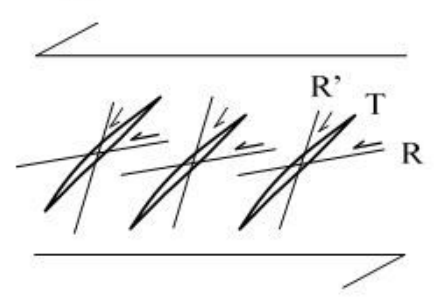

(b)

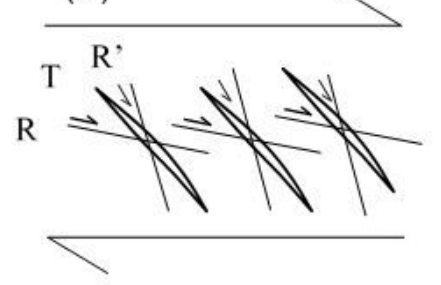

(c)

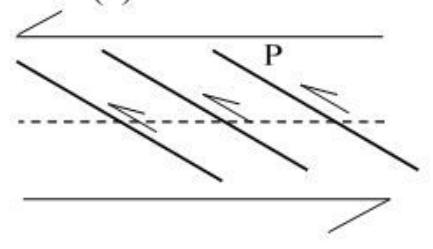

(d)

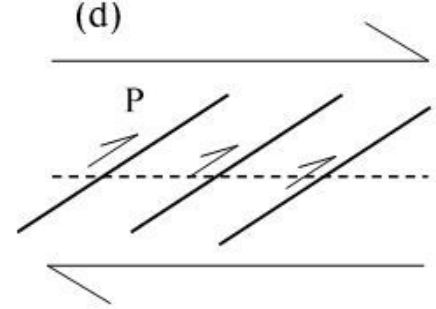

Figure 21

Mechanisms of crack propagation under cyclic shear stress, a. sinistral tension cracks, b. dextral tension cracks, c sinistral compressive- torsion cracks, d dextral compressive- torsion cracks 

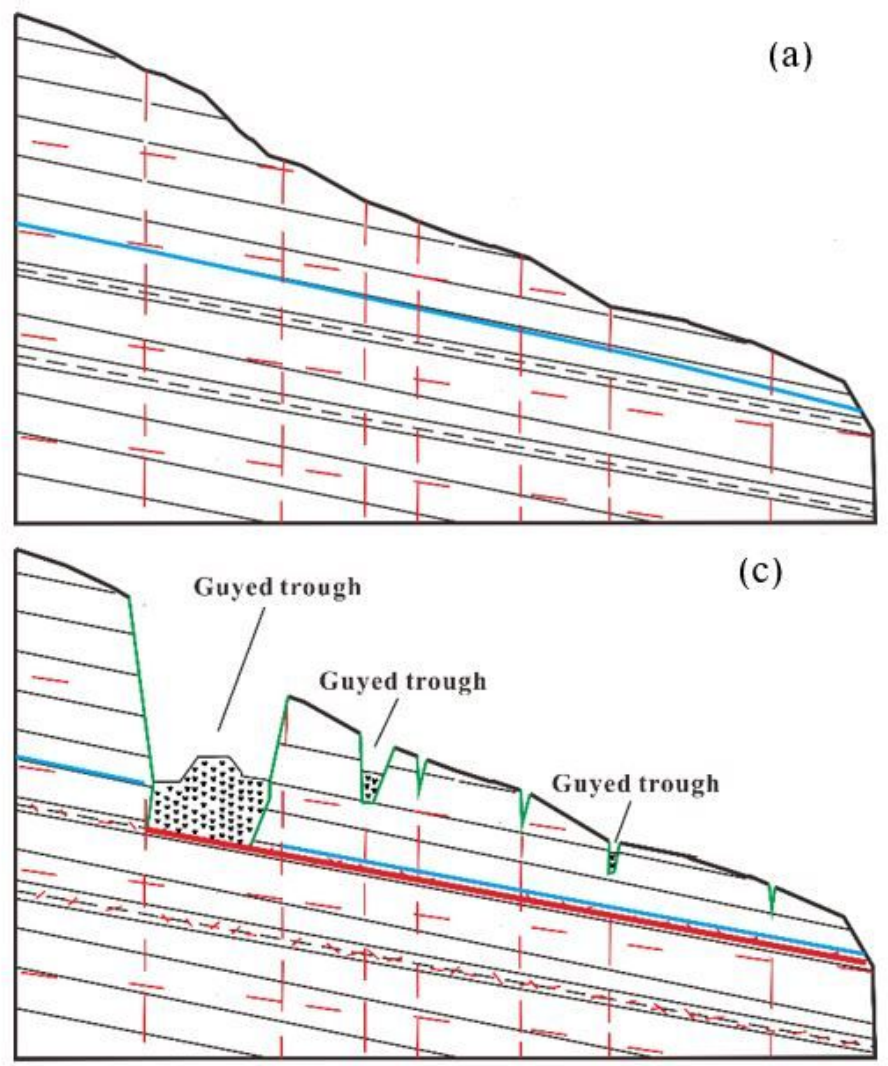
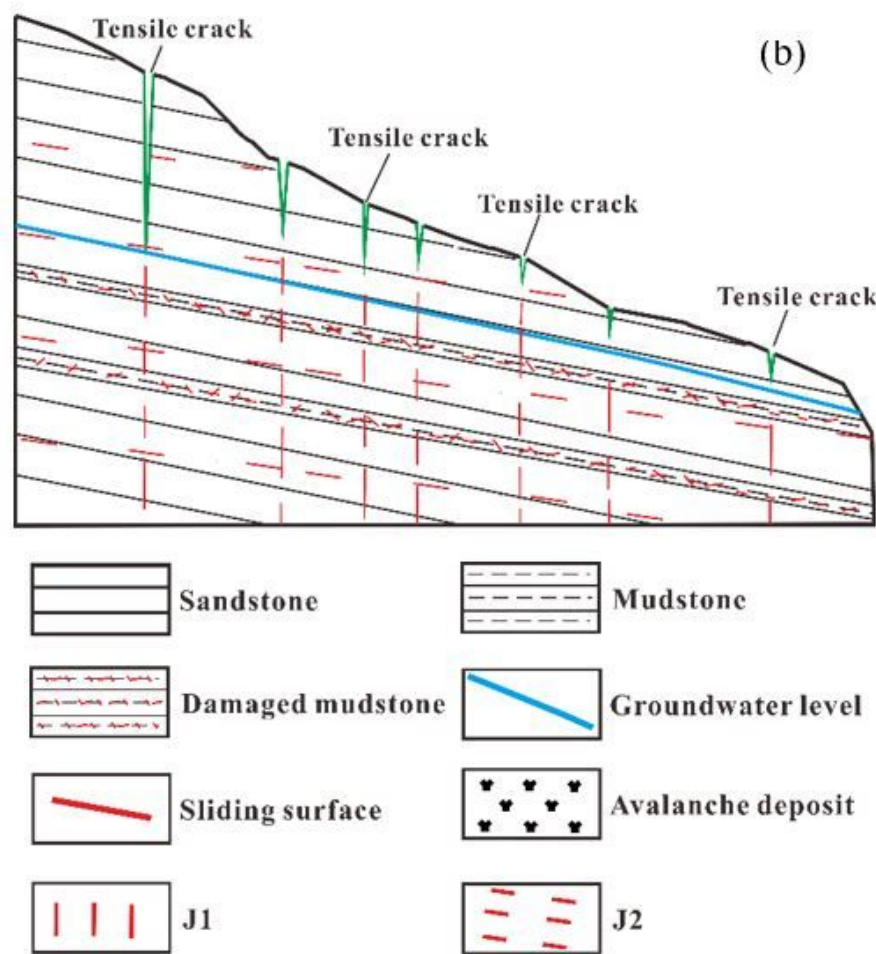

Tensile crack/guyed trough

Figure 22

Formation and evolution process of the cracked slope, (a) original slope with joints (b) seismic cracks formed by historical earthquakes, (c) progressive deformation of slope and the formation of tension cracks under the combined influence of earthquake, rainfall and gravity 


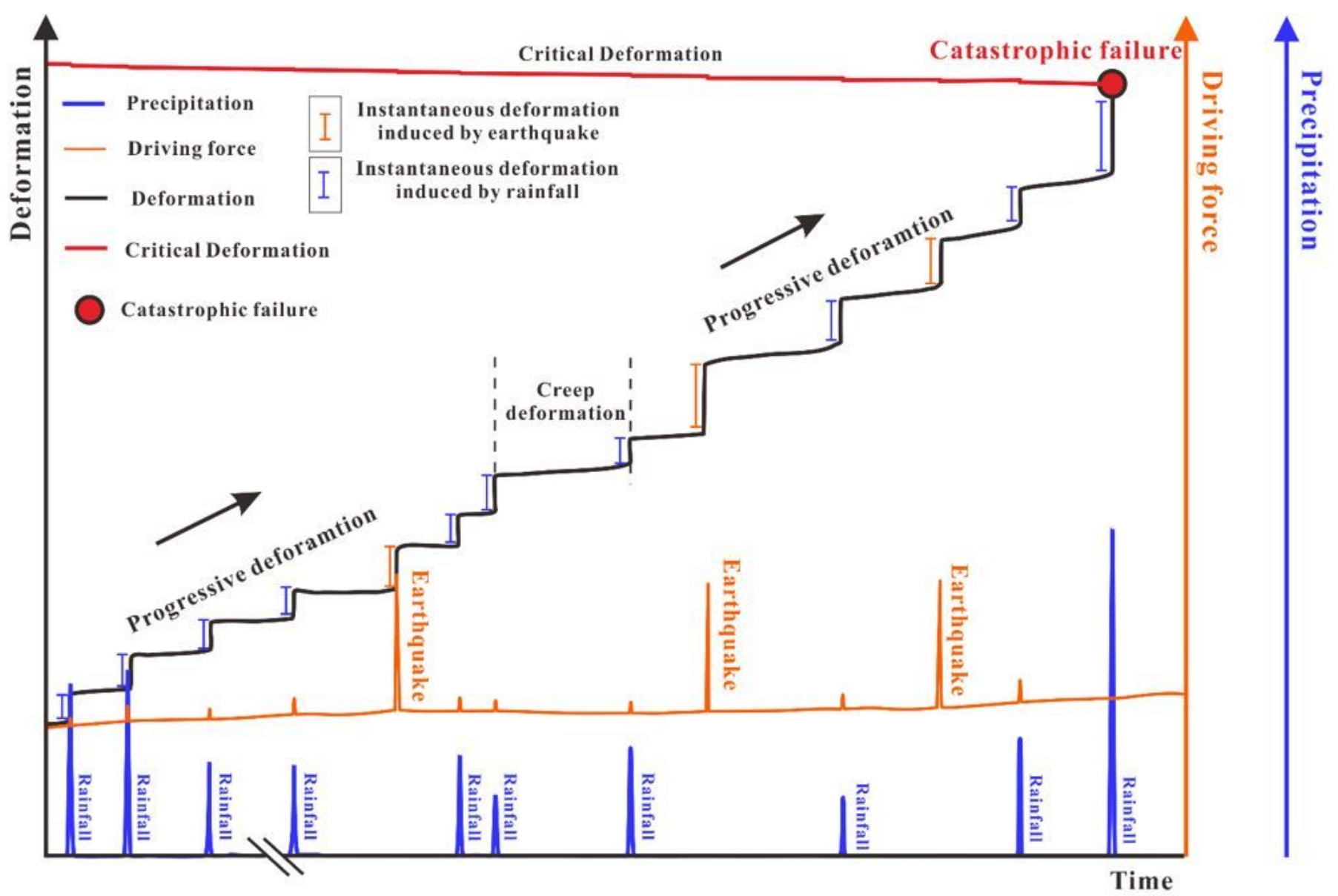

Figure 23

Progressive deformation process of SXC slope under the influence of historical earthquakes, gravity and rainfall 


\section{Topographic condiction}

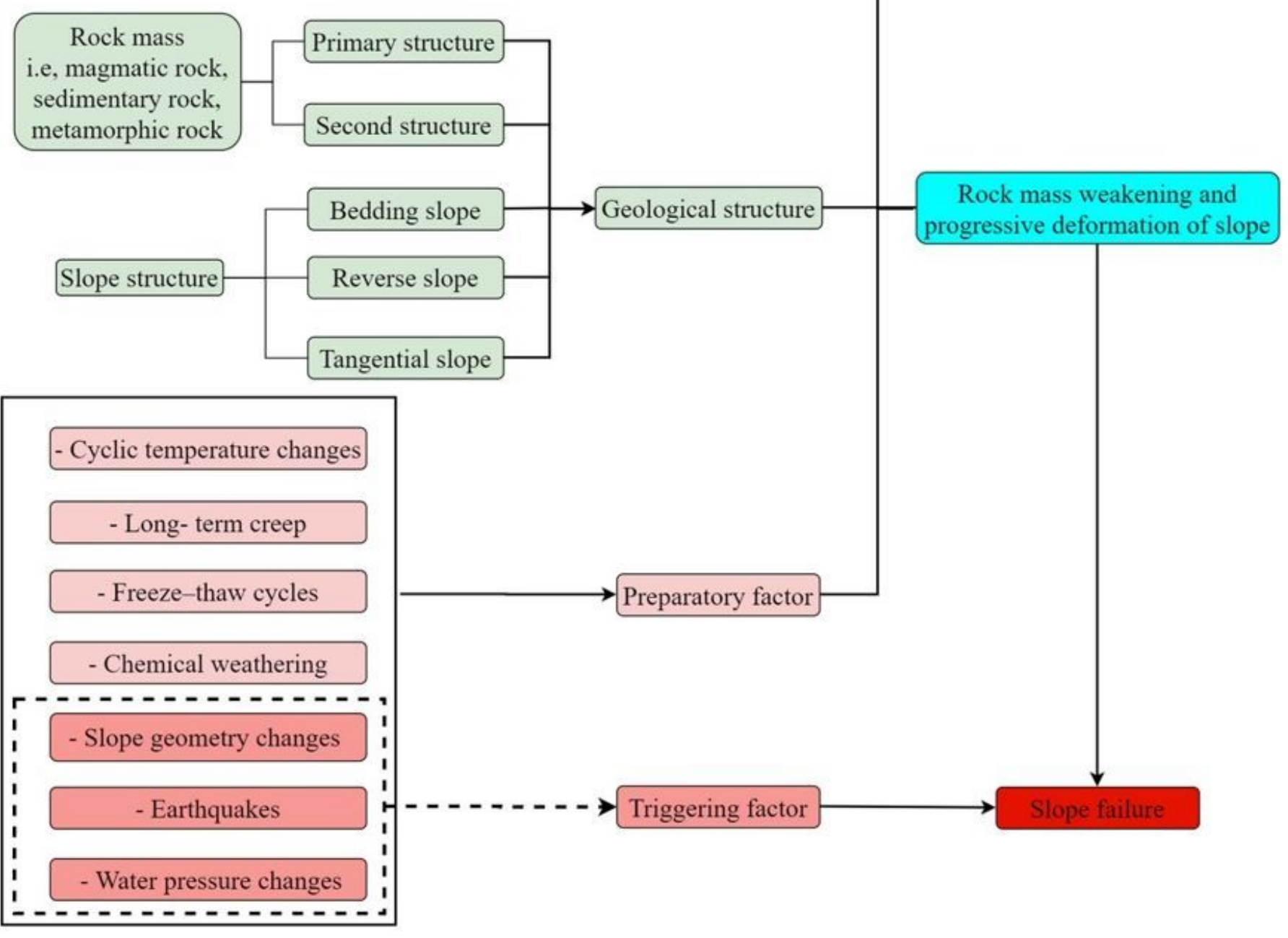

Figure 24

Flowchart illustrating the rock mass weakening and progressive failure of slope 